\author{
Universidade de São Paulo \\ Faculdade de Filosofia, Letras e Ciências Humanas \\ Departamento de Ciência Política
}

Maurício Yoshida Izumi

\title{
Velhas questões, novos métodos: posições, agenda, ideologia e dinheiro na política brasileira
}

(Versão corrigida)

São Paulo 
Velhas questões, novos métodos: posições, agenda, ideologia e dinheiro na política brasileira

(Versão corrigida)

\author{
Tese apresentada ao programa de Pós- \\ graduação do Departamento de \\ Ciência Política da Universidade de \\ São Paulo como requisito parcial para \\ a obtenção do título de Doutor em \\ Ciência Política
}

Orientador: Prof. Dr. Fernando de Magalhães Papaterra Limongi

São Paulo 
Izumi, M. Velhas questões, novos métodos: posições, agenda, ideologia e dinheiro na política brasileira. Tese apresentada à Faculdade de Filosofia, Letras e Ciências Humanas da Universidade de São Paulo para obtenção do título de Doutor em Ciência Política. 2017.

Aprovado em:

Banca Examinadora:

Prof. Dr.:

Julgamento:

Prof. Dr.:

Julgamento:

Prof. Dr.:

Julgamento:

Prof. Dr.:

Julgamento:

Prof. Dr.:

Julgamento:
Instituição:

Assinatura:

Instituição:

Assinatura:

Instituição:

Assinatura:

Instituição:

Assinatura:

Instituição:

Assinatura: 


\section{Agradecimentos}

Muitas pessoas e instituições contribuíram para a minha formação desde a graduação até o doutorado. Em primeiro lugar, agradeço ao Departamento de Ciência Politíca e ao Instituto de Matemática e Estatística da USP, à Universidade da Califórnia em San Diego, ao Cebrap e ao NECI. Nessas instituições eu tive a oportunidade de aprender com as pessoas mais brilhantes que eu já conheci. Também tive a sorte de me tornar amigo dessas pessoas.

Agradeço a Andréa Freitas por ser um exemplo, não apenas para mim, de dedicação à pesquisa e por ter me ensinado tudo o que eu sei sobre pesquisa empírica. Agradeço a Danilo Medeiros pela amizade e pela disposição em resolver problemas, muitas vezes não acadêmicos. Aos amigos cebrapianos de mais longa data agradeço ainda a Jaqueline Zulini, Rafael Freitas, Patrick Silva, Pedro Neiva e Samuel Moura por todo apoio.

A Alexia Aslan, Ana Beatriz Dutra, Andréa Junqueira, Camila Gonçalves, Cássio Santos, Davi Moreira, Diego Corrêa, Fernanda Machado, Graziele Silotto, Joyce Luz, Juliana Oliveira, Leonardo Diegues, Ligiane Alves, Marina Merlo, Natália Moreira, Nathan Alves, Paulo Hubert, Pedro Savadovsky, Rodrigo Sartori, Samir Luna, Tiago Borges e Vanessa Rossetti agradeço pela amizade e por transformarem o ambiente de trabalho em um lugar muito agradável. A Joyce Luz agradeço também por resolver todos os problemas da vida acadêmica.

Agradeço aos professores Glauco Silva e Fernando Guarnieri por terem participado do meu exame de qualificação. Agradeço também a Lorena Barberia, Marcos Nakaguma, Ricardo Ceneviva e Sebastian Saiegh pelos comentários ao trabalho.

A Marcos Silveira, Rafael Magalhães, Sérgio Simoni Jr. e Victor Araújo agradeço pela amizade e pelos comentários ao trabalho.

Agradeço aos funcionários do departamento de Ciência Política Léo, Márcia, Rai e Vasne pelo trabalho prestado ao longo desses anos.

A Fernando Limongi, meu orientador, agradeço pela orientação e pela confiança total em meu trabalho. 
Agradeço a Fundação de Amparo a Pesquisa do Estado de São Paulo (FAPESP) pelo fomento à pesquisa vinculada ao processo $2013 / 24210-4^{1}$.

Por fim, agradeço aos meus pais, Israel e Maria, pelo apoio e por me proporcionarem oportunidades que eles nunca tiveram.

\footnotetext{
${ }^{1}$ Agradeço a FAPESP por ter concedido a bolsa de doutorado e pelo apoio financeiro (processo 2013/24210-4) para a realização dessa pesquisa. As opiniões, hipóteses e conclusões ou recomendações expressas nesse material são de responsabilidade do autor e não necessariamente refletem a visão da FAPESP.
} 


\section{Resumo}

Esta tese é formada por quatro capítulos independentes. No primeiro capítulo desenvolvemos um modelo Bayesiano da Teoria da Resposta ao Item para estimar posições políticas utilizando textos como dados. A literatura tem utilizado a matriz de frequência de palavras como fonte primária para modelar as posições políticas. Ao contrário desta abordagem, utilizamos classificações feitas por meio de análise de sentimentos. Para demonstrar a aplicação desse modelo, estimamos as posições políticas dos partidos políticos brasileiros entre 1995 e 2014 utilizando os discursos dos senadores. Os resultados sugerem que, em vez de uma clivagem ideológica, os partidos estão organizados em uma dimensão que representa o conflito entre governo e oposição.

O objetivo do segundo capítulo é analisar como ideias sobre políticas são construídas ao longo do tempo. Em termos empíricos, verificamos como o conteúdo presente em um projeto de lei reaparece de forma semelhante em outros projetos. Avaliamos também qual o impacto inclusão de interesses sobre a sua probabilidade de aprovação. Para isso utilizamos todos os projetos de lei apresentados durante a $54^{\mathrm{a}}$ legislatura na Câmara dos Deputados e técnicas de análise quantitativa de textos. Mostramos que projetos que foram influenciados por outros projetos tem mais chances de aprovação, principalmente se eles forem de origem do Executivo. Sugerimos que a inclusão de interesses é o fator chave para um projeto se tornar lei.

No terceiro capítulo partimos do principal pressuposto da teoria espacial do voto. De acordo com esse pressuposto, eleitores diante de dois (ou mais) candidatos escolherão aquele que estiver mais próximo de suas preferências. $\mathrm{O}$ primeiro objetivo deste capítulo será testar esse pressuposto para as eleições presidenciais no Brasil entre 2002 e 2014. Para isso utilizamos os dados do Estudo Eleitoral Brasileiro e técnicas de escalonamento. Os resultados apontam que a probabilidade de um eleitor votar no candidato que está mais próximo dele do ponto de vista ideológico é extremamente alta. O segundo objetivo do capítulo é verificar se esse resultado se sustenta a despeito do nível de sofisticação política do eleitor. Isto é, testamos a hipótese de que eleitores pouco informados toma- 
riam as suas decisões a partir de elementos não espaciais (não ideológicos). Os resultados contrariam essa ideia. Eleitores pouco sofisticados do ponto de vista político também escolhem os candidatos que estão mais próximos deles.

Por fim, no quarto capítulo, o objetivo será testar qual o efeito de ser eleito para um cargo público sobre o patrimônio individual. Sendo mais preciso, iremos estimar o efeito de ser eleito para o cargo de prefeito no Brasil sobre o total de bens declarados pelos candidatos no futuro. Para isso utilizaremos modelos de regressão descontínua comparando os pares de candidatos que foram eleitos e que não foram eleitos em eleições apertadas e que se reapresentaram na eleição subsequente para o mesmo cargo. Os resultados sugerem que ser eleito a um cargo público não tem efeito sobre a quantidade de bens declarada pelos candidatos. Eleitos e não eleitos em eleições acirradas apresentam um patrimônio semelhante após os primeiros exercerem o cargo de prefeito. Além disso, esse resultado não varia conforme a filiação partidária, região ou experiência política do candidato. Também não encontramos efeitos sobre o patrimônio dos familiares e nem efeitos de longo prazo.

Palavras-chave: Posições políticas, Agenda política, Ideologia, Corrupção. 


\begin{abstract}
This dissertation consists of four distinct chapters. In the first chapter we develop a Bayesian procedure to estimate policy positions from text data. Instead of using word frequencies to model policy positions, our approach is based on sentiment analysis classifications. We demonstrate our procedure by estimating the position of Brazilian political parties between 1995 and 2014 using the speeches of senators. The results suggest that, instead of an ideological cleavage, parties are organized in a government-opposition dimension.

In the second chapter we examine how policy ideas are built over time. Empirically, we examine how the content of a bill appears in a similar way in other bills. We also examine what is the impact of preference's inclusion on the probability of a bill be passed. In order to do that, we use all bills proposed during the 54th term in Câmara dos Deputados and we employ quantitative text analysis. The results suggest that bills that have been influenced by other bills have more chances to be passed. This result is stronger for bills written by the executive branch. We suggest that the inclusion of preferences is the key factor for a bill to be passed.

In the third chapter we examine the main assumption of the spatial theory of voting. According to this assumption, voters will cast their votes for the candidate whose policy position is the closest to their own views. The goal of this chapter is twofold: the first one is to test this assumption for the Brazilian presidential elections between 2002 and 2014. In order to do that we use data from the Brazilian Electoral Study and scaling methods. The results suggest that the probability of a voter cast his vote for the candidate whose policy position is the closest to their own is pretty high. The second goal of this paper is to assess if this result holds despite of voters' political sophistication. In other words, we test if ill-informed voters make their electoral decisions based on nonspatial candidate characteristics. The results contradict this wisdom. Politically illinformed voters also choose the candidates who are closer to themselves.

In the last chapter we examine the monetary returns to incumbency in Brazilian mayoral elections. In other words, we estimate the causal effect of winning a
\end{abstract}


close election on the wealth declared by Brazilian mayoral candidates in the subsequent election. In order to do that we employ a regression discontinuity design of close elections focused on pairs of repeated candidates. The results suggest no causal effects of winning a close election on the wealth of the candidates. The results are robust to incumbent partisanship, region, political experience and holds if the definition of wealth is extended to relatives and long term wealth.

Keywords: Policy positions, Political agenda, Ideology, Corruption. 


\section{Sumário}

I Medindo posições políticas a partir de textos $\quad 6$

1.1 Introdução .......................... 6

1.2 Técnicas de escalonamento para textos . . . . . . . . . 7

1.3 Modelo estatístico para escalonamento de opiniões . . . . . . . 10

1.4 Aplicação: partidos políticos brasileiros . . . . . . . . . . . . . . 14

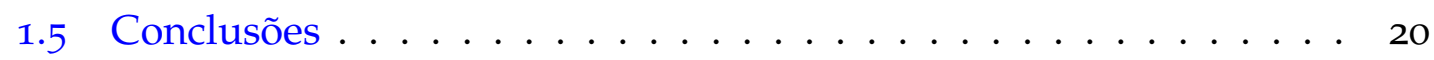

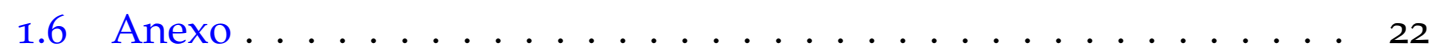

2 Construindo a agenda política $\quad 23$

2.1 Introdução ... . . . . . . . . . . . . . . 23

2.2 Dados e métodos . . . . . . . . . . . . . . 25

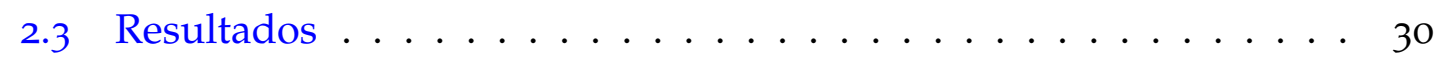

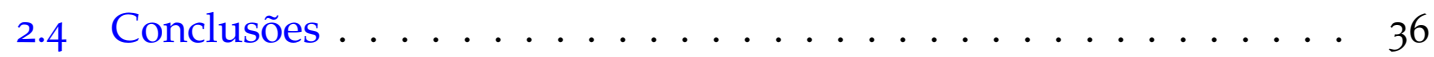

3 Ideologia, sofisticação política e voto no Brasil 38

3.1 Introdução . . . . . . . . . . . . . . . 38

3.2 Ideologia, voto e questões metodológicas . . . . . . . . . . 40

3.3 Escalonamento Bayesiano de Aldrich-McKelvey . . . . . . . . . 42

3.4 Modelo estatístico . . . . . . . . . . . . . . . . . . 44

3.5 Dados e estatística descritiva . . . . . . . . . . 47

3.6 Resultados .......................... 51

3.7 Sofisticação política e voto . . . . . . . . . . . . . . 55

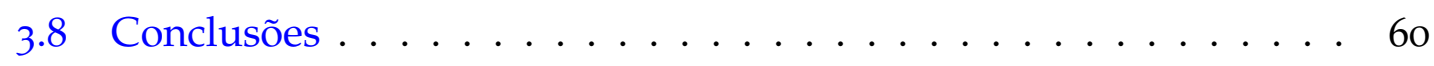

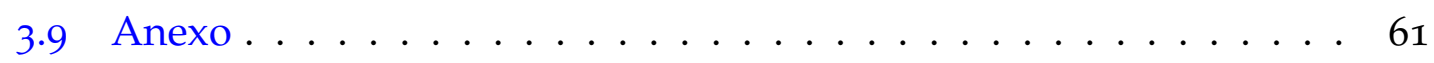


4 Ser eleito para um cargo público é um bom negócio? Evidências das eleições municipais no Brasil $\quad 65$

4.1 Introdução . . . . . . . . . . . . . . . . . . . . . 65

4.2 Dados e estratégia empírica . . . . . . . . . . . . . . 67

4.3 Balanceamento dos grupos . . . . . . . . . . . 72

4.4 Resultados ... . . . . . . . . . . . . 73

4.5 Hipóteses alternativas . . . . . . . . . . . 76

4.5 .1 Autosseleção . . . . . . . . . . . . 76

4.5 .2 Patrimônio não declarado . . . . . . . . . . . 81

4.5 .3 Municípios competitivos ... . . . . . . . . . 83

4.5.4 Patrimônio dos familiares . . . . . . . . . . . . 84

4.5 .5 Efeitos de longo prazo . . . . . . . . . . 86

4.6 Heterogeneidade dos efeitos . . . . . . . . . . . . 87

4.6.1 Partidos políticos . . . . . . . . . . . . . 8 87

4.6 .2 Região ....................... 89

4.6 .3 Experiência política ................. 90

4.7 Discussão e conclusão . . . . . . . . . . . . . . . . 90

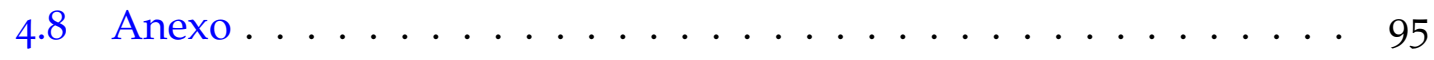




\section{Lista de Figuras}

1.1 Exemplo do resumo de um discurso . . . . . . . . . . . . . 15

1.2 Posições políticas dos partidos políticos brasileiros . . . . . . . . 17

1.3 Comparação entre o W-Nominate e o Sentiment-IRT . . . . . . . . 19

2.1 Impacto do número de projetos similares sobre a probabilidade de aprovação por origem do projeto . . . . . . . . . . . . 32

3.1 Estímulos e distribuição dos entrevistados no ano de 2010 . . . . 49

3.2 Comparação entre o autoposicionamento e os pontos ideais estimados no de $2010 \ldots \ldots \ldots$. . . . . . . . . . . . . .

3.3 Distribuição dos entrevistados por voto nas eleições de 2010 . . . . 52

3.4 Probabilidade de votar no candidato do PSDB em função dos pontos ideais dos entrevistados . . . . . . . . . . . . 53

3.5 Probabilidade de votar no candidato do PSDB em função dos pontos ideais dos entrevistados por nível de sofisticação política . . . . 59

3.6 Estímulos e distribuição dos entrevistados . . . . . . . . . . . 61

3.7 Comparação entre o autoposicionamento e os pontos ideais estimados ........................... 62

3.8 Distribuição dos entrevistados por voto . . . . . . . . . . . 63

4.1 Balanceamento dos grupos de tratamento e controle . . . . . . 73

4.2 Efeito de ser eleito sobre o patrimônio . . . . . . . . . . . 75

4.3 Simulação .......................... 82

4.4 Teste de McCrary (2008) . . . . . . . . . . . . . . 95 


\section{Lista de Tabelas}

1.1 Número de discursos, senadores e tópicos por legislatura . . . . 15

1.2 Acurácia do modelo . . . . . . . . . . . . . . . 16

2.1 Inteiro teor do PLioo/2011 . . . . . . . . . . . . . . . 26

2.2 Comparação entre o PL1375/2011 e o PL7480/2014 . . . . . . . . . 29

2.3 Resultados da regressão logística . . . . . . . . . . . . . . 32

3.1 Dados utilizados . . . . . . . . . . . . . . 48

3.2 Estimativas dos parâmetros do modelo espacial . . . . . . . . 52

3.3 Estimativas dos parâmetros do modelo espacial extendido . . . . . 57

3.4 Questões de conhecimento político . . . . . . . . . . . . . . . 64

4.1 Estatística descritiva do patrimônio dos candidatos . . . . . 70

4.2 Efeito do tratamento sobre o patrimônio . . . . . . . . . . 75

4.3 Efeito do tratamento sobre a probabilidade de concorrer a prefeito

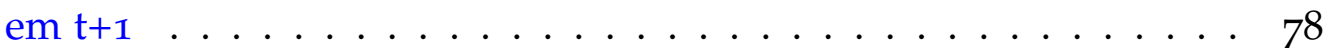

4.4 Análise de sensibilidade imputando a média e o primeiro e terceiro quartil . . . . . . . . . . . . . . . . . . 79

4.5 Análise de sensibilidade imputando valores preditos pelo modelo de regressão . . . . . . . . . . . . . . . 80

4.6 Regressão incluindo municípios com eleições não apertadas . . . . 83

4.7 Efeito do tratamento sobre o patrimônio dos familiares . . . . . . . 86

4.8 Efeitos de longo prazo do tratamento sobre o patrimônio . . . . . . 87

4.9 Efeito do tratamento sobre o patrimônio por partido . . . . . . . 88

4.1o Efeito do tratamento sobre o patrimônio por região . . . . . . . . 89 
4.11 Efeito do tratamento sobre o patrimônio por experiência política 91 


\section{Capítulo 1}

\section{Medindo posições políticas a partir}

\section{de textos}

\subsection{Introdução}

O posicionamento dos atores políticos é uma variável fundamental para a ciência política. Diversas teorias em política comparada dependem do conhecimento da posição dos partidos, candidatos e eleitores em um espaço de baixa dimensionalidade. O teste de modelos espaciais do voto, de teorias sobre a formação de coalizões e de modelos de produção de políticas, apenas para citar alguns exemplos, depende do conhecimento dessa variável. Mas infelizmente estimar as posições políticas não é uma tarefa fácil. Elas não são diretamente observáveis.

Ao longo dos anos diversas fontes de dados tem sido utilizadas para estimar posições políticas. Bons exemplos disso são votações nominais (Poole and Rosenthal, 2007; Clinton et al., 2004), pesquisas de opinião (Aldrich and McKelvey, 1977) e, mais recentemente, textos (Laver et al., 2003; Slapin and Proksch, 2008). Em particular, o uso de textos como dados tem crescido continuamente na ciência política. Isso é uma boa notícia já que o conflito político frequentemente é expressado por meio de palavras (Monroe and Schrodt, 2009; Grimmer and Stewart, 2013). Candidatos debatem uns com os outros em campanhas eleitorais, deputados escrevem projetos de leis no interior das casas legislativas, 
partidos de oposição criticam o governo nos meios de comunicação e assim por diante. Isto é, a linguagem é um importante meio para expressar as preferências políticas.

Neste capítulo desenvolvemos um modelo Bayesiano baseado na Teoria da Resposta ao Item (IRT) para estimar posições políticas utilizando discursos. A literatura que tratou do tema tem utilizado a matriz de frequência de palavras como fonte primária para modelar as posições políticas (Laver et al., 2003; Slapin and Proksch, 2008). Ao contrário dessa abordagem, utilizamos classificações feitas por meio de análise de sentimentos (Pang and Lee, 2008; Liu, 2012). Assumimos que os atores políticos que possuem opiniões divergentes sobre um amplo leque de questões também possuem preferências políticas diferentes. Por exemplo, um partido de esquerda provavelmente possui opiniões positivas sobre a expansão dos direitos dos trabalhadores e opiniões negativas sobre o direito dos cidadãos possuírem armas de fogo. Por outro lado, partidos de direita provavelmente possuem opiniões opostas sobre os mesmos tópicos. Se esse pressuposto for verdadeiro, então é possível modelar o número de opiniões positivas (ou negativas) sobre cada tópico como um modelo Binomial.

Para demonstrar a aplicação desse modelo, estimamos as posições políticas dos partidos políticos brasileiros entre 1995 e 2014 utilizando os discursos dos senadores. Os resultados sugerem que, em vez de uma clivagem ideológica, os partidos estão organizados em uma dimensão que representa o conflito entre governo e oposição.

\subsection{Técnicas de escalonamento para textos}

Nesta seção apresentamos brevemente os dois principais métodos de escalonamento para textos. O primeiro é um algoritmo supervisionado desenvolvido por Laver et al. (2003): Wordscores. Neste algoritmo, um conjunto de documentos deve ser classificado manualmente em uma dimensão definida previamente pelo pesquisador. Geralmente essa dimensão é uma escala ideológica. A partir desse conjunto já classificado o algoritmo 'aprende' a classificar novos documen- 
tos baseado na similaridade da distribuição da frequência das palavras. Dito de outra forma, Wordscores utiliza dois conjuntos de textos. O primeiro, conhecido como textos de referência (ou training set), é um conjunto de documentos cujas posições políticas são conhecidas. $\mathrm{O}$ analista deve conhecer a dimensão política previamente e localizar os textos de referência nessa escala. Geralmente os textos de referência são os extremos da escala. Em um escala ideológica, por exemplo, os extremos seriam os documentos mais de esquerda e mais de direita. Já o segundo conjunto, conhecido como textos virgens (ou test set), é composto por textos cujas posições políticas são desconhecidas. Para esses documentos observamos apenas o número de vezes que cada palavra aparece em cada documento. O objetivo do algoritmo é utilizar essa matriz com a frequência de palavras para estimar as posições políticas. O algoritmo classifica os documentos do test set em um contínuo entre os documentos do training set baseado no número de vezes que cada palavra ocorre em ambos cojuntos de textos.

Este método constitui um importante avanço na análise quantitativa de textos. No entanto ele possui algumas limitações. O principal problema é que ele depende fortemente dos textos de referência. Assim, para pesquisadores que possuem diferentes textos de referência, o método irá gerar diferentes estimativas para um mesmo conjunto de dados. Outra limitação é a possibilidade de que as diferenças entre os textos esteja mais relacionada com o estilo linguístico do que com as posições políticas. Como apontado por Lowe $(2008,361)$, no Wordscores todas as palavras adicionam a mesma quantidade de informação sobre o documento. Isso implica que palavras politicamente informativas sobre um tópico (como 'impostos' para um tema de política econômica) e palavras funcionais (como pronomes e artigos) são igualmente ponderadas pelo algoritmo.

O segundo método de escalonamento para textos é o Wordfish (Slapin and Proksch, 2008). Este é um algoritmo não supervisionado pois não depende de textos de referência. No Wordfish cada palavra $j$ de um documento $i\left(W_{i j}\right)$ é distribuída como uma Poisson de parâmetro $\lambda_{i j}, W_{i j} \sim \operatorname{Poisson}\left(\lambda_{i j}\right)$. O parâmetro da distribuição é definido como $\lambda_{i j}=\exp \left(\alpha_{i}+\psi_{j}+\beta_{j} \times \omega_{i}\right)$, onde $\alpha_{i}$ é o efeito fixo dos documentos, $\psi_{j}$ é o efeito fixo das palavras, $\beta_{j}$ é o parâmetro de discri- 
minação (ele captura a importância da palavra j em discriminar os documentos) e $\omega_{i}$ é a posição política do documento. Este modelo é similar a um modelo da Teoria da Resposta ao Item para dados de contagem.

Assim como o Wordscores, este método assume que os documentos que utilizam o mesmo conjunto de palavras são mais similares do que os documentos que utilizam um conjunto diferente. A limitação dessa abordagem está no fato de que existem outras fontes de variação no uso da palavra além das preferências políticas (Lauderdale and Herzog, 2016). Por exemplo, se observamos um documento sobre economia e outro sobre esportes, provavelmente a variação no uso das palavras é determinada inteiramente pelo tópico e não pelas posições políticas dos autores. Além disso, é possível que documentos sobre um mesmo tópico expressando as mesmas opiniões utilizem um conjunto completamente diferente de palavras. Um exemplo simples pode nos ajudar a deixar esse ponto mais claro. Suponha que observamos as seguintes frases: (1) 'Eu amo comer brócolis' e (2) 'Eu odeio comer brócolis'. As duas frases utilizam quase o mesmo conjunto de palavras. Mas expressam opiniões completamente opostas. Por outro lado, a frase (3) 'Minha comida favorita é brócolis' manifesta a mesma opinião que a frase (1), mas utiliza um conjunto bem diferente de palavras. Nessas três frases as palavras 'amo', 'odeio' e 'favorita' são fundamentais para definir o sentimento (ou opinião) sobre o tópico. Essas palavras são conhecidas como opinion words e são frequentemente utilizadas para expressar sentimentos positivos ou negativos (Liu, 2012, 5). A análise de sentimentos é o campo de estudos que utiliza opinion words para descobrir os sentimentos dos autores a respeito de um tema. Embora seja razoável imaginar que as opiniões (positivas e negativas) sobre diversos tópicos sejam relevantes para se conhecer a posição política dos atores políticos, os métodos existentes de escalonamento para textos não tem levado isso em consideração. Eles apenas levam em consideração a distribuição das palavras. 


\subsection{Modelo estatístico para escalonamento de opiniões}

Opiniões são fundamentais para todas as atividades humanas (Pang and Lee, 2008; Liu, 2012). Pessoas tendem a se relacionar com aqueles que compartilham as mesmas ideias e opiniões. Em uma eleição, eleitores escolhem os candidatos cujas opiniões são similares às suas. De acordo com Liu (2012, 11), 'uma opinião é uma quádrupla, $(g, s, h, t)$, onde $g$ é o alvo da opinião (ou sentimento), s é o sentimento a respeito do alvo, $h$ é o detentor da opinião e $t$ é o momento em que a opinião foi expressada.' Na análise de sentimentos, o foco está sobre opiniões que expressam sentimentos positivos ou negativos. Por exemplo, em seu discurso no momento da promulgação da Constituição de 1988 (5 de Outubro de 1988), Ulysses Guimarães disse: 'Eu tenho ódio e nojo à ditadura'. Nessa citação, o detentor da opinião (h) é o deputado Ulysses Guimarães. Ele possui um sentimento (s) negativo com relação à ditadura $(\mathrm{g})$ e sua opinião foi expressada no dia 5 de Outubro de $1988(\mathrm{t})$.

Assumimos que atores políticos possuem opiniões sobre um leque variado de tópicos. Isto é, eles não estão restritos a uma agenda política limitada. Além disso, atores com diferentes posições políticas possuem opiniões diferentes sobre diversos tópicos. Provavelmente políticos liberais possuem opiniões positivas sobre o casamento de pessoas do mesmo sexo e opiniões negativas sobre a pena de morte. Políticos conservadores, por outro lado, possuem posições opostas sobre os mesmos tópicos.

Em geral, opiniões são expressadas por meio de palavras. Candidatos entram em debates para defender as suas opiniões. Partidos políticos utilizam os seus programas partidários para apresentar os seus projetos aos eleitores. Parlamentares se posicionam politicamente escrevendo projetos de lei e fazendo discursos. Seguindo essa abordagem, assumimos que as opiniões expressadas por meio de palavras fornecem informações relevantes sobre as posições políticas dos atores. Se este pressuposto for verdadeiro e se assumirmos também que as opiniões são independentes e identicamente distribuídas, podemos modelar o número de opiniões positivas (ou negativas) sobre um tópico $k \in\{1, \ldots, K\}$ de 
um ator $i \in\{1, \ldots, I\}$ como um modelo Binomial. A forma funcional do modelo pode ser dada por:

$$
\begin{aligned}
& Y_{i k} \sim \operatorname{Binomial}\left(p_{i k}, n_{i k}\right) \\
& \operatorname{logit}\left(p_{i k}\right)=\alpha_{k}+\beta_{k} \times \theta_{i}
\end{aligned}
$$

onde $Y_{i k}$ é o número de opiniões positivas (ou negativas) e $n_{i k}$ é a soma de opiniões positivas e negativas expressadas pelo ator $i$ sobre o tópico $k^{1}$. $\alpha_{k}$ e $\beta_{k}$ são parâmetros associados à probabilidade de se observar uma opinião positiva (ou negativa). $\theta_{i}$ é a posição política do ator $i$. Este modelo é similar a um modelo Binomial da Teoria da Resposta ao Item com $\alpha_{k}$ sendo o parâmetro de dificuldade, $\beta_{k}$ o parâmetro de discriminação e $\theta_{i}$ o parâmetro de habilidade.

Podemos escrever a função de verossimilhança como:

$$
\begin{aligned}
\mathcal{L}(\boldsymbol{\alpha}, \boldsymbol{\beta}, \theta \mid \mathbf{N}, \mathbf{Y})= & \prod_{i=1}^{\mathrm{I}} \prod_{k=1}^{\mathrm{K}}\left(\begin{array}{c}
\mathrm{n}_{\mathrm{ik}} \\
Y_{i k}
\end{array}\right)\left\{\operatorname{logit}^{-1}\left(\alpha_{\mathrm{k}}+\beta_{\mathrm{k}} \times \theta_{i}\right)\right\}^{Y_{\mathrm{ik}}} \times \\
& \left\{\mathbf{I}-\left[\operatorname{logit}^{-1}\left(\alpha_{\mathrm{k}}+\beta_{\mathrm{k}} \times \theta_{i}\right)\right]\right\}^{n_{i k}-Y_{i k}}
\end{aligned}
$$

onde $\alpha$ é um vetor de comprimento $K$ formado pelos valores $\alpha_{k}, \beta$ é um vetor de comprimento $K$ formado pelos valores $\beta_{k}, \theta$ é um vetor de comprimento I formado pelos valores $\theta_{i}, \mathbf{N}$ é uma matriz de dimensão $\mathrm{I} \times \mathrm{K}$ formada pelos valores $n_{i k}$ e $Y$ é uma matriz de dimensão $I \times K$ formada pelos valores $Y_{i k}$.

Para completar o modelo estatístico precisamos especificar algumas distribuições a priori não informativas:

${ }^{1}$ Se o ator $i$ não expressou nenhuma opiniões sobre o tópico $k$, consideramos o número de opiniões positivas (ou negativas) como desconhecido e o número total de opiniões igual a 10. Essa é a mesma estratégia adotada por Armstrong et al. (2014, 305). 


$$
\begin{aligned}
& \alpha_{k} \sim N(0,1) \\
& \beta_{k} \sim N(0,1) \\
& \theta_{i} \sim N(0,1)
\end{aligned}
$$

Isto nos leva para a distribuição a posteriori:

$$
P(\alpha, \beta, \theta \mid \mathbf{N}, \mathbf{Y}) \propto P(\alpha, \beta, \theta) \times \mathcal{L}(\boldsymbol{\alpha}, \boldsymbol{\beta}, \theta \mid \mathbf{N}, \mathbf{Y})
$$

Seguindo Hare et al. (2014, 762), fixamos a polaridade da escala constrangendo dois atores em $\theta_{1} \sim \mathrm{N}(0,1) \mathrm{T}(-1.1,-0.9)$ e $\theta_{2} \sim \mathrm{N}(0,1) \mathrm{T}(0.9,1.1)$. Estimamos o modelo pelo Método de Monte Carlo via Cadeias de Markov (MCMC) e implementamos o código em JAGS utilizando o pacote rjags (Plummer, 2015) do R. O código está disponível no Apêndice.

Mas antes de estimarmos o modelo precisamos conhecer os tópicos e as opiniões sobre os tópicos dos documentos. Isso é necessário pois ao invés de utilizar a matriz de documentos por palavras, nós utilizamos o número de opiniões positivas/negativas em relação aos tópicos. Felizmente, existem diversas técnicas para conhecermos as duas quantidades. Existe uma literatura rica sobre a modelagem de tópicos. Desde o modelo de Alocação Latente de Dirichlet (LDA) desenvolvido por Blei et al. (2003), diversos avanços tem sido feitos. Particularmente na ciência política, Quinn et al. (2010) desenvolveram um modelo dinâmico para classificar discursos ao longo do tempo, Grimmer (2010) desenvolveu um modelo para estimar a atenção que os parlamentares dão aos diversos tópicos e Roberts et al. (2013) desenvolveram um modelo estrutural que incorpora metadados ao nível dos documentos.

De maneira semelhante, a literatura sobre análise de sentimentos tambem é rica (Pang and Lee, 2008; Liu, 2012). Uma ampla quantidade de algoritmos não supervisionados tem sido desenvolvido nos últimos anos. Um dos mais populares é uma abordagem por meio de dicionários anotados (Taboada et al., 2011). Neste tipo de técnica, o sentimento de um documento é estimado com a ajuda 
de um dicionário cujas palavras são anotadas com a orientação semântica. Por exemplo, palavras como 'ódio' e 'infelizmente' são anotadas com uma orientação negativa. Já palavras como 'amor' e 'incrível' são anotadas com uma orientação positiva. Documentos que usam mais palavras negativas do que positivas provavelmente expressam uma opinião negativa.

Outra técnica bastante utilizada em análise de sentimentos é o Classificador de Naive Bayes (Murphy, 2012). Esta abordagem é similar ao Wordscores na medida em que necessitamos de um training set. Em primeiro lugar, selecionamos um conjunto de documentos e classificamos manualmente os sentimentos (training set). Depois classificamos os sentimentos de novos documentos (test set) por meio de uma regra. Como o nome sugere, esta técnica classifica os sentimentos aplicando a regra de Bayes com um pressuposto de independência entre as frequências de palavras. Mais formalmente, seja d um documento composto pelas palavras $\left\{w_{1}, \ldots, w_{n}\right\}$ e $S=\left\{s_{1}, \ldots, s_{k}\right\}$ as opiniões expressadas em $d$. Pela regra de Bayes:

$$
\mathrm{P}\left(\mathrm{S}=s_{\mathrm{i}} \mid w_{1}, \ldots, w_{\mathrm{n}}\right)=\frac{\mathrm{P}\left(\mathrm{S}=\mathrm{s}_{\mathrm{i}}\right) \mathrm{P}\left(w_{1}, \ldots, w_{\mathrm{n}} \mid \mathrm{S}=\mathrm{s}_{\mathrm{i}}\right)}{\mathrm{P}\left(w_{1}, \ldots, w_{\mathrm{n}}\right)}
$$

Assumindo independência condicional entre os $w_{i}$ (pressuposto naive), temos:

$$
P\left(S=s_{i} \mid w_{1}, \ldots, w_{n}\right)=\frac{P\left(S=s_{i}\right) \prod_{j=1}^{n} P\left(w_{j} \mid S=s_{i}\right)}{P\left(w_{1}, \ldots, w_{n}\right)}
$$

Utizamos o training set para estimar $\mathrm{P}\left(\mathrm{S}=\mathrm{s}_{\mathfrak{i}}\right)=\frac{\operatorname{count}\left(s_{i}\right)}{\mathrm{T}}$ e $\mathrm{P}\left(w_{\mathrm{k}} \mid \mathrm{S}=s_{\mathfrak{i}}\right)=$ $\frac{\operatorname{count}\left(w_{k}, s_{i}\right)+1}{\operatorname{count}\left(s_{i}\right)+\mid \text { Vocabulary } \mid}$, onde count $\left(s_{i}\right)$ é o número de documentos classificados como $s_{i}$, $T$ é número total de documentos no training $\operatorname{set}, \operatorname{count}\left(\mathcal{w}_{k}, s_{i}\right)$ é o número de vezes que a palavra $w_{k}$ ocorre em $s_{i}$ e $\mid$ Vocabulary| é o número de total de palavras únicas.

Com isso a regra de classificação para um documento $\mathrm{d}^{*}$ composto pelas palavras $\left\{w_{1}^{*}, \ldots, w_{n}^{*}\right\}$ é dado por: 


$$
S^{*} \leftarrow \arg \max _{s_{i} \in S} P\left(S=s_{i}\right) \prod_{j=1}^{n} P\left(w_{j}^{*} \mid S=s_{i}\right)
$$

Em resumo, para implementar o modelo estatístico proposto é necessário conhecer o tópico e a opinião sobre o tópico de cada documento. Se tivermos essas informações, podemos estimar as posições políticas dos atores modelando o número de opiniões positivas (ou negativas) sobre um tópico como um modelo Binomial.

\subsection{Aplicação: partidos políticos brasileiros}

Nesta seção estimamos a posição dos principais partidos políticos brasileiros entre 1995 e $2014^{2}$. Ao todo observamos cinco legislaturas sob o governo de três presidentes diferentes. Utilizamos o resumo dos discursos feitos no plenário do Senado Federal como fonte primária. Na figura 1.1 apresentamos um exemplo de resumo. Nele temos as principais informações do autor e do discurso. Neste caso, o discurso foi proferido pelo senador Álvaro Dias (PDT-PR) e trata sobre a atuação do governo brasileiro no que se refere à política protecionista das nações desenvolvidas. Junto com o resumo do discurso também temos um conjunto de palavras-chave ('Indexação') e uma classificação temática ('Catálogo'). Neste caso o discurso foi classificado em duas categorias: 'Política agrícola' e 'Comércio exterior'.

Na tabela 1.1 apresentamos uma estatística descritiva dos dados. Ao todos observamos 64.097 discursos feitos por 347 senadores. PT, PSDB e PMDB foram responsáveis por mais de $60 \%$ dos discursos.

Como os discursos foram classificados em tópicos pelo staff do Senado Federal, não precisamos aplicar nenhuma técnica de modelagem de tópicos para recuperar os temas dos discursos. Ao todo temos 275 tópicos. Os cinco mais falados são 'Homenagem' (12.141), 'Atuação' (7074), 'Governo Federal' (5604), 'Desenvolvimento Regional' (3138) e 'Senado' (2922). Alguns discursos foram

\footnotetext{
${ }^{2}$ Selecionamos os partidos com pelo menos três senadores e que fizeram pelo menos 500 discursos por legislatura.
} 
Figura 1.1: Exemplo do resumo de um discurso

Pronunciamento de Alvaro Dias em 14/05/2002

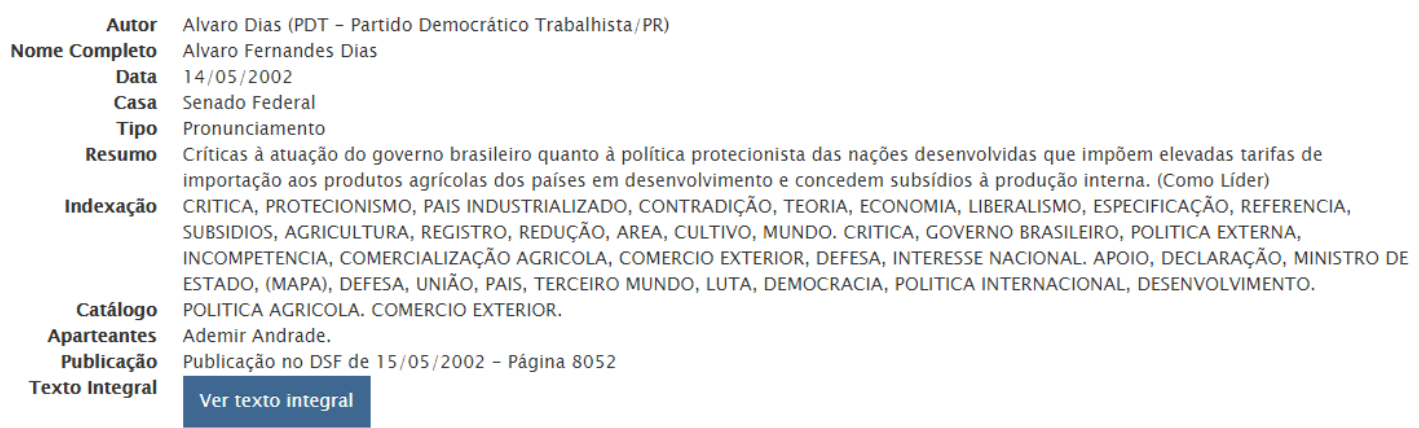

Fonte: Senado Federal

Tabela 1.1: Número de discursos, senadores e tópicos por legislatura

\begin{tabular}{lccc}
\hline Legislatura & N de discursos & N de senadores & N de tópicos \\
\hline FHC 1 (1995-1998) & 9960 & 125 & 181 \\
FHC 2 (1999-2002) & 9291 & 128 & 189 \\
Lula 1 (2003-2006) & 18.019 & 108 & 200 \\
Lula 2 (2007-2010) & 15.951 & 111 & 189 \\
Dilma 1 (2011-2014) & 10.876 & 109 & 209 \\
\hline Todas (1995-2014) & 64.097 & 347 & 275 \\
\hline
\end{tabular}

classificados em mais de um tópico. Em situações como essa, nós duplicamos o discurso em nossa base de dados. Assim, no exemplo acima, temos um entrada para 'Política agrícola' e outra para 'Comércio exterior'. Cerca de $45 \%$ dos discurso dizem respeito a mais de um tópico.

Para classificar as opiniões utilizamos o Classificador de Naive Bayes apresentado na seção anterior. Para treinar o modelo selecionamos uma amostra aleatória dos discursos de tamanho 1000 e os classificamos manualmente como positivos ou negativos. A classificação foi feita com base no resumo dos discursos. Em geral, os resumos apresentam as opiniões dos autores sobre os tópicos. Em nosso training set, $52,5 \%$ dos discursos foram classificados como positivos e $47,5 \%$ como negativos. Utilizamos então esse training set para classificar o restante dos discursos. $45 \%$ deles foram classificados como positivos e $55 \%$ como 
negativos ${ }^{3}$.

Para avaliar a acurácia do modelo, selecionamos uma amostra aleatória de tamanho 1000 dos discursos que foram classificados pelo algoritmo e os classificamos manualmente. Então cruzamos a classificação manual com a classificação feita pelo modelo de Naive Bayes. Os resultados são apresentados na tabela 1.2. Como podemos ver, a acurácia é alta, 76,2\%.

Tabela 1.2: Acurácia do modelo

\begin{tabular}{lc|c|c|} 
& \multicolumn{3}{c}{ Classificador de Naive Bayes } \\
& & \multicolumn{1}{c}{ Positivo } & Negativo \\
\cline { 3 - 4 } Classificação manual & Positivo & 378 & 141 \\
\cline { 3 - 4 } & Negativo & 97 & 384 \\
\cline { 3 - 4 } & & &
\end{tabular}

Na figura 1.2 nós apresentamos os resultados para cada legislatura. Para identificar o modelo nós restringimos as posições do PT e do PSDB em $\theta_{\mathrm{PT}} \sim$ $\mathrm{N}(\mathrm{O}, 1) \mathrm{T}(-1.1,-0.9)$ e $\theta_{\mathrm{PSDB}} \sim \mathrm{N}(\mathrm{O}, \mathrm{I}) \mathrm{T}(0.9,1.1)$, respectivamente. Estamos modelando o número de opiniões positivas.

Geramos 55.000 amostras, descartamos as primeiras 5000 e retemos as restantes por um fator de 50. Isso produziu um conjunto de 1000 amostras. Para avaliar formalmente a convergência da cadeia nós utilizamos o diagnóstico proposto por Geweke (1992). Este método é baseado em um teste de igualdade de médias da primeira (10\%) e da última (50\%) parte da cadeia de Markov. Se as duas médias são iguais, nós podemos concluir que as amostras foram retiradas da distribuição estacionária. A estatística do teste é um escore $z$ padronizado. Desta forma, não gostaríamos de observar parâmetros fora do intervalo [-1.96, 1.96] para um intervalo de $95 \%$. Os resultados mostram que apenas 109 dos $1979(6 \%)$ dos parâmetros tem estatísticas fora desse intervalo. Isso sugere que as amostras são provenientes da distribuição estacionária.

Como podemos ver na figura 1.2, o modelo não recupera uma clivagem ideológica. Em verdade, o que nós podemos observar é uma dimensão governo-

\footnotetext{
${ }^{3}$ Antes de aplicar o Classificador de Naive Bayes, nós limpamos os textos removendo pontuações, letras maiúsculas, stop words e palavras muito e pouco frequentes (que apareceram em menos de $1 \%$ e em mais de $99 \%$ dos discursos). Nós também simplificamos o vocabulário por meio do stemming.
} 
Figura 1.2: Posições políticas dos partidos políticos brasileiros
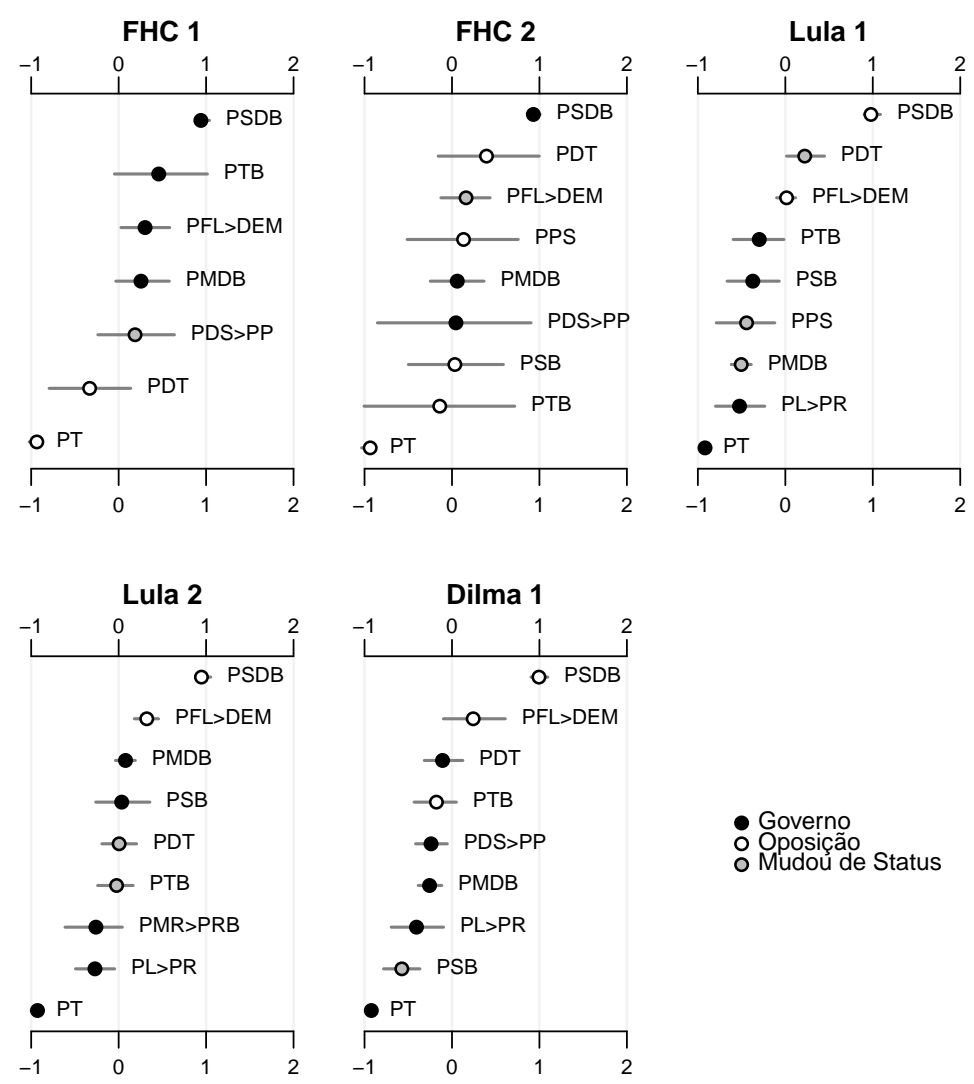

Nota: Cada ponto representa a média a posteriori das posições políticas $\left(\theta_{i}\right)$. As linhas horizontais em cinza representam os intervalos de credibilidade de $95 \%$. 
oposição com o PT e o PSDB nas extremidades da escala.

Durante o primeiro governo do presidente Fernando Henrique Cardoso (PSDB), a divisão entre governo e oposição foi mais clara. Ele governou com uma aliança formada por partidos de centro-direita. No lado esquerdo da escala, vemos os dois principais partidos de oposição da época, PT e PDT (ambos partidos de esquerda). Do outro lado da escala, estão os partidos com cargos ministeriais, PTB, PFL4 e PMDB, mais o partido do presidente. Entre os dois blocos está localizado o PPB5 , um dos partidos mais à direita do ponto de vista ideológico durante o período. Este partido começou a legislatura na oposição e depois juntou-se ao governo em Abril de 1996. O PPB foi incluído à coalizão governamental para passar a emenda constitucional da reeleição. Mas mesmo antes desse evento, evidências mostram que o partido já apoiava o governo em votações nominais (Izumi, 2016).

O segundo governo do presidente Fernando Henrique Cardoso foi mais complicado. Não há muita diferença entre os partidos. Todos eles apoiaram o presidente, com exceção do PT. A composição da coalizão foi semelhante à do governo anterior, uma coalizão de centro-direita composta por três partidos, $\mathrm{PFL}^{6}$, PMDB e PPB. Mas durante este período, mesmo partidos de esquerda sem pastas ministeriais, como é o caso do PDT, deram suporte ao presidente. Resultados similares foram encontrados por Zucco and Lauderdale (2011). De acordo com os autores, este resultado estaria relacionado com a coerência ideológica da coalizão formada.

O presidente Lula (PT) começou o seu governo com uma ampla coalizão formada por sete partidos de todo espectro ideológico (PL7, PCdoB, PSB, PTB, PDT, PPS e PV). Após um ano de governo, duas mudanças ocorreram na composição do gabinete: PMDB juntou-se ao governo e o PDT foi para a oposição após desacordos sobre a condução de algumas políticas. Estes movimentos são consistentes com o que é apresentado no gráfico. Basicamente, a oposição é

\footnotetext{
4Em 2007, o PFL mudou o seu nome para DEM.

5PPB é o nome atual do PDS, sucessor da ARENA. Em 1993, o PDS incorporou o PDC e mudou o seu nome para PPR. Por sua vez, o PPR incorporou o PP em 1995.

${ }^{6} \mathrm{O}$ PFL deixou a coalizão de governo em Março de 2002 por razões eleitorais.

7Em 2006, o PL se fundiu ao PRONA e mudou o seu nome para PR.
} 
Figura 1.3: Comparação entre o W-Nominate e o Sentiment-IRT

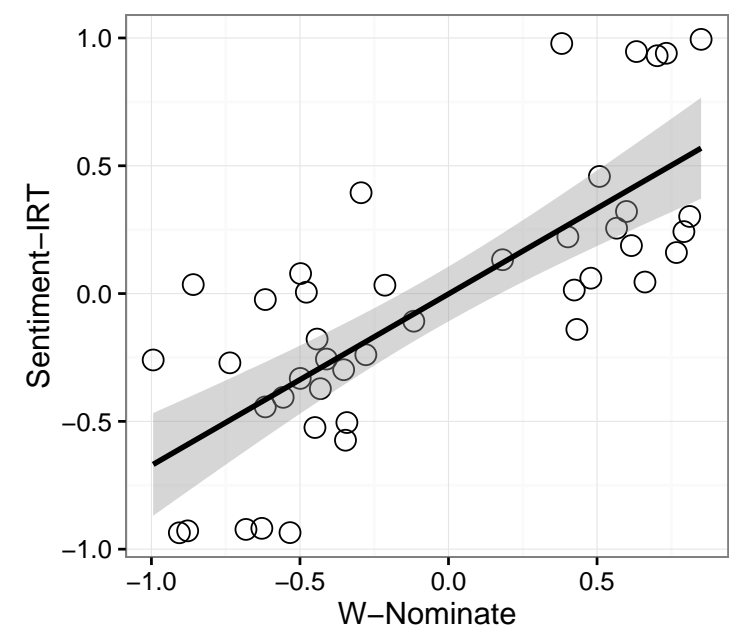

Nota: O eixo horizontal representa a média das coordenadas dos senadores agrupadas por partido estimada pelo W-Nominate. As coordenadas foram estimadas utilizando as votações nominais do Senado Federal. O eixo vertical representa a média a posteriori das posições dos partidos $\left(\theta_{i}\right)$.

composta por PSDB, PFL e PDT. Já os demais partidos apoiaram o governo.

Em seu segundo mandato, Lula formou uma aliança com PR, PCdoB, PSB, PTB, PMDB, PP e PRB ${ }^{8}$. Quatro meses depois, o PDT juntou-se aos governistas após um convite do presidente e, em Setembro de 2009, o PTB foi para a oposição. Ambos, PDT e PTB, apresentaram um comportamento pró governo. Por outro lado, PSDB e DEM se opuseram a ele.

Em 2011, Dilma Rousseff (PT) começou o seu governo com o apoio de seis partidos (PR, PCdoB, PSB, PMDB, PDT e PP). A primeira mudança na coalizão ocorreu em Março de 2012 quando o PRB se juntou ao governo. A segunda ocorreu em Outubro de 2013 quando o PSB, o aliado natural do PT nas disputas estaduais, deixou a coalizão para apoiar o candidato Eduardo Campos para a corrida presidencial de 2014. Mas mesmo após a sua saída, o PSB continou a apoiar a agenda governamental. De forma similar, o PTB também apoiou o governo em plenário, a despeito de não possuir uma posição ministerial. Do outro lado da escala estão concentrados PSDB e DEM, os principais partidos de oposição durante a gestão do PT.

\footnotetext{
${ }^{8}$ Em 2006, o PMR mudou o seu nome para PRB.
} 
Para corroborar a nossa interpretação de que as medidas geradas pelo nosso modelo representam o conflito entre governo e oposição, nós comparamos as posições estimadas (baseadas nos discursos dos senadores) com as coordenadas produzidas pelo W-Nominate (baseadas em votações nominais). Zucco (2009) apresenta evidências de que os pontos ideais em uma dimensão gerados pelo W-Nominate no caso brasileiro representam o conflito entre governo e oposição. De acordo com ele, os presidentes possuem um papel importante no comportamento em plenário dos parlamentares. Por meio de seus recursos institucionais e da distribuição de benefícios, os presidentes seriam capazes de alterar as posições políticas dos parlamentares.

Na figura 1.3 nós apresentamos a comparação entre as duas medidas. A forte correlação $(r=0.76)$ entre elas dá suporte à ideia de que a nossa medida também representa a dimensão governo-oposição.

Este resultado é interessante. Tradicionalmente, as análises sobre a influência exercida pelos presidentes sobre os partidos políticos e sobre os parlamentares tem sido confinadas às votações nominais. Neste capítulo, nós mostramos que essa influência pode ser extendida a outras atividades legislativas, como os discursos.

\subsection{Conclusões}

A disponibilidade de fontes de dados textuais tem crescido enormemente nos últimos anos, assim como as técnicas para analisá-las. Esses tipos de dados e de métodos são fundamentais para a ciência política já que palavras, sejam elas faladas, sejam elas escritas, são um importante veículo pelo qual o conflito político é expressado.

Neste capítulo nós desenvolvemos um modelo estatístico para estimar as posições políticas dos atores usando textos como dados. Nossa abordagem está baseada em análise de sentimentos. Em vez de modelar a distribuição da frequência de palavras, como os métodos existentes modelam, nosso modelo utiliza as opiniões expressadas pelos documentos. Dessa forma conseguimos conectar a 
Teoria da Resposta ao Item com a análise de sentimentos.

Para validar nosso método estimamos as posições dos partidos políticos brasileiros. Como vimos, os partidos estão organizados em uma dimensão não ideológica que representa o conflito entre governo e oposição. Esse resultado é similar aos achados anteriores provenientes de análises das votações nominais. Assim, presidentes e partidos políticos exercem uma influência signficativa não apenas em como os parlamentares votam, mas também em sobre como eles falam.

Além de parecer uma alternativa mais frutífera estimar posições políticas a partir de opiniões sobre tópicos do que utilizar uma matriz de frequência de palavras, nossa abordagem tem outras vantagens. Uma delas é a possibilidade de abranger especificações alternativas. Por exemplo, é possível estimar um modelo dinâmico permitindo que os parâmetros $\theta_{i}$ variem ao longo do tempo (Martin and Quinn, 2002). Nessa especificação, poderíamos assumir que as posições políticas $\theta_{i, t}$ não são independentes de $\theta_{i, t-1}$.

Outra possibilidade é incluir outras informações além dos discursos. Seguindo Clinton and Jackman (2009), poderíamos utilizar uma distribuição a priori informativa por meio de uma modelagem hierárquica. Tais informações adicionais poderiam ter origem no conhecimento acumulado produzido por pesquisas anteriores. Particularmente ao caso brasileiro, um longo debate tem sido feito sobre como os parlamentares se comportam e qual o papel dos presidentes em modelar as suas preferências. Nosso modelo permite incluir essas informações. 


\subsection{Anexo}

Código em JAGS para implementar o Sentiment-IRT

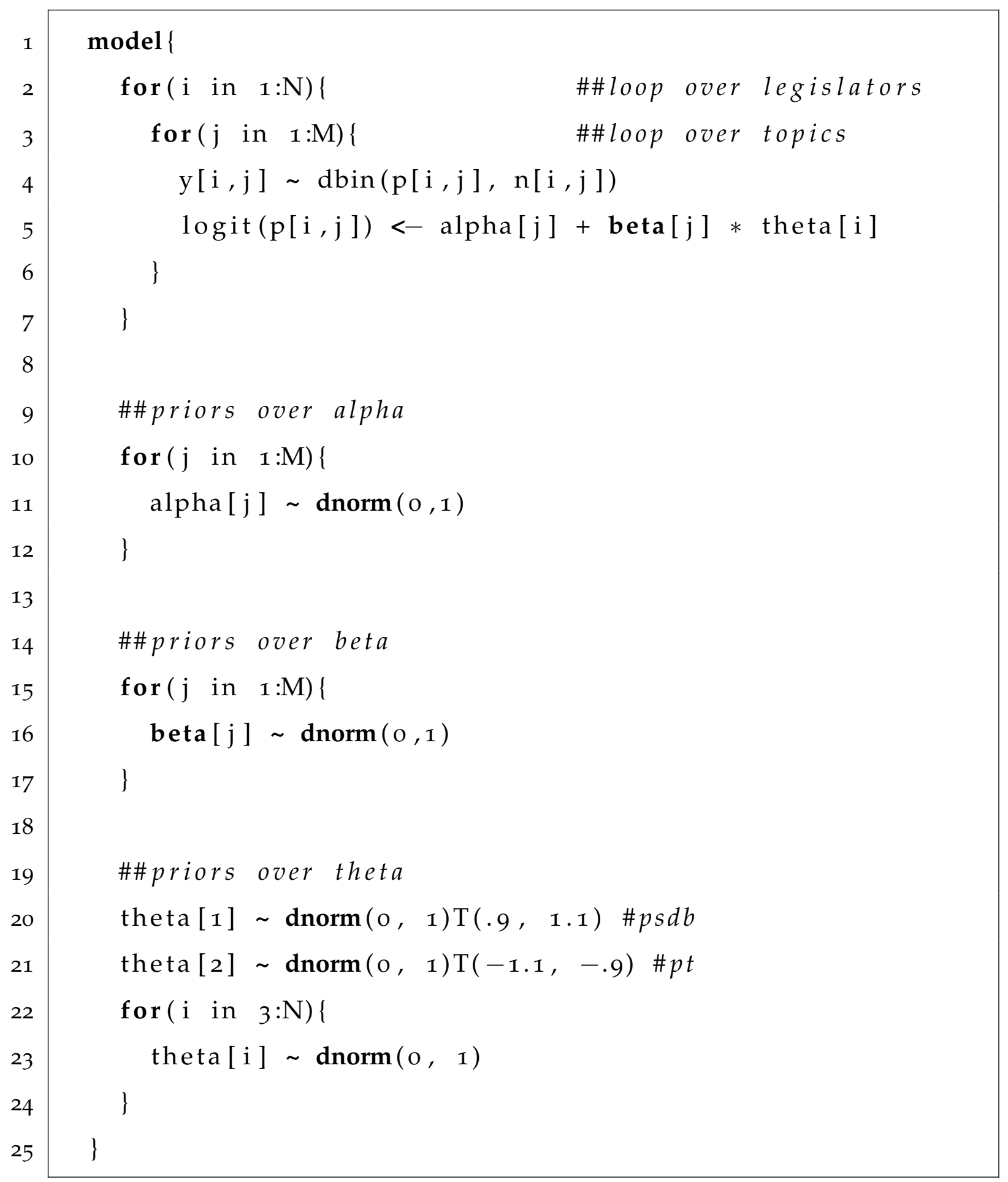




\section{Capítulo 2}

\section{Construindo a agenda política}

\subsection{Introdução}

A produção de leis é uma das principais atividades de um governo. É por meio da formulação de leis que os governos são capazes de implementar as suas agendas políticas e mudar o status quo. Durante uma legislatura milhares de projetos de lei (PL's) são apresentados por parlamentares, por membros do Poder Executivo e do Judiciário e pela população em geral. No entanto, apenas uma pequena porcentagem desses projetos realmente se tornam uma norma jurídica. Durante a $54^{\text {a }}$ legislatura da Câmara dos Deputados (2011-2015), por exemplo, quase 7000 projetos de lei foram apresentados, mas apenas $1 \%$ deles foram aprovados.

Embora essa taxa de aprovação seja baixa, argumentamos neste capítulo que projetos que não foram aprovados estão longe de serem irrelevantes. As ideias apresentadas neles muitas vezes influenciam o conteúdo de outros projetos. Isto é, as ideais sobre políticas presentes em um projeto apresentado por um deputado $i$ no tempo $t$ reaparecem em um projeto de um deputado $j$ (ou pelo Executivo) no tempo $t+1$.

Assim o objetivo deste capítulo é analisar como ideias sobre políticas são construídas ao longo do tempo. Em termos empíricos, verificamos como o conteúdo presente em um projeto de lei reaparece de forma semelhante em outros projetos. Avaliamos também qual o impacto da inclusão de preferências sobre a 
sua probabilidade de aprovação. Para isso utilizaremos todos os projetos de lei apresentados durante a $54^{\mathrm{a}}$ legislatura na Câmara dos Deputados e técnicas de análise quantitativa de textos.

A literatura brasileira sobre produção legislativa tem se concentrado sobre o processo de tramitação individual dos projetos e os mecanismos institucionais dos presidentes. De acordo com Figueiredo and Limongi (1999), o Executivo domina a produção legal - mais de $70 \%$ dos projetos aprovados são de origem do Executivo - e tem uma alta taxa de sucesso na apresentação de seus projetos - mais de $85 \%$ dos projetos enviados por ele são aprovados. A explicação para esses resultados estaria nos poderes legislativos do presidente. Ao controlar a agenda, isto é, o que será votado e quando o será, os presidentes estariam em uma posição estratégica para aprovar os seus projetos.

Em uma abordagem diferente, Freitas (2016) mostra o papel exercido pelo Legislativo no processo de formatação das leis. Analisando os projetos apresentados pelo Executivo que foram aprovados entre 1995 e 2010, a autora mostra que o Legislativo participa ativamente da formulação de políticas modificando, adicionando e suprimindo conteúdo dos projetos do Executivo. Os resultados apontam que, em média, 36\% do texto das leis são produzidas pelo Legislativo e $64 \%$ pelo Executivo. Isto é, mesmo que o Executivo domine a agenda, isso não quer dizer que o Legislativo não participe na formatação do seu conteúdo.

Silva and Araújo (2010), por sua vez, mostram como o Executivo tem se apropriado de projetos do Legislativo para construir sua própria agenda. A partir de uma análise aprofundada de vinte proposições legislativas e de entrevistas realizadas com consultores legislativos, os autores dão indícios de que o Executivo se apropria do conteúdo de projetos elaborados por parlamentares ao apresentá-los por meio de medidas provisórias ou como PL's de sua autoria.

Este capítulo busca contribuir com esse debate de duas formas. A primeira contribuição é metodológica: por meio de técnicas de análise quantitativa de texto, procuramos fornecer uma medida mais objetiva da similaridade das ideias sobre políticas das proposições legislativas. A segunda contribuição é substantiva: mostramos como o fato de um projeto ter ideias que foram apresentadas 
em projetos anteriores aumentam as suas chances de aprovação. $\mathrm{O}$ argumento aqui é que ao apresentar um projeto muito semelhante a outro já existente, o autor não está apenas reproduzindo as suas ideias, mas sim adicionando conteúdo novo a ele. A adição de conteúdo ao projeto agrega preferências que não estavam presentes em suas versões anteriores. Assim, a inclusão de interesses seria o mecanismo associado ao aumento das chances de aprovação.

Este capítulo possui duas seções, além desta introdução e da conclusão. $\mathrm{Na}$ seção que se segue apresentamos os nossos dados e métodos. Para medir a similaridade das ideias sobre políticas entre os projetos de lei utilizamos técnicas de análise quantitativa de textos. Em particular, aplicamos um algoritmo frequentemente utilizado na detecção de plágio (similaridade de cosseno). Em seguida, apresentamos os nossos resultados. Mostramos que cerca de $8 \%$ dos projetos apresentados foram influenciados por outros projetos apresentados durante a mesma legislatura. Mostramos também que projetos que foram influenciados por outros projetos tem mais chances de aprovação, principalmente se eles forem de origem do Executivo. Projetos que foram aprovados foram influenciados, em média, por 2,63 projetos. Já projetos que não foram aprovados foram influenciados, em média, por apenas 0,19 projetos.

Por fim, sugerimos que a inclusão de interesses é o fator chave para um projeto se tornar lei. Mostramos que em mais de 70\% dos casos eles foram influenciados por ideias formuladas por outros partidos. Isso sugere que, em geral, preferências distintas as dos autores dos projetos estão sendo incluídas. Mostramos também que em mais de dois terços das vezes os projetos adicionaram conteúdo em relação a versões anteriores. Quando comparados com aqueles projetos que suprimiram conteúdo ou que são meras cópias, os projetos que adicionaram conteúdo tem dez vezes mais chances de serem aprovados.

\subsection{Dados e métodos}

O primeiro objetivo deste capítulo é verificar como ideias sobre políticas que aparecem em um projeto de lei ressurgem em outros projetos futuros. Para isso 
Tabela 2.1: Inteiro teor do PL10o/2011

Estabelece normas para facilitar o acesso das pessoas portadoras de deficiência com com mobilidade reduzida nos centros comerciais, 'shopping centers' e hipermercados e dá outras providências.

O Congresso Nacional decreta:

Art. $1^{\mathrm{O}}$ - Os centros comerciais e 'shopping centers' e hipermercados, instalados em todo o território nacional disponibilizarão elevadores para uso exclusivo de portadores de deficiência física.

Art. $2^{\mathrm{O}}$ - Deverão ser afixadas em local de grande visibilidade, nas dependências externa e interna dos centros comerciais, 'shopping centers' e hipermercados, placas indicativas da localização dos respectivos elevadores.

Art. $3^{\mathrm{O}}$ - A não-observância desta lei sujeitará o infrator à multa pecuniária de $\mathrm{R} \$ 5.000,00$ (cinco mil reais), valor que será corrigido anualmente Índice Geral de Preços do Mercado (IGPM), aplicada em dobro em caso de reincidência.

Art. $4^{\mathrm{O}}$ - A fiscalização do cumprimento desta lei caberá competentes do Poder Executivo.

Art. $5^{\mathrm{o}}$ - Esta lei entra em vigor na data de sua publicação.

iremos utilizar todos os projetos de lei apresentados na Câmara dos Deputados entre $1^{\mathrm{O}}$ de fevereiro de 2011 e 31 de janeiro de 2015 ( $54^{\mathrm{a}}$ legislatura). Esse período coincide com o primeiro governo da presidente Dilma Rousseff (PT).

De acordo com a Constituição brasileira, um projeto de lei pode ser proposto por qualquer membro do Poder Legislativo (deputados ou senadores), por comissões (da Câmara, do Senado ou do Congresso Nacional), pelo presidente, por membros do Poder Judiciário (Supremo Tribunal Federal, Tribunais Superiores ou pelo Procurador-Geral da República) e por cidadãos comuns (por meio dos projetos de iniciativa popular). Com exceção dos projetos de lei de autoria dos senadores que iniciam a tramitação no Senado Federal, todos eles são apresentados na Câmara dos Deputados. Ao todo observamos 6732 projetos de lei apresentados na Câmara dos Deputados. Mais de 96\% deles são de autoria de deputados (de forma individual ou coletiva).

Iremos trabalhar com o inteiro teor dos projetos. Isto é, o texto da lei na forma em que ele foi apresentado. Na tabela 2.1 temos um exemplo do PL10o/2011 de autoria do deputado Walter Tosta (PMN-MG). 
Em geral, os projetos de lei seguem esse formato. Primeiramente temos uma ementa onde é apresentado o objetivo do projeto. Logo em seguida temos os artigos do projeto. Em média, os projetos são constituídos por 382 palavras. Mas isso varia bastante, o desvio padrão é de 1446 palavras. O menor projeto tem $5^{1}$ palavras e o maior tem mais de 85.000 palavras.

O primeiro passo para se analisar quantitativamente os textos das leis é reduzir a sua complexidade (Grimmer and Stewart, 2013). Para isso excluímos pontuações, números, palavras poucos informativas que possuem funções gramaticais (stopwords) e palavras muito e pouco frequentes (que aparecem em mais de $99 \%$ e em menos de $1 \%$ dos textos). Além disso, simplificamos o vocabulário por meio de stemming. Isto é, reduzimos as palavras que se referem ao mesmo conceito a uma única raíz. Por exemplo, as palavras 'economia', 'economista' e 'economistas' foram reduzidas à raíz 'econom'. Com isso criamos a nossa matriz de documentos por termos (document-term matrix). Essa matriz é formada por 6732 linhas (número de documentos) e 1551 colunas (número de termos) cujas entradas são o número de vezes que cada termo apareceu em cada documento. Dessa forma, cada documento pode ser definido como um vetor em um espaço de dimensão 1551 .

A partir desses vetores podemos criar uma medida de similaridade baseada no produto interno entre eles. Sejam $\mathbf{u}$ e $\mathbf{v}$ dois vetores em $\mathbb{R}^{1551}$, o produto interno entre $\mathbf{u}$ e $\mathbf{v}$ é dado por: $\mathbf{u} \cdot \mathbf{v}=\sum_{i=1}^{1551} u_{i} v_{i}$. Quando os dois vetores tem valores altos nas mesmas dimensões, maior será o produto interno. Dito de outra forma, quando temos um produto interno alto, temos um indício de que a distribuição do conjunto de termos utilizada pelos documentos é similar.

Mas se definirmos o comprimento (ou norma) de um vetor $\mathbf{v}$ como $\|\mathbf{v}\|=$ $\sqrt{\sum_{i=1}^{1551} v_{i}^{2}}$, é fácil observar que quanto maior o comprimento dos vetores, maior será o produto interno. Quando o vetor possui valores altos em cada dimensão, maior será o seu comprimento e, consequentemente, maior será o produto interno entre os vetores. Assim, documentos que utilizam palavras muito frequentes terão um comprimento maior e, como palavras frequentes tendem a ocorrer em vários documentos, maior será o produto interno entre os documentos. 
A solução para esse problema é dividir o produto interno pelo produto dos comprimentos dos vetores, $\frac{\mathbf{u} \cdot \mathbf{v}}{\|\mathbf{u}\| \cdot\|\mathbf{v}\|}$. Mas sabemos da geometria analítica que $\mathbf{u} \cdot \mathbf{v}=\|\mathbf{u}\| \cdot\|\mathbf{v}\| \cdot \cos \theta$. Portanto, $\cos \theta=\frac{\mathbf{u} \cdot \mathbf{v}}{\|\mathbf{u}\| \cdot\|\mathbf{v}\|}$. Essa medida $\cos \theta$, que nada mais é do que o cosseno do ângulo entre $\mathbf{u}$ e $\mathbf{v}$, é conhecida como similaridade de cosseno (Jurafsky and Martin, 2014). Ela varia de zero a um, já que as entradas da matriz de documentos por termos assumem apenas valores positivos. Quanto mais próximo de um, maior a similaridade entre os documentos. Utilizamos essa medida para avaliar como as ideias sobre políticas de um projeto de lei ressurgem em outros projetos.

Excluímos da análise todos os projetos que tratam de homenagens e de criações de datas comemorativas por terem pouca relevância. Com isso temos um total de 6355 projetos. Comparamos cada projeto de lei com todos os outros projetos que foram apresentados anteriormente a ele. Por exemplo, se um projeto foi apresentado em $1^{\mathrm{O}}$ de abril de 2012, comparamos este projeto com todos os outros apresentados entre $1^{0}$ de janeiro de 2011 e $1^{0}$ de abril de 2012. Assim, podemos traçar a evolução de uma ideia ao longo da legislatura.

Seguimos uma estratégia conservadora para classificar quais projetos estão relacionados. Não consideramos simplesmente que um projeto possui uma ideia semelhante a outro projeto se o cosseno entre eles for maior do que zero. Consideramos apenas cossenos maiores do que o,8 entre projetos que tratam do mesmo tema. Utilizamos esses critérios porque uma importante fonte de variação no uso de palavras é o estilo do documento (Lauderdale and Herzog, 2016). Textos de leis tendem a ser similares entre si pois possuem a mesma estrutura. Por se tratar de projetos de lei, eles compartilham uma similaridade que não está relacionada às ideias políticas que eles carregam. Utilizando esses critérios de classificação, estamos reduzindo as chances de classificar projetos como relacionados, quando na verdade eles não o são. Por outro, estamos deixando de classificar projetos como relacionados quando na verdade eles são relacionados. Preferimos errar pelo lado conservador.

Na tabela 2.2 temos uma comparação entre o PL7480/2014 de autoria do deputado Gustavo Petta (PCdoB-SP) e o PL1375/2011 da deputada Professora 
Tabela 2.2: Comparação entre o PL1375/2011 e o PL7480/2014

\begin{tabular}{|c|c|}
\hline PL1375/2011 & PL748o/2014 \\
\hline $\begin{array}{l}\text { Altera a redação do art. 11 da Lei } n^{\circ} \\
11.180 \text {, de } 23 \text { de setembro de 2005, no que } \\
\text { se refere ao valor da bolsa-permanência } \\
\text { do Programa Universidade para Todos - } \\
\text { PROUNI. } \\
\text { O Congresso Nacional decreta: } \\
\text { Art. } 1^{0} \text { O art. 11 da Lei } n^{0} 11.180 \text {, } \\
\text { de } 23 \text { de setembro de 2005, passa a } \\
\text { vigorar com a seguinte redação: } \\
\text { 'Art. 11. Fica autorizada a conces- } \\
\text { são de bolsa-permanência, no valor } \\
\text { de até um salário mínimo mensal, ex- } \\
\text { clusivamente para custeio das despe- } \\
\text { sas educacionais, a estudante benefi- } \\
\text { ciário de bolsa integral do Programa } \\
\text { Universidade para Todos - Prouni, } \\
\text { instituído pela Lei no } 11.096 \text {, de } 13 \\
\text { de janeiro de } 2005 \text {, matriculado em } \\
\text { curso de turno integral, conforme cri- } \\
\text { térios de concessão, distribuição, ma- } \\
\text { nutenção e cancelamento de bolsas a } \\
\text { serem estabelecidos em regulamento, } \\
\text { inclusive quanto ao aproveitamento e } \\
\text { à freqüência mínima a ser exigida do } \\
\text { estudante.' (NR) } \\
\text { Art. } 2^{\circ} \text { Esta lei entra em vigor na data } \\
\text { de sua publicação. }\end{array}$ & $\begin{array}{l}\text { Altera a redação do art. } 11 \text { da Lei } n^{\circ} \\
11.180 \text {, de } 23 \text { de setembro de } 2005 \text {, com } \\
\text { relação à concessão de bolsa-permanência } \\
\text { para estudantes beneficiários do Pro- } \\
\text { grama Universidade para Todos (Prouni). } \\
\text { O Congresso Nacional decreta: } \\
\text { Art. } 1^{\circ} \text { O art. 11 da Lei no } 11.180 \text {, } \\
\text { de } 23 \text { de setembro de 2005, passa a } \\
\text { vigorar com a seguinte redação: } \\
\text { 'Art. 11. Fica autorizada a conces- } \\
\text { são de bolsa-permanência, até o va- } \\
\text { lor equivalente ao praticado na po- } \\
\text { lítica federal de concessão de bol- } \\
\text { sas de iniciação científica, exclusiva- } \\
\text { mente para custeio das despesas edu- } \\
\text { cacionais, a estudantes beneficiários } \\
\text { de bolsa integral do Programa Uni- } \\
\text { versidade para Todos (Prouni), ins- } \\
\text { tituído pela Lei n o 11.og6, de 13 } \\
\text { de janeiro de } 2005 \text {, conforme crité- } \\
\text { rios de concessão, distribuição, ma- } \\
\text { nutenção e cancelamento de bolsas a } \\
\text { serem estabelecidos em regulamento, } \\
\text { inclusive quanto ao aproveitamento e } \\
\text { à frequência mínima a ser exigida do } \\
\text { estudante. } \\
\text { Parágrafo único. Os critérios de con- } \\
\text { cessão referidos no caput considera- } \\
\text { rão especialmente a situação de im- } \\
\text { possibilidade de compatibilidade en- } \\
\text { tre a frequência ao curso, em turno } \\
\text { parcial ou integral, e o exercício de } \\
\text { atividade remunerada, no caso de o } \\
\text { estudante não contar com renda pró- } \\
\text { pria ou familiar suficiente para pro- } \\
\text { ver sua subsistência.' (NR) } \\
\text { Art. } 2^{\circ} \text { Esta lei entra em vigor na data } \\
\text { de sua publicação. }\end{array}$ \\
\hline
\end{tabular}


Dorinha Seabra Rezende (DEM-TO). A influência do texto da deputada do DEM (PL1375/2011) sobre o projeto do deputado do PCdoB (PL7480/2014) é evidente. A ementa dos projetos possui o mesmo conteúdo com pequenas mudanças de redação. $\mathrm{O}_{1}{ }^{\mathrm{O}}$ e $\mathrm{o} 2^{\mathrm{O}}$ artigos são idênticos. Apenas o artigo 11 possui mudanças de conteúdo. Além disso, o projeto de 2014 acrescentou conteúdo novo (Parágrafo único) em relação ao projeto de 2011. Neste exemplo, o cosseno do ângulo entre os dois vetores é de 0,85 . Na seção seguinte apresentamos os nossos resultados.

\subsection{Resultados}

A literatura brasileira não tem dado atenção para o conteúdo textual dos projetos e a sua relação com a probabilidade de aprovação. Para o caso norte-americano, alguns trabalhos mostraram o poder preditivo dos textos das leis na probabilidade de sobrevivência nas comissões (Yano et al., 2012), na previsão do comportamento em votações nominais (Gerrish and Blei, 2011) e na probabilidade de aprovação (Nay, 2016).

Outros trabalhos estudaram a difusão de ideias na produção legislativa das assembleias estaduais. Garrett and Jansa (2015) e Kroeger (2015) mostraram o papel fundamental dos grupos de interesse. De acordo com os autores, legisladores estaduais frequentemente recorrem à expertise desses grupos no processo de formulação de políticas. Burgess et al. (2016) mostraram que legisladores estaduais aumentam a sua produtividade utilizado projetos formulados em outros estados e por grupos de interesse.

Por meio da análise dos projetos de lei, diversos trabalhos traçaram o fluxo de ideias no interior congresso (Wilkerson et al., 2015; Li et al., 2014; Smith et al., 2014). Os autores mostraram como muitas ideias propostas em um projeto acabam por se tornar parte de outros projetos. Um bom exemplo disso é o Obamacare, cuja origem é um plano de reforma do sistema de saúde proposta pelos Republicanos em 1993 (Wilkerson et al., 2015).

Para o caso brasileiro, verificamos que $92 \%$ dos projetos apresentados na $54^{\text {a }}$ 
legislatura da Câmara dos Deputados não foram influenciados por nenhum outro projeto apresentado durante o mesmo período. No entanto, é importante ressaltar que isso não quer dizer que esses projetos sejam totamente novos. Existe a possibilidade deles terem sido influenciados por projetos apresentados em legislaturas passadas.

Em média, os projetos foram influenciados por 0,20 projetos com um desvio padrão de 1,17. O projeto com o maior número de conexões é o PL7944/2014 de autoria do deputado Alceu Moreira (PMDB-RS) com 24 projetos relacionados. Entre os projetos aprovados essa média sobe para 1,46 com um desvio padrão de 2,63 (o mínimo é o e o máximo é 8). Entre aqueles que não foram aprovados a média é menor, 0,19 projetos relacionados com um desvio padrão de 1,14. Mas a amplitude é maior, o mínimo é o e o máximo é 24. Essa simples comparação de médias sugere que projetos que foram influenciados por um maior número de projetos tendem a ter mais chances de serem aprovados.

Para testarmos essa ideia de forma mais acurada propomos um modelo de regressão logística tendo como unidade de análise o projeto. A nossa variável dependente é um indicador que vale 1 , caso o projeto tenha sido aprovado no período analisado, e o, caso contrário. A principal variável explicativa é o número de projetos que o influenciou. Esperamos que quanto maior o número de projetos similares, maiores as chances de aprovação.

Utilizamos como variável de controle um indicador de se o projeto é de origem do Executivo (1, se o projeto é de origem do Executivo; o, caso contrário). Como sabemos, projetos do Executivo tem mais chances de serem aprovados devido aos poderes de agenda dos presidentes (Figueiredo and Limongi, 1999). Assim, esperamos um impacto positivo dessa variável sobre a probabilidade de aprovação do projeto.

$\mathrm{Na}$ tabela 2.3 apresentamos os resultados. Como podemos observar, todas as variáveis tem o sinal esperado e são estatisticamente significantes aos níveis convencionais. Do ponto de vista substantivo, podemos dizer que projetos do Executivo tem mais chances de serem aprovados. E mais importante, projetos que foram influenciados por outros projetos com ideias semelhantes também 
Tabela 2.3: Resultados da regressão logística

\begin{tabular}{lcc}
\hline Variável & Coeficiente & Erro padrão \\
\hline Intercepto & $-5,12$ & 0,16 \\
Número de projetos similares & 0,21 & 0,03 \\
Executivo & 4,93 & 0,40 \\
\hline
\end{tabular}

Nota: unidade de análise = projeto; variável dependente $=$ número de projetos similares; número de observações $=6355$.

Figura 2.1: Impacto do número de projetos similares sobre a probabilidade de aprovação por origem do projeto

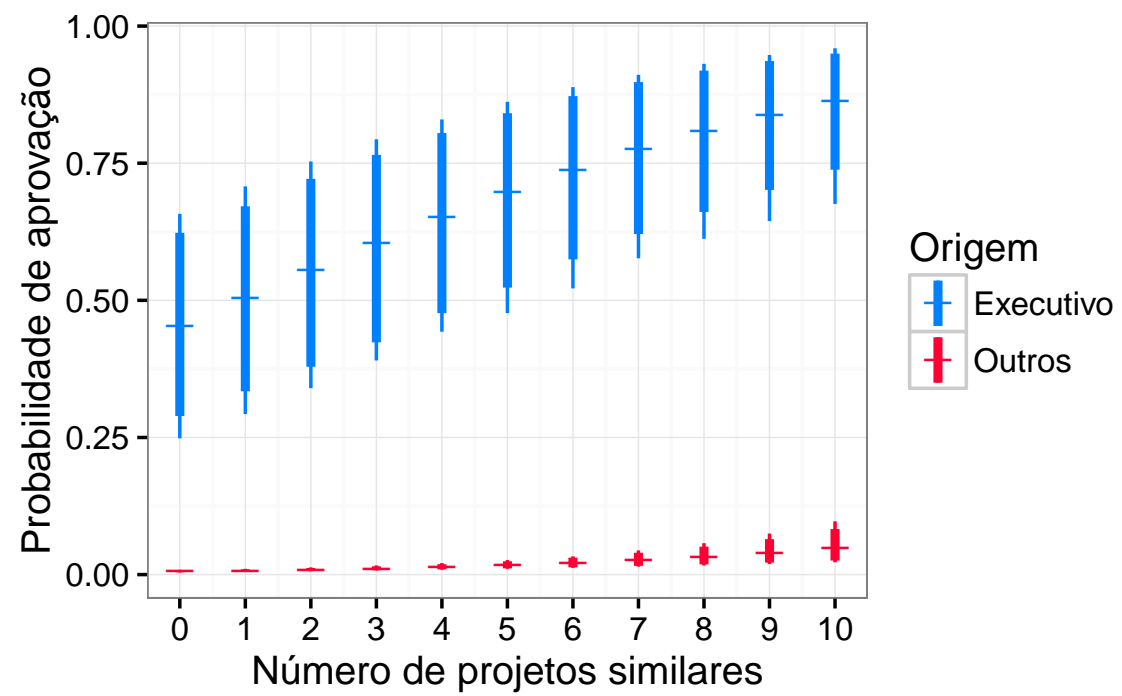

Nota: Os valores preditos foram calculados utilizando o pacote Zelig do R (Imai et al., 2008). As linhas na horizontal indicam os valores preditos. As linhas grossas na vertical indicam o intervalo de confiança de $90 \%$ e as linhas finas na vertical indicam o intervalo de confiança de $95 \%$.

possuem mais chances de se tornarem lei.

Para termos uma ideia mais clara desse impacto, no gráfico 2.1 temos a relação entre a probabilidade de aprovação e o número de projetos similares, controlando pela origem do projeto. Quando um projeto do Executivo não possui nenhum outro projeto similar, ele tem $45 \%$ de chances de ser aprovado (IC95\% : $[0,25 ; 0,66])$. Sob as mesmas condições, um projeto cuja origem não é o Executivo, essa probabilidade é bem menor, o,6\% (IC95\% : [0, 004; o, 008]). Esse resultado era esperado já que os poderes legislativos dos presidentes influenciam diretamente no andamento das proposições.

O simples fato de um projeto do Executivo ter apenas um outro projeto si- 
milar aumenta a probabilidade de aprovação para 50\% (IC $95 \%$ : $[0,29 ; 0,71])$. Se forem dois projetos similares, temos $56 \%$ de chances de aprovação (IC $95 \%$ : $[0,34 ; 0,75])$. Mas o mesmo não ocorre com os projetos cuja origem não é o Executivo. Um projeto que foi influenciado por outros 1o projetos similares tem apenas $5 \%$ de chances de ser aprovado (IC $95 \%$ : [0, 02; 0,10$]$ ).

Sugerimos que ao apresentar um projeto muito semelhante a outro já existente, o autor não está apenas reproduzindo as suas ideias, mas adicionando conteúdo novo a ele. Ao trazer novas ideias a um projeto já existente, o autor estaria agregando preferências em torno dele. Assim, o mecanismo que estaria associado ao aumento das chances de aprovação seria a inclusão de interesses.

Do ponto de vista empírico, isso tem duas implicações. A primeira é a de que os projetos devem ser influenciados por projetos apresentados por indivíduos com preferências distintas. Um projeto de um deputado $X$ que influencia um projeto de um deputado $\mathrm{Y}$ só estará agregando interesses se o deputado $\mathrm{X}$ tiver preferências diferentes das do deputado $Y$. Se as preferências forem iguais, nenhum interesse estará sendo agregado. A segunda implicação é a de que os projetos que foram influenciados adicionam conteúdo em relação àqueles que os influenciaram. Se conteúdo novo não é adicionado, isto é, se os projetos são meras cópias de versões anteriores, também não temos a inclusão de interesses.

Vamos avaliar a primeira implicação. Se os projetos forem influenciados por projetos de indivíduos que possuem as mesmas preferências, não podemos dizer que houve a inclusão de interesses. Por exemplo, se um deputado apresenta um projeto que foi influenciado por projetos apresentados por ele mesmo no passado, não houve inclusão de ideias novas. A agregação de preferências ocorre quando ideias de deputados que possuem posições políticas diferentes são adicionadas ao projeto.

Uma forma de verificar isso é olhando para o partido dos autores dos projetos. É razoável imaginar que indivíduos de diferentes partidos tenham interesses distintos. Dos 534 projetos que foram influenciados por pelo menos um projeto, 506 são de autoria de deputados. Nesse subconjunto somos capazes de saber qual o partido do autor do projeto e quais são os partidos dos autores dos 
projetos que os influenciaram. Assim, podemos verificar se os projetos são influenciados por projetos do próprio partido ou se são influenciados por projetos de outros partidos.

Desses 506 projetos, 59\% foram influenciados somente por projetos cuja autoria não é o partido do próprio parlamentar; $28 \%$ foram influenciados somente por projetos cuja autoria é um parlamentar do próprio partido; e $13 \%$ foram influenciados por projetos tanto do próprio partido quanto de partidos diferentes. Em outras palavras, em mais de $70 \%$ dos casos, os projetos que foram influenciados por outros projetos levaram em consideração as ideias de outros partidos. Isso sugere que as ideias de parlamentares com preferências distintas são levadas em consideração na formatação das leis.

Vamos avaliar a segunda implicação. Embora seja difícil verificar se um projeto traz ideias novas em relação a outros projetos, podemos ter uma ideia olhando para o comprimento dos textos. Se os projetos forem simples cópias de versões anteriores, esperamos que o comprimento dos projetos seja igual. Por outro lado, a adição de novas ideias levaria a um aumento do texto em termos do número de palavras. Podemos então calcular o número de palavras em cada projeto de lei e o número médio de palavras nos projetos que influenciaram cada projeto. Por exemplo, o PL1337/2011 tem 175 palavras e foi influenciado pelo PL581/2011 (106 palavras) e pelo PL877/2011 (165 palavras). Portanto, a média do número de palavras dos projetos que influenciaram o PL1337/2011 é igual a 135,5. Consequentemente, o PL1337/2011 adicionou conteúdo com relação aos projetos anteriores.

O tamanho médio dos projetos que foram influenciados por pelo menos um projeto é de 517 palavras (com um desvio padrão de 1615). Já o tamanho médio dos projetos que influenciaram os projetos é de 369 (com um desvio padrão de 1086). A comparação entre essas médias sugere que os projetos que foram influeciados por outros projetos são maiores do que aqueles que os influenciaram. $\mathrm{O}$ teste de diferenças de médias unilateral à direita indica que essa diferença não é fruto do acaso (valor de $\mathrm{p}=\mathrm{0,039}$ ). Assim, em termos substantivos, em média, conteúdo novo foi adicionado às versões anteriores. 
Podemos classificar os 534 projetos que foram influenciados por pelo menos um projeto em três categorias. Um projeto pode ser menor do que aqueles que o influenciou. Neste caso, houve supressão de conteúdo da versão anterior para a versão mais recente. Um projeto também pode ser maior do que aqueles que o influenciou. Isso ocorre quando uma versão é aprimorada com a adição de conteúdo. Por fim, um projeto pode ser igual àqueles que o influenciou. Neste caso, o projeto é uma simples cópia. Utilizamos o seguinte critério para classificar os projetos:

$$
\text { Projeto }_{i}= \begin{cases}\text { menor, }_{i} & \text { se } \| \text { Projeto }_{i}\|+10<\| \overline{\text { Similares }_{i}} \| \\ \text { igual, } & \text { se } \| \text { Projeto }_{i}\|+10 \geqslant\| \overline{\text { Similares }_{i}}\|\geqslant\| \text { Projeto }_{i} \|-10 \\ \text { maior, } & \text { se } \| \text { Projeto }_{i}\|-10>\| \overline{\text { Similares }_{i}} \|\end{cases}
$$

onde $\|$ Projeto $_{i} \|$ é o comprimento do projeto $i=\{1, \ldots, 534\}$ e $\left\|\overline{\text { Similares }_{i}}\right\|$ é a média do comprimento dos projetos que influenciaram i. Consideramos um projeto igual àqueles que o influenciou sempre que os seus comprimentos forem iguais, adicionando uma margem de 10 palavras. Essa margem tem o intuito de garantir que diferenças muito pequenas nos textos não sejam classificadas como uma adição ou supressão de conteúdo.

Seguindo essa classificação temos que $62 \%$ dos projetos tem um comprimento maior do que os projetos que os influenciaram. Em outras palavras, em quase dois terços das vezes, os projetos que foram influenciados por outros projetos adicionaram conteúdo em relação a versões anteriores. Em $17 \%$ dos casos houve supressão de conteúdo. Isto é, o comprimento do projeto é menor do que daqueles que o influenciou. E em $21 \%$ das vezes os projetos mantiveram o mesmo tamanho.

Calculando a razão de chances entre projetos que adicionaram conteúdo e projetos que reduziram ou que permaneceram com o mesmo tamanho encontramos um valor de 9,67. Isto quer dizer que projetos que são maiores do que aqueles que os influenciaram tem quase 10 vezes mais chances de serem apro- 
vados do que aqueles que suprimiram conteúdo ou que são simples cópias. Em termos substantivos, isso indica que projetos que trazem novas ideias em relação a versões anteriores tem mais chances de se tornarem lei do que projetos que são cópias ou que suprimiram conteúdo.

\subsection{Conclusões}

O objetivo deste capítulo foi analisar como ideias sobre políticas são construídas ao longo do tempo. Em termos empíricos, verificamos como o conteúdo presente em um projeto de lei reaparece de forma semelhante em outros projetos. Avaliamos também qual o impacto da inclusão de interesses nos projetos de lei sobre a sua probabilidade de aprovação. Para isso utilizamos todos os projetos de lei apresentados durante a $54^{\mathrm{a}}$ legislatura na Câmara dos Deputados e técnicas de análise quantitativa de textos.

Mostramos que cerca de $8 \%$ dos projetos apresentados foram influenciados por outros projetos apresentados durante a mesma legislatura. Mostramos também que projetos que foram influenciados por outros projetos tem mais chances de aprovação, principalmente se eles forem de origem do Executivo. Sugerimos que a inclusão de diferentes interesses é o fator chave para um projeto se tornar lei.

O argumento aqui é que ao apresentar um projeto muito semelhante a outro já existente, o autor não está apenas reproduzindo as suas ideias, mas sim adicionando conteúdo novo a ele. Dessa forma, a agregação de preferências em torno do projeto é o que aumentaria as suas chances de aprovação. Dentre os projetos que foram influenciados por pelo menos um projeto, mais de $70 \%$ foram influenciados por projetos de outros partido. Além disso, quase dois terços deles adicionaram conteúdo novo à uma versão anterior. Mostramos, por fim, que projetos que foram agregaram interesses tem dez vezes mais chances de serem aprovados do que aqueles que suprimiram conteúdo ou que são meras cópias de outros projetos.

Os estudos legislativos no Brasil tem focado as suas análises sobre o processo 
de tramitação individual dos projetos e sobre os mecanismos institucionais dos presidentes. Essas análises assumem que os projetos são independentes uns dos outros. Assim, dois projetos que compartilham o mesmo conteúdo teriam as mesmas chances de aprovação, mesmo que um agregue mais interesses do que o outro. Este capítulo buscou uma abordagem diferente. Procuramos verificar como ideias políticas evoluem ao longo do tempo. Ou seja, como ideias que surgiram em um projeto em um determinado momento são incluídas em projetos futuros. Nesse sentido, entendemos a história de projetos políticos como a construção de ideias ao longo do processo legislativo. 


\section{Capítulo 3}

\section{Ideologia, sofisticação política e voto no Brasil}

\subsection{Introdução}

Quão próximos das preferências dos eleitores os governantes estão? Essa questão é fundamental para a ciência política contemporânea. Pois, como lembra Dahl $(1997,25)$, 'uma característica-chave da democracia é a contínua responsividade do governo às preferências de seus cidadãos'.

A teoria espacial do voto (Downs, 1957; Enelow and Hinich, 1984) tem dado muitas contribuições para iluminar essa questão. $\mathrm{O}$ seu principal pressuposto é o de que indivíduos diante de duas (ou mais) escolhas preferirão aquela que estiver mais próxima de suas visões. O primeiro objetivo deste capítulo será testar esse pressuposto para o Brasil. Mais especificamente iremos testar o modelo espacial nas eleições presidenciais de 2002 a 2014.

Parece trivial afirmar que eleitores de esquerda tendem a votar no candidato de esquerda e eleitores de direita no candidato de direita. No entanto, parte importante da literatura que tratou da relação entre ideologia e voto no Brasil afirma que apenas uma parcela muito reduzida da população se comportaria dessa forma.

O raciocínio parte do fato de que a maioria do eleitorado brasileiro é composta por indivíduos pobres e pouco escolarizados. Tais eleitores seriam também 
pouco informados do ponto de vista político (Reis and de Castro, 2006; Pereira, 2013). Por serem pouco informados, esses eleitores não escolheriam os políticos que melhor representam as suas reais preferências. Eles trocam os seus votos por benefícios sociais e, dessa forma, não expressam de forma independente a própria vontade política. Isto é, eles não sabem votar ou expressar as suas reais preferências nas urnas.

Na visão de Reis (2000), a grande massa do eleitorado brasileiro é incapaz de relacionar importantes temas do debate político com opiniões esperadas por alguém de sua classe. Da mesma forma, a natureza da identificação partidária não teria nenhuma relação com o conteúdo de suas ações, ou seja, não teria nada de ideológico. Antes sim, uma identificação difusa e de conteúdo rarefeito. Os eleitores criariam uma imagem tosca dos partidos, estabelecida a partir de relações afetivas sem ligação com os conteúdos das políticas.

Dito em outras palavras, a decisão do voto de uma parcela significativa do eleitorado brasileiro seria baseada exclusivamente em componentes não espaciais. Justamente por serem pouco escolarizados e pouco sofisticados do ponto de vista político, os eleitores não teriam os requisitos básicos para um voto ideológico. O segundo objetivo deste capítulo será testar essas afirmações. Iremos verificar se eleitores pouco informados tendem a se comportar de uma forma não prevista pelo modelo espacial.

Na seção que se segue iremos apresentar a principal estratégia adotada pela literatura brasileira para medir a ideologia dos eleitores e qual o problema decorrente dessa estratégia. Os estudos que se propuseram a avaliar o impacto da ideologia sobre o voto basearam as suas medidas nos dados brutos da autolocalização na escala esquerda-direita. O problema dessas medidas é a incomparabilidade interpessoal (Brady, 1985; King et al., 2004). Na seção 'Escalonamento Bayesiano de Aldrich-McKelvey' apresentamos a solução para esse problema. Iremos utilizar a solução proposta por Aldrich and McKelvey (1977) e implementada em uma versão Bayesiana por Hare et al. (2014). Em seguida, na seção 'Modelo estatístico', apresentamos o modelo estatístico de Jessee (2012) que iremos utilizar para testar o modelo espacial. Partindo de poucos pressupostos esse 
modelo conecta os parâmetros do modelo básico da teoria espacial do voto com os coeficientes de um modelo de regressão probit. Na seção 'Dados e estatística descritiva' temos os dados utilizados neste trabalho. Utilizamos o Estudo Eleitoral Brasileiro (ESEB) dos anos de 2002, 2006, 2010 e 2014 (Cesop, 2017). Na seção 'Resultados' veremos que a probabilidade de um eleitor votar no candidato que está mais próximo dele do ponto de vista ideológico é extremamente alta. Isto é, eleitores brasileiros se comportam como o modelo espacial pressupõe. $\mathrm{Na}$ seção 'Sofisticação política e voto', veremos que isso independe do nível de sofisticação política dos eleitores. Eleitores pouco informados também tomam as suas decisões baseadas na distância relativa dos candidatos. Na última seção concluímos.

\subsection{Ideologia, voto e questões metodológicas}

Singer (1999) foi quem introduziu no Brasil a ideia de que a ideologia é um fator central na escolha eleitoral. De acordo com ele, a identificação ideológica - entendida como a adesão difusa a uma posição na escala esquerda-direita que sinaliza uma orientação geral do eleitor na arena política - é um componente fundamental na explicação do voto nas eleições presidenciais. O autor analisou as eleições de 1989 e 1994 e utilizou a autolocalização na escala esquerda-direita para medir a identificação ideológica dos eleitores. Os seus resultados apontam para uma forte associação dessa variável com a escolha eleitoral.

Analisando as três eleições presidenciais ocorridas entre 1989 e 1998, Carreirão (2002) chegou a uma conclusão diferente. Apenas a parcela mais escolarizada do eleitorado utiliza a dimensão ideológica como guia na escolha política. Segundo ele (Carreirão, 2002, 17), o Brasil não tem um eleitorado "altamente informado e que vota ideologicamente no partido cujas posições políticas mais se aproximem das suas; apenas uma minoria, concentrada especialmente entre os eleitores de maior escolaridade, comporta-se desta forma."A maioria dos eleitores decide o seu voto com base em certas imagens políticas que eles formam dos partidos e dos candidatos. Além disso, a avaliação do desempenho do go- 
verno e a avaliação de atributos pessoais dos candidatos seriam outros fatores relevantes.

Holzhacker and Balbachevsky (2007), por sua vez, analisaram os impactos da estratificação social e da identidade ideológica sobre o voto nas eleições presidenciais de 2002 e 2006. De acordo com as autoras, nas eleições de 2002 a estratificação social foi pouco relevante para prever o voto para presidente. Por outro lado, a autolocalização na escala ideológica influenciou significativamente a decisão eleitoral. Eleitores de esquerda tinham mais chances de votar no candidato de esquerda e eleitores de direita de votar no candidato de direita. Porém, os resultados para a eleição de 2006 apontaram para um cenário diferente. Nesse pleito a estratificação social se mostrou uma variável importante na predição do voto ao mesmo tempo em que a questão ideológica perdeu a sua força explicativa.

Resultado semelhante foi encontrado por Carreirão (2007) para as eleições de 2006. As suas análises apontam para a redução do poder explicativo da variável ideologia como preditora do voto, quando comparado aos pleitos anteriores. A correlação entre identificação ideológica e voto foi fraca. Apenas para o estrato de eleitores com nível superior houve uma correlação de magnitude moderada. A explicação para isso seria o fato de que após os escândalos de corrupção e da política econômica adotada no primeiro mandato do presidente Lula houve uma diminuição das diferenças ideológicas entre os partidos na visão dos eleitores. Como consequência dessa diluição houve uma redução da associação entre identificação ideológica e voto.

Em resumo, não há consenso na literatura sobre qual a importância da variável ideologia como determinante do voto no período recente. Alguns trabalhos encontraram resultados favoráveis para a hipótese de que eleitores votam nos candidatos que estão mais próximos deles na dimensão ideológica, como sustenta a teoria espacial do voto. Outros trabalhos, porém, concluíram que outras variáveis, como a classe social e avaliações do desempenho do governo, são mais relevantes.

A despeito dessas diferenças, esses trabalhos tem uma característica em co- 
mum. Todos utilizaram os dados brutos do autoposicionamento ideológico como medida da posição dos eleitores na escala ideológica ou agregaram esses dados em categorias (esquerda, centro e direita) ${ }^{1}$.

O problema de utilizar os dados brutos é que os entrevistados podem interpretar a escala ideológica de formas muito diferentes. Dois indivíduos com as mesmas posições políticas podem se localizar na escala ideológica em lugares distintos. Assim como indivíduos com visões de mundo completamente diferentes podem se localizar no mesmo lugar da escala ideológica. De maneira semelhante, um eleitor de direita pode ver um candidato de centro esquerda como um extremista de esquerda. Mas um eleitor de esquerda pode ver o mesmo candidato como sendo de direita. Esse é o problema da incomparabilidade interpessoal dessas escalas (Brady, 1985; King et al., 2004). Por exemplo, quando um eleitor se localiza na posição de número cinco em uma escala ideológica de dez pontos não sabemos se ele se considera de centro, de esquerda ou de direita. A resposta depende de como ele utiliza essa escala.

\subsection{Escalonamento Bayesiano de Aldrich-McKelvey}

Para contornar o problema da incomparabilidade interpessoal iremos utilizar a solução proposta por Aldrich and McKelvey (1977) e implementada em uma versão Bayesiana por Hare et al. (2014). Essa solução desenvolvida no final dos anos de 1970 ainda é largamente utilizada pela literatura internacional (Hare et al., 2014; Lo et al., 2014; Saiegh, 2015). No entanto, no Brasil são raros os esforços nessa direção ${ }^{2}$. A solução está baseada no pressuposto de que, em geral, os eleitores sabem a ordem correta dos estímulos (partidos e candidatos), embora eles não saibam exatamente onde eles estão. Por exemplo, dificilmente ouvimos alguém dizer que o candidato José Serra (PSDB) é mais de esquerda do

\footnotetext{
${ }^{1}$ Carreirão (2007), por exemplo, agrupa as posições na escala de o a 1o da seguinte forma: esquerda de o a 3; centro de 4 a 6; e direita de 7 a 10. Já Singer (1999) utilizando uma escala de 1 (esquerda) a 7 (direita) agrupou os dados como: esquerda de 1 a 2; centro de 3 a 5; e direita de 6 a 7.

${ }^{2}$ A exceção é o trabalho de Power and Zucco Jr (2009) que utilizaram esse modelo para estimar as posições ideológicas dos partidos políticos a partir de entrevistas com parlamentares.
} 
que a candidata Dilma Rousseff (PT). Mesmo que o eleitor não saiba exatamente qual é a localização deles na escala ideológica, ele provavelmente irá posicionálos na ordem correta. Se isso for verdade, as respostas dos eleitores aos estímulos podem ser entendidas como uma transformação linear das posições "reais"dos candidatos mais um termo de erro aleatório. Assim, se estimarmos os parâmetros de distorção dos entrevistados, podemos recuperar as posições "reais"dos estímulos e dos próprios entrevistados.

Em termos mais formais, seja $\zeta_{j}$ a posição "real"do estímulo $j=\{1, \ldots, m\} ; z_{i j}$ a posição do estímulo $j$ reportada pelo entrevistado $i=\{1, \ldots, n\} ; \alpha_{i}$ e $\beta_{i}$ escalares; e $\epsilon_{i j}$ um termo de erro aleatório. As respostas dos entrevistados aos estímulos podem ser escritas como:

$$
z_{i j}=\alpha_{i}+\beta_{i} \zeta_{j}+\epsilon_{i j}
$$

Estimar os parâmetros $\alpha_{i}$ e $\beta_{i}$ nada mais é do que regredir as posições dos candidatos reportadas pelos entrevistados sobre as posições "reais"não observadas dos candidatos.

Com esses parâmetros podemos recuperar as posições "reais"dos candidatos. E se assumirmos que os entrevistados utilizam a mesma escala para posicionar os candidatos e se autoposicionarem, temos que a "real"posição (ponto ideal) de um eleitor $i$ é dada por:

$$
x_{i}=\frac{z_{i i}-\alpha_{i}}{\beta_{i}}
$$

onde $z_{i i}$ é a autolocalização do entrevistado $i$.

Em sua implementação Bayesiana (Hare et al., 2014) assume-se que:

$$
\begin{gathered}
z_{i j} \sim N\left(\mu_{i j}, \tau_{i j}\right) \\
\mu_{i j}=\alpha_{i}+\beta_{i} \zeta_{j} \\
\tau_{i j}=\tau_{i} \tau_{j}
\end{gathered}
$$


Para completarmos o modelo atribuímos uma distribuição a priori para os parâmetros de interesse:

$$
\begin{gathered}
\alpha_{i} \sim U(-100,100) \\
\beta_{i} \sim U(-100,100) \\
\zeta_{j} \sim N(0,1) \\
\tau_{j} \sim \operatorname{Gamma}(0,1 ; 0,1) \\
\tau_{i} \sim \operatorname{Gamma}(v, \omega) \\
v \sim \operatorname{Gamma}(0,1 ; 0,1) \\
\omega \sim \operatorname{Gamma}(0,1 ; 0,1)
\end{gathered}
$$

Para definirmos a polaridade da escala e identificarmos o modelo precisamos fixar dois estímulos (Clinton et al., 2004). Fixamos o candidato do PT em -0,25 e o candidato do PSDB em 0,25. A escolha desses valores serão importantes para deduzirmos o modelo estatístico da próxima seção. Todos os modelos deste capítulo foram estimados pelo método de Monte Carlo via Cadeias de Markov e foram implementados em JAGS utilizando o pacote rjags. Geramos 110.000 amostras, descartamos as 100.000 primeiras e retemos as restantes por um fator de 10. Isso produziu um conjunto de 1.000 amostras.

\subsection{Modelo estatístico}

Para testarmos os pressupostos da teoria espacial do voto no Brasil utilizaremos o modelo proposto por Jessee (2012, 78-81). Partindo de um modelo probabilístico da teoria espacial do voto escrevemos a função de utilidade de um eleitor $i$ votar em um candidato $\mathrm{k}$ como:

$$
\mathrm{u}_{i}(\mathrm{k})=-\mathrm{a}\left(\mathrm{x}_{\mathrm{i}}-\mathrm{c}_{\mathrm{k}}\right)^{2}+\mathrm{b}_{\mathrm{k}}+e_{i k}
$$

onde $x_{i}$ é o ponto ideal do eleitor $i$ e $c_{k}$ é a posição do candidato $k$. Considerando 
que iremos analisar o segundo turno das eleições presidenciais entre 2002 e 2014, temos que $c_{k}$ assume apenas dois valores, $c_{P S D B}$ e $c_{P T}$. Já $b_{k}$ é um termo que indica a tendência ou disposição do eleitor votar no candidato k, a despeito de sua proximidade. Ele indica uma vantagem baseada em elementos não espaciais, como o carisma, o gênero ou o desempenho anterior do candidato (Enelow and Hinich, 1982). Aqui ele assume dois valores, $b_{\mathrm{PSDB}}$ e $b_{\mathrm{PT}}$. $e_{i k}$ é o termo de erro aleatório independente dos eleitores e dos candidatos com $e_{i k} \sim N(0 ; 0,5)$. A escolha dessa distribuição será importante para a dedução do modelo estatístico. O parâmetro a indica o quanto a utilidade do eleitor em votar em um candidato está relacionada com a sua proximidade dele (policy weight).

A partir dessa função de utilidade podemos calcular a probabilidade de um eleitor $i$ votar no candidato do PSDB como:

$$
\begin{aligned}
\mathrm{P}\left(v_{i}=\mathrm{PSDB}\right) & =\mathrm{P}\left(\mathrm{u}_{i}(\mathrm{PSDB})>\mathrm{u}_{i}(\mathrm{PT})\right) \\
& =\mathrm{P}\left(-\mathrm{a}\left(x_{i}-c_{\mathrm{PSDB}}\right)^{2}+b_{\mathrm{PSDB}}+e_{i \mathrm{PSDB}}>-a\left(x_{i}-c_{\mathrm{PT}}\right)^{2}+b_{\mathrm{PT}}+e_{i \mathrm{PT}}\right) \\
& =\mathrm{P}\left(-a\left(x_{i}-c_{\mathrm{PSDB}}\right)^{2}+b_{\mathrm{PSDB}}+a\left(x_{i}-c_{\mathrm{PT}}\right)^{2}-b_{\mathrm{PT}}>e_{i \mathrm{PT}}-e_{i \mathrm{PSDB}}\right) \\
& =\mathrm{P}\left(-a\left(x_{i}^{2}-2 x_{i} c_{\mathrm{PSDB}}+c_{\mathrm{PSDB}}^{2}\right)+a\left(x_{i}^{2}-2 x_{i} c_{\mathrm{PT}}+c_{\mathrm{PT}}^{2}\right)\right. \\
& \left.+b_{\mathrm{PSDB}}-b_{\mathrm{PT}}>e_{i \mathrm{PT}}-e_{i \mathrm{PSDB}}\right) \\
& =\mathrm{P}\left(2 a x_{i}\left(c_{\mathrm{PSDB}}-c_{\mathrm{PT}}\right)+a\left(c_{\mathrm{PT}}^{2}-c_{\mathrm{PSDB}}^{2}\right)+b_{\mathrm{PSDB}}-b_{\mathrm{PT}}>e_{i \mathrm{PT}}-e_{i \mathrm{PSDB}}\right) \\
& =\Phi\left(\lambda x_{i}+\pi+\delta\right)
\end{aligned}
$$

onde $\lambda=2 a\left(c_{P S D B}-c_{P T}\right) ; \pi=a\left(c_{P T}^{2}-c_{P S D B}^{2}\right) ; \delta=b_{P S D B}-b_{P T} ;$ e $\Phi(\cdot)$ é a função de distribuição acumulada da normal padrão. A passagem da penúltima para a última linha da equação 3.14 é possível porque assumimos que $e_{i P T}$ e $e_{i P S D B}$ seguem a distribuição normal com média o e variância o,5. Com isso, $\left(e_{i P T}-e_{i P S D B}\right) \sim N(0,1)$.

Como é possível notar, podemos escrever essa probabilidade como um modelo de regressão probit: 


$$
\mathrm{P}\left(v_{\mathrm{i}}=\mathrm{PSDB}\right)=\Phi\left(\gamma_{\mathrm{o}}+\gamma_{1} x_{i}\right)
$$

onde a correspondência entre os coeficientes da regressão, $\gamma_{0}$ e $\gamma_{1}$, e o modelo espacial da equação 3.13 é expressada por:

$$
\begin{array}{r}
\gamma_{1}=\lambda=2 a\left(c_{\mathrm{PSDB}}-c_{\mathrm{PT}}\right) \\
\gamma_{\mathrm{o}}=\pi+\delta=a\left(c_{\mathrm{PT}}^{2}-c_{\mathrm{PSDB}}^{2}\right)+\left(b_{\mathrm{PSDB}}-b_{\mathrm{PT}}\right)
\end{array}
$$

Como fixamos na seção anterior $c_{\mathrm{PSDB}}=0,25$ e $c_{\mathrm{PT}}=-0,25$, podemos resolver as equações de 3.16 em termos de $a, \delta$ e $\pi$ e concluir que:

$$
\begin{gathered}
a=\frac{\gamma_{1}}{2\left(c_{\mathrm{PSDB}}-\mathrm{c}_{\mathrm{PT}}\right)} \\
=\frac{\gamma_{1}}{2(0,25-(-0,25))} \\
=\gamma_{1} \\
\delta=\gamma_{\mathrm{O}}-\mathrm{a}\left(\mathrm{c}_{\mathrm{PT}}^{2}-\mathrm{c}_{\mathrm{PSDB}}^{2}\right) \\
=\gamma_{\mathrm{O}}-\frac{\gamma_{1}\left(\mathrm{c}_{\mathrm{PT}}^{2}-\mathrm{c}_{\mathrm{PSDB}}^{2}\right)}{2\left(\mathrm{c}_{\mathrm{PSDB}}-\mathrm{c}_{\mathrm{PT}}\right)} \\
=\gamma_{\mathrm{O}}-\frac{\gamma_{1}\left((\mathrm{o}, 25)^{2}-(-\mathrm{O}, 25)^{2}\right)}{2(-0,25-0,25)} \\
=\gamma_{\mathrm{O}} \\
\pi=\mathrm{a}\left(\mathrm{c}_{\mathrm{PT}}^{2}-\mathrm{c}_{\mathrm{PSDB}}^{2}\right) \\
=\frac{\gamma_{1}\left(\mathrm{c}_{\mathrm{PT}}^{2}-\mathrm{c}_{\mathrm{PSDB}}^{2}\right)}{2\left(\mathrm{c}_{\mathrm{PSDB}}-\mathrm{c}_{\mathrm{PT}}\right)} \\
=\frac{\gamma_{1}\left((0,25)^{2}-(-0,25)^{2}\right)}{2(-0,25-0,25)} \\
=0
\end{gathered}
$$


Assim, o modelo proposto por Jessee (2012) conecta os parâmetros do modelo espacial diretamente aos coeficientes do modelo de regressão. Em termos substantivos, se a for positivo, maior será a probabilidade de um eleitor de esquerda (ou direita) votar no candidato de esquerda (ou direita). Esperamos encontrar um valor positivo para esse parâmetro. Como $\delta$ é a diferença entre o viés em relação ao candidato do PSDB e o viés em relação ao candidato do PT $\left(\delta=b_{\mathrm{PSDB}}-\mathrm{b}_{\mathrm{PT}}\right)$, temos que: se $\delta>0$, temos um viés do eleitorado em relação ao candidato do PSDB; se $\delta<0$, temos um viés para ao candidato do PT; e se $\delta=0$, os eleitores não estão viesados em nenhuma direção.

\subsection{Dados e estatística descritiva}

Os dados que utilizaremos neste capítulo são do Estudo Eleitoral Brasileiro dos anos de 2002, 2006, 2010 e 2014. O ESEB é coordenado pelo Centro de Estudos de Opinião Pública (Cesop) da Universidade Estadual de Campinas (Unicamp) e é largamente utilizado por cientistas políticos brasileiros pois cobre uma grande variedade de temas. Em particular, iremos utilizar os tópicos relacionados ao autoposicionamento dos entrevistados e posicionamento dos partidos e dos candidatos em uma escala ideológica. Esta escala vai de zero à dez, sendo que zero significa ser de esquerda e dez de direita. Nas questões relacionadas ao posicionamento dos partidos políticos é perguntado aos entrevistados: 'Na política as pessoas falam muito de esquerda e de direita. Gostaria que o(a) sr(a) usasse um número de zero a 1o para dizer se o partido político que eu vou dizer é de esquerda ou de direita. Quando eu falar o nome de um partido que o(a) $\operatorname{sr}(a)$ não conhece, apenas diga que não o conhece. Como classificaria o _ ?' Nesse espaço em branco o entrevistador diz o nome do partido (PT, PSDB, PMDB...). De maneira semelhante, para as questões sobre o posicionamento dos políticos é oferecida uma lista com o nome dos políticos (Aécio Neves, Ciro Gomes, Dilma Rousseff, José Serra...) $)^{3}$. Na questão do autoposicionamento, é pergutado ao

${ }^{3}$ A pergunta é: 'Agora eu gostaria que o(a) $\operatorname{sr}(a)$ usasse um número de zero a 10 para dizer qual político é de esquerda e qual é de direita. Zero significa que o político é de esquerda e 10 que é de direita. De zero a 10 como o(a) sr(a) classificaria o _ ?' 
Tabela 3.1: Dados utilizados

\begin{tabular}{lllll}
\hline & 2002 & 2006 & 2010 & 2014 \\
\hline \# Entrevistados & 1302 & 1000 & 2000 & 3136 \\
\# Entrevistados utilizados & 973 & 536 & 1077 & 1501 \\
& $(74,7 \%)$ & $(53,6 \%)$ & $(53,9 \%)$ & $(47,9 \%)$ \\
\# Questões sobre política & 4 & 4 & 21 & 4 \\
Estímulos utilizados & PT, PSDB, & PT, PSDB, PT, PSDB, PT, PSDB \\
& PMDB, & PMDB, & PMDB, & e PMDB \\
& Lula, & Lula, & Dilma, & \\
& Serra e & Alckmin e & Serra e & \\
$c_{\text {PSDB }}$ & Garotinho & Heloísa & Marina & \\
c $_{\text {PT }}$ & Serra & Alckmin & Serra & PSDB \\
\hline
\end{tabular}

entrevistado: 'Como o(a) sr(a) se considera? Zero significa que o(a) sr(a) é de esquerda e 10 que o (a) sr(a) é de direita.' Para todos as questões o entrevistado deve escolher um número inteiro dentro do intervalo [0, 10].

Na tabela 3.1 temos uma descrição dos dados utilizados ${ }^{4}$. Utilizamos como estímulos os três principais partidos (PT, PSDB e PMDB) e os três principais candidatos das eleições presidenciais. A exceção ficou por conta do ESEB do ano de 2014 que não possui questões sobre o posicionamento na escala ideológica dos candidatos, apenas dos partidos. Para medir a sofisticação política dos eleitores utilizamos 4 questões sobre conhecimento político nos anos de 2002, 2006 e 2014 e 21 questões no ano de 2010. Analizaremos apenas os entrevistados que responderam à questão do autoposicionamento e que localizaram pelo menos um dos estímulos selecionados. Como vemos, o número de indivíduos que atendem a esses critérios cai ao longo do tempo. No entanto, a despeito do número de indivíduos, estímulos e questões sobre conhecimento político, os nossos resultados são semelhantes para todos os anos.

Na figura 3.1 apresentamos os pontos ideais dos entrevistados juntamente

\footnotetext{
4Cabe uma nota sobre o ESEB de 2002. O número total de entrevistados foi de 2514 indivíduos. No entanto, metade da amostra (1302) utilizou uma escala ideológica de onze pontos na qual zero significava ser de esquerda e dez significava ser de direita. Mas a outra metade da amostra (1212) utilizou uma escala invertida (zero significava direita e dez significava esquerda). Limitamos a análise ao primeiro conjunto de entrevistados. Não há problemas em se utilizar apenas essa amostra porque ambas são representativas da população alvo.
} 
Figura 3.1: Estímulos e distribuição dos entrevistados no ano de 2010

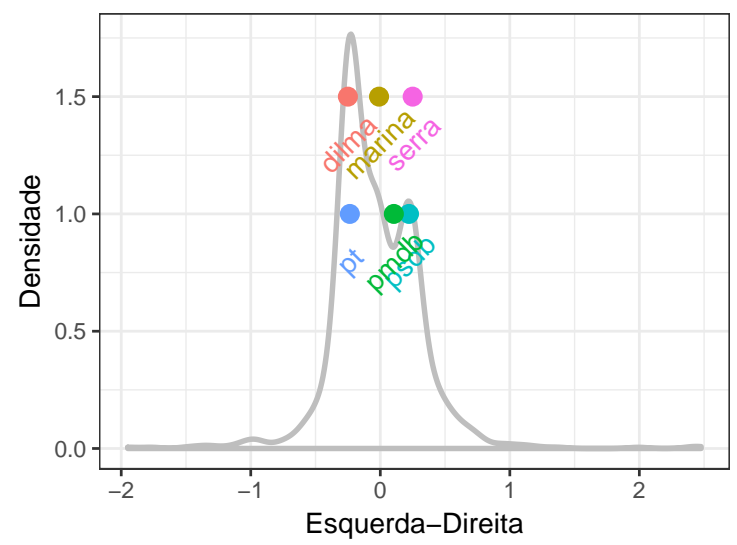

com as posições dos partidos e dos candidatos estimados pelo escalonamento Bayesiano de Aldrich-McKelvey para o ano de 2010 ${ }^{5}$. A distribuição em cinza são os pontos ideias dos entrevistados e os pontos são os candidatos e os partidos. Em primeiro lugar, podemos notar a validade de nossos resultados. Os três candidatos estão ordenados da esquerda para direita no espectro ideológico como seria esperado. A candidata Dilma Rousseff está mais à esquerda, o candidato José Serra mais à direita e entre eles está Marina Silva. Da mesma forma, os partidos políticos estão localizados como convencionalmente eles são vistos. Indo da esquerda para a direita temos PT, PMDB e PSDB. Nota-se também a proximidade da posição dos partidos políticos com os seus respectivos candidatos (Dilma e Serra).

Ao comparar os pontos ideais estimados dos entrevistados com os dados brutos da autolocalização vemos diferenças significativas (figura 3.2 para o ano de $\left.2010^{6}\right)$. No gráfico da esquerda temos os dados da autolocalização na escala ideológica. Nele observamos a tendência dos entrevistados em se localizarem nas categorias proeminentes - isto é, nos valores extremos zero e dez e no valor central cinco. Mais da metade dos eleitores se classificaram em um desses três valores. Além disso, os dados brutos indicam um eleitorado mais à direita

\footnotetext{
${ }^{5}$ Os pontos ideais e as posições dos estímulos são a mediana da distribuição a posteriori. Por questões de espaço mostramos apenas os resultados da eleição de 2010. Os resultados para as eleições de 2002, 2006 e 2014 estão no Anexo.

${ }^{6}$ Para os demais anos, ver o Anexo.
} 
Figura 3.2: Comparação entre o autoposicionamento e os pontos ideais estimados no de 2010

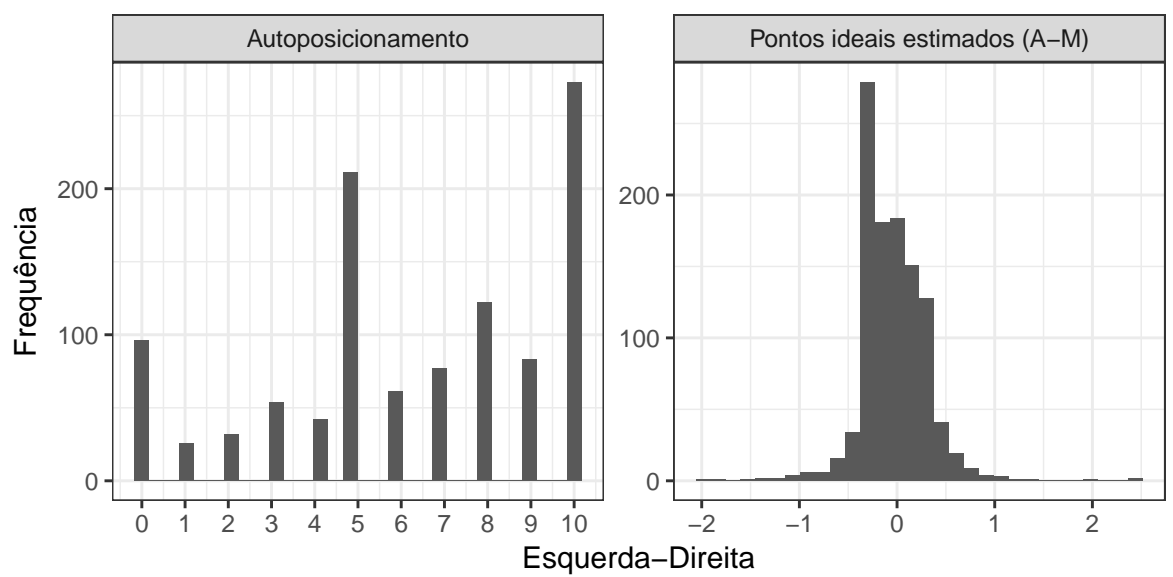

do espectro. Somando os indivíduos que se classificaram com valores maiores do que cinco, temos quase $60 \%$ dos entrevistados. Por outro lado, os resultados estimados mostram um cenário diferente. No gráfico da direita temos um eleitorado localizado mais ao centro da escala em torno do zero com uma distribuição próxima da normal.

É interessante notar que essas diferenças encontradas nas medidas da posição ideológica dos eleitores tem impactos substantivos na forma como vemos a relação entre ideologia e voto. Por exemplo, Carreirão (2007) ao analisar as eleições de 2002 e 2006 argumenta que a identificação ideológica parece ter perdido boa parte do poder analítico para o entendimento do voto nas eleições presidenciais. De acordo com ele (Carreirão, 2007, 332), 'a tendência mais provável, no curto prazo, é a de que o próprio contínuo esquerda-direita perca parte do poder analítico (e preditivo) como referencial para a compreensão do comportamento dos partidos e dos eleitores, comparativamente ao poder que teve até recentemente'.

Podemos testar essa afirmação para as eleições de 2010. Para isso podemos verificar qual a relação entre voto e ideologia utilizando o coeficiente de correlação bisserial de ponto 7 . As variáveis que iremos correlacionar são um indicador

${ }^{7} \mathrm{~A}$ correlação bisserial de ponto é adequada quando uma das variáveis é contínua $(X)$ e a outra dicotômica (Y). A sua interpretação é similiar a do coeficiente de Pearson e é definida 
de se o entrevistado votou no candidato José Serra no $2^{\circ}$ turno e o autoposicionamento na escala ideológica. O coeficiente de correlação indica uma associação fraca entre as duas variáveis $(r=0,15)$. Esse resultado corrobora as previsões feitas por Carreirão (2007). Saber se um eleitor é de esquerda ou de direita parece não ser uma informação relevante se quisermos prever o seu voto.

No entanto, se substituirmos a variável do autoposicionamento pelos pontos ideais estimados, encontramos uma associação mais forte $(r=0,38)$. Isto é, quando corrigimos as posições dos entrevistados utilizando o método proposto por Aldrich and McKelvey (1977) encontramos uma associação moderada entre ideologia e comportamento eleitoral. Este resultado sugere que eleitores de direita tendem a escolher o candidato que está mais à direita da escala ideológica e eleitores de esquerda tendem a escolher o candidato que está mais à esquerda. Embora esses resultados sejam sugestivos, precisamos de um modelo que leve em consideração a distância da posição dos eleitores em relação aos candidatos para fazermos um teste mais acurado da teoria espacial do voto. Esse é o objetivo da próxima seção.

\subsection{Resultados}

Antes de apresentarmos a análise formal, na figura 3.3 apresentamos a distribuição das preferências dos eleitores de acordo com o candidato escolhido no $2^{\mathrm{O}}$ turno das eleições de $2010^{8}$. Nela podemos ver que os eleitores que votaram na candidata Dilma Rousseff são aqueles que, em geral, estão mais à esquerda do espectro ideológico. Da mesma forma que os eleitores que votaram em José Serra estão mais à direita. Esses resultados são indícios favoráveis para a ideia de que eleitores votam nos candidatos que estão mais próximos deles do ponto de vista ideológico, como aponta a teoria espacial do voto.

Para estimar os parâmetros do modelo espacial proposto na equação 3.15 utilizamos um modelo Bayesiano de regressão probit tendo como variável de-

como: $r=\frac{\left(\bar{X}_{1}-\bar{X}_{0}\right) \sqrt{\pi(1-\pi)}}{S_{X}}$, onde $\bar{X}_{1}$ e $\bar{X}_{0}$ são as médias amostrais dos valores de $X$ dos níveis 1 e o, respectivamente; $S_{\chi}$ é o desvio padrão amostral de $X$; e $\pi$ é a proporção amostral para $Y=1$.

${ }^{8}$ Para os demais anos ver o Anexo. 
Figura 3.3: Distribuição dos entrevistados por voto nas eleiç̃os de 2010

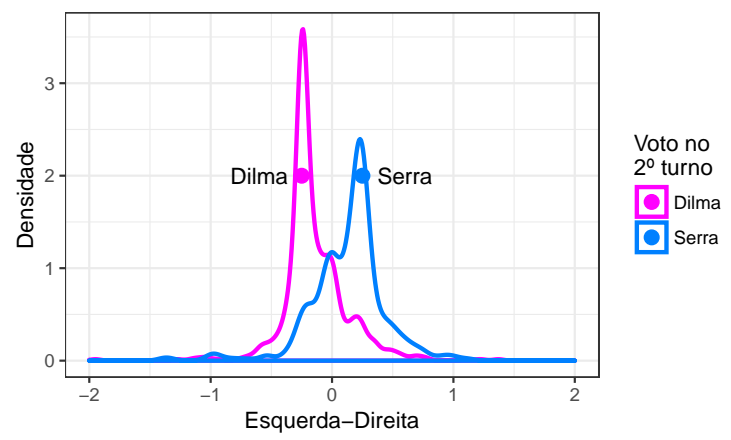

Tabela 3.2: Estimativas dos parâmetros do modelo espacial

\begin{tabular}{ccccc}
\hline & 2002 & 2006 & 2010 & 2014 \\
\hline Intercepto $(\delta)$ & $-0,55$ & $-0,50$ & $-0,26$ & $-0,18$ \\
& {$[-0,64 ;-0,45]$} & {$[-0,61 ;-0,37]$} & {$[-0,34 ;-0,17]$} & {$[-0,26 ;-0,11]$} \\
Ponto ideal (a) & 1,32 & 0,82 & 1,48 & 2,31 \\
& {$[0,98 ; 1,63]$} & {$[0,52 ; 1,13]$} & {$[1,22 ; 1,72]$} & {$[1,95 ; 2,65]$} \\
\hline $\mathrm{N}$ & 937 & 536 & 1077 & 1501 \\
\hline
\end{tabular}

As estimativas são a mediana da distribuição a posteriori. Intervalos de credibilidade de $95 \%$ estão entre colchetes.

pendente um indicador de se o entrevistado votou no candidato do PSDB no segundo turno das eleições ( $\mathrm{PSDB}=1 ; \mathrm{PT}=0$ ). A nossa variável independente é a mediana da distribuição a posteriori das posições ideológicas dos entrevistados $\left(x_{i}\right)$. Os resultados estão na tabela 3.2.

O parâmetro $\delta$, que indica a diferença de viés dos eleitores em relação aos candidatos, possui um valor negativo. Isso indica um viés para os candidatos do PT. A despeito da proximidade ideológica, em média, os eleitores estavam predispostos a votar nos candidatos do PT. Ou seja, existia um componente não espacial, embora pequeno, favorável aos petistas.

Analisando o valor estimado do parâmetro a vemos que ele é positivo e com uma magnitude forte. Esse resultado indica que quanto mais à esquerda da escala ideológica um eleitor está, maiores são as chances dele votar no candidato de esquerda. Isto é, mais sensível à posição do candidato o eleitor está.

Podemos analisar também o gráfico com a probabilidade predita pelo modelo de votar no candidato do PSDB em função dos pontos ideais dos entrevistados 
Figura 3.4: Probabilidade de votar no candidato do PSDB em função dos pontos ideais dos entrevistados

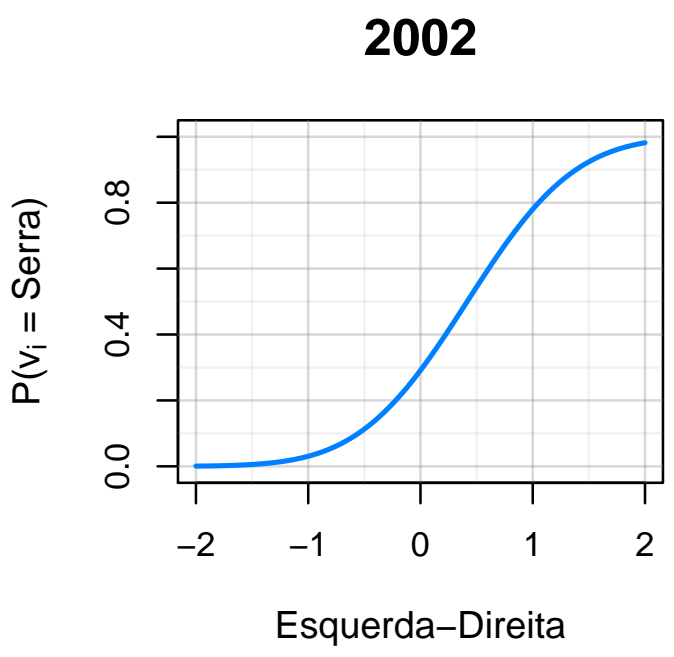

2010

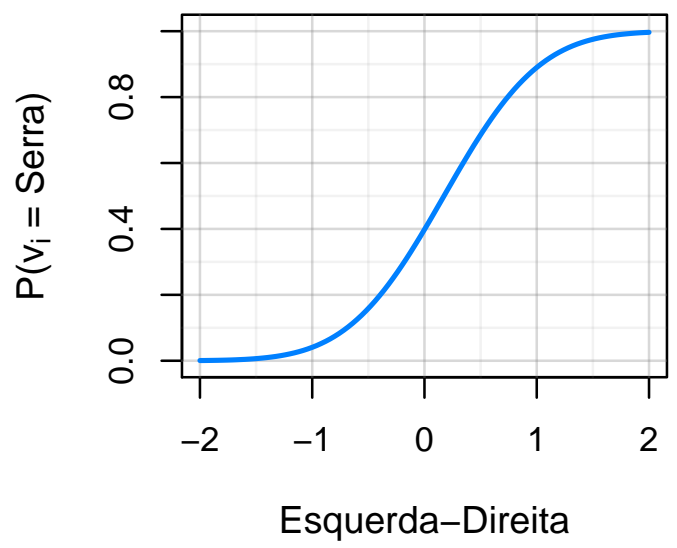

2006

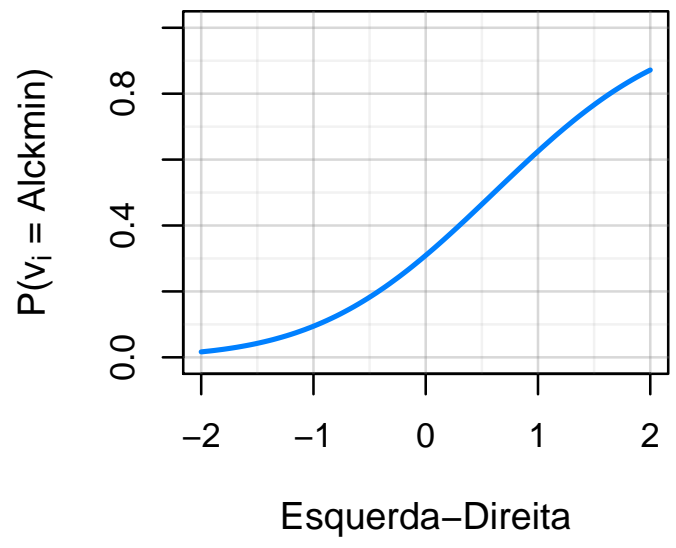

2014

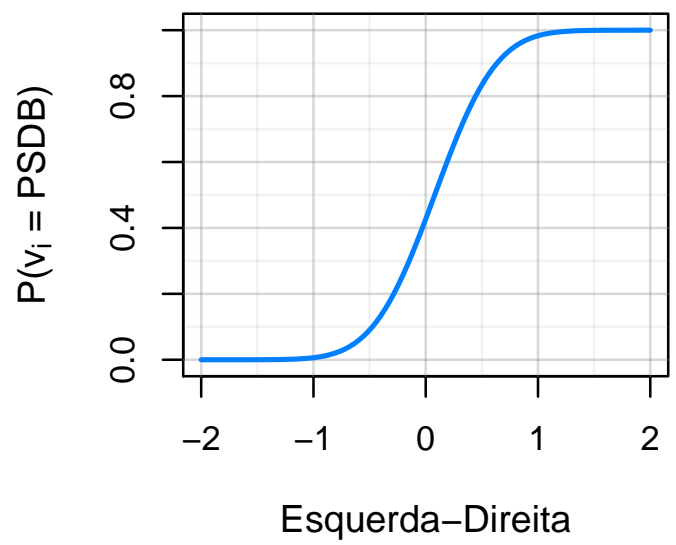


(figura 3.4). Com isso temos uma noção mais clara da relação entre proximidade ideológica e escolha eleitoral. Por exemplo, para as eleições de 2010, um eleitor que possui um ponto ideal de -0,5 - e que portanto está a 0,25 pontos de distância da candidata Dilma e a 0,75 do candidato Serra - possui apenas 15,9\% de chances de votar no candidato José Serra. Mas um eleitor que possui um ponto ideal de 0,5 - e que portanto está a 0,25 pontos de distância do candidato Serra e a 0,75 da candidata Dilma - possui $68,6 \%$ de chances de escolher o candidato do PSDB. Para as eleições de 2002 e 2006 esses valores são um pouco mais baixos: 11,3\% (2002) e 18,2\% (2006) para eleitores com pontos ideais de -0,5 e 54,4\% (2002) e 46,4\% (2006) para eleitores com pontos ideais de 0,5. Já para as eleições de 2014, o fator ideológico foi mais forte. A chance de eleitores com um ponto ideal de $-0,5$ votar no candidato do PSDB era de $9 \%$. Por outro lado, eleitores com um ponto ideal de 0,5 a chance era de $83,4 \%$.

Outro ponto interessante de se analisar é aquele que está exatamente entre os dois candidatos. Esse ponto médio que está localizado no $x_{i}=0$ é aquele em que o eleitor seria indiferente aos candidatos, caso não existisse viés. Ou seja, se nenhum candidato possuir uma vantagem baseada em elementos não espaciais, esperamos que a probabilidade de um eleitor votar em qualquer um dos dois candidatos seja igual a 50\%. Como observamos no gráfico, para as eleições de 2010, um eleitor que possui um ponto ideal igual a zero tem $39,8 \%$ de chances de votar no candidato Serra. Esse resultado indica a existência de uma vantagem a favor da candidata Dilma Rousseff. Resultado semelhante foi encontrado para a eleição de 2014 (42,7\%). Essa vantagem, por outro lado, é pequena em termos substantivos. Esse viés baseado em componentes não ideológicos foi mais forte durante os dois pleitos anteriores. Eleitores no ponto de indiferença tinham 29,1\% (2002) e 30,9\% (2006) de votar no candidato do PSDB.

Em resumo, a proximidade ideológica entre eleitores e candidatos está fortemente associada com a escolha eleitoral. Eleitores de esquerda tendem a votar no candidato de esquerda e eleitores de direita tendem a votar no candidato de direita. No que diz respeito ao viés fruto de elementos não espaciais, os candidatos do PT possuem uma vantagem pequena em relação aos candidatos do 
PSDB. No entanto, essa vantagem tem diminuído ao longo do tempo.

\subsection{Sofisticação política e voto}

Nesta seção iremos verificar se a probabilidade de um eleitor votar no candidato que está mais próximo dele varia conforme o seu nível de sofisticação política. Para isso podemos extender o modelo proposto na equação 3.15 incluindo um termo de interação:

$$
\mathrm{P}\left(v_{i}=\mathrm{PSDB}\right)=\Phi\left(\gamma_{\mathrm{o}}+\gamma_{1} x_{i}+\gamma_{2} \text { sof }_{i}+\gamma_{3} x_{i} \text { sof }_{i}\right)
$$

onde sof $_{i}$ é o índice de sofisticação política do eleitor $i$.

A conexão dos coeficientes do modelo de regressão com os parâmetros do modelo espacial é dada por:

$$
\begin{aligned}
& \delta_{i}=\gamma_{o}+\gamma_{2} \text { sof }_{i} \\
& a_{i}=\gamma_{1}+\gamma_{3} \text { sof }_{i}
\end{aligned}
$$

Mas antes de estimarmos esse modelo precisamos de uma medida de sofisticação política dos eleitores $\left(s_{\mathrm{i}} \mathrm{f}_{\mathrm{i}}\right)$. Isso pode ser feito por meio de modelos da Teoria da Resposta ao Item (IRT) aplicados a questões (itens) sobre importantes figuras do cenário político brasileiro e sobre o funcionamento do sistema político. Essa é a estratégia que tem sido utilizada pela literatura (Lawrence, 2007; Levendusky and Jackman, 2003; Pereira, 2013).

Para o ano de 2010 serão utilizadas 21 questões de conhecimento político. Dessas, 4 são questões fechadas do tipo 'Certo' ou 'Errado'. Foi perguntado ao entrevistado o seguinte: 'Gostaria que o(a) sr(a) dissesse se as seguintes frases estão certas ou erradas'. Por exemplo umas das afirmações era: 'O presidente da República tem um mandato de 4 anos'. O entrevistado deveria responder se esta afirmação era correta ou não. As demais questões (17) eram abertas. Era dito ao entrevistado o seguinte: 'Vou ler para o(a) sr(a) o nome de alguns políticos 
e gostaria que me dissesse a qual partidos eles são filiados.' Por exemplo, uma das perguntas era 'De qual partido Eduardo Suplicy é filiado?' Caso ele tenha respondido 'PT', a resposta foi codificada como 'Certo'. Caso o entrevistado tenha respondido 'Não sabe' ou 'Não respondeu', as respostas foram codificadas como 'Errado'. Para os demais anos foram feitas apenas quatro questões de conhecimento político. Mas, a despeito dessas diferenças, os resultados são semelhantes para todas as eleições 9 .

A principal vantagem de se utilizar modelos de IRT é o fato deles levarem em consideração a dificuldade das questões e como elas discriminam os respondentes ${ }^{10}$. Por exemplo, não é difícil perceber que a questão "De qual partido Lula é filiado?"não deve ter o mesmo peso que a questão "De qual partido Jorge Bornhausen é filiado?". A primeira questão provavelmente receberá muito mais respostas corretas do que a segunda.

No modelo de IRT de dois parâmetros a probabilidade de um entrevistado $i$ responder corretamente ao item q é dada por:

$$
\mathrm{P}\left(\mathrm{q}_{\mathrm{ik}}=1\right)=\Phi\left(\operatorname{sof}_{i} \psi_{\mathrm{q}}-\theta_{\mathrm{q}}\right)
$$

onde $\psi$ é o parâmetro de discriminação e $\theta$ é o parâmetro de dificuldade da questão. Um item é dito mais difícil quando a probabilidade de acerto é menor em comparação à outro item, dado o mesmo nível de sofisticação política. O parâmetro de discriminação indica quão bem um item é capaz de discriminar entre um indivíduo mais sofisticado e um menos sofisticado.

Em sua implementação Bayesiana (Fox, 2010) assume-se que:

\footnotetext{
${ }^{9}$ As questões utilizadas estão no Anexo.

${ }^{10}$ As opções mais simples seriam apenas somar o número de respostas corretas (dando o mesmo peso para todos os itens) ou atribuir pesos diferentes a cada uma das questões. Essas não parecem ser as formas ideais, dado o grau de subjetividade na definição dos pesos de cada item.
} 
Tabela 3.3: Estimativas dos parâmetros do modelo espacial extendido

\begin{tabular}{ccccc}
\hline & 2002 & 2006 & 2010 & 2014 \\
\hline Intercepto & $-0,55$ & $-0,50$ & $-0,25$ & $-0,19$ \\
& {$[-0,64 ;-0,46]$} & {$[-0,63 ;-0,38]$} & {$[-0,38 ;-0,17]$} & {$[-0,26 ;-0,12]$} \\
Ponto ideal & 1,37 & 0,82 & 2,09 & 2,32 \\
& {$[1,04 ; 1,67]$} & {$[0,54 ; 1,15]$} & {$[1,77 ; 2,35]$} & {$[1,97 ; 2,72]$} \\
Sofisticação & $-0,08$ & 0,02 & 0,08 & $-0,01$ \\
& {$[-0,24 ; 0,07]$} & {$[-0,17 ; 0,24]$} & {$[-0,01 ; 0,17]$} & {$[-0,14 ; 0,11]$} \\
Interação & 0,44 & 0,09 & 1,28 & $-0,04$ \\
& {$[-0,03 ; 0,90]$} & {$[-0,34 ; 0,51]$} & {$[0,95 ; 1,57]$} & {$[-0,62 ; 0,52]$} \\
\hline $\mathrm{N}$ & 973 & 536 & 1077 & 1501 \\
\hline
\end{tabular}

As estimativas são a mediana da distribuição a posteriori. Intervalos de credibilidade de $95 \%$ estão entre colchetes.

$$
\begin{gathered}
\operatorname{sof}_{i} \sim N(0,1) \\
\psi_{q} \sim N_{+}(0 ; 0,01) \\
\theta_{q} \sim N(0 ; 0,01)
\end{gathered}
$$

Para identificarmos o modelo fixamos os parâmetros de discriminação e de dificuldade do primeiro item em zero.

Na tabela 3.3 temos os resultados do modelo 3.20. Como é possível notar para o ano de 2010, para os eleitores com um nível de sofisticação médio $\left(\right.$ sof $\left._{i}=0,004\right)$ os parâmetros $\delta=-0,25+0,08(0,004)=-0,25$ e a $=$ $2,09+1,28(0,004)=2,10$ são muito semelhantes aos parâmetros encontrados na tabela $3.2(\delta=-0,26$ e $a=1,48)$. Isso corrobora os achados anteriores indicando a existência de um pequeno viés favorável à candidada do PT e uma probabilidade maior de um eleitor de esquerda (direita) votar no candidato esquerda (direita). Assim como indicam um baixo poder explicativo da variável de sofisticação política.

Para termos uma ideia mais clara das implicações desse resultado podemos olhar para o gráfico com as probabilidades preditas pelo modelo. Na figura 3.5 apresentamos a probabilidade de se votar no candidato do PSDB em função dos 
pontos ideais dos eleitores por nível de sofisticação. Dividimos os eleitores em três grupos: baixa sofisticação (o,25 percentil de sof), média sofisticação (mediana de sof) e alta sofisticação (o,75 percentil de sof). Se a sofisticação política for importante na decisão do voto, esperamos que a probabilidade de um eleitor pouco sofisticado votar no candidato mais próximo dele seja muito diferente da probabilidade de um eleitor altamente sofisticado. Em outras palavras, eleitores pouco informados utilizariam componentes não espaciais na hora de votar ao passo que eleitores informados utilizariam o critério ideológico.

Os resultados da figura 3.5 contradizem a ideia de que eleitores menos informados votariam de uma forma diferente de eleitores mais sofisticados. Diferentes níveis de sofisticação política pouco afetam a probabilidade de um eleitor votar no candidato que está mais próximo dele.

Vejamos as eleições de 2010 no caso de um eleitor com um ponto ideal igual a 0,5 . Se este eleitor for altamente sofisticado, a probabilidade dele votar no candidato do PSDB é de 88,4\%. Se ele possuir um nível médio de sofisticação, essa probabilidade é de $78 \%$. E se ele pouco sofisticado, a probabilidade é de $64 \%$. Embora essas probabilidades aumentem com o nível de informação política, não podemos afirmar que eleitores menos informados guiem os seus votos por critérios não espaciais. Isso fica mais claro para as outras eleições. Para as eleições de 2002, um eleitor muito sofisticado tem $59,7 \%$ de chances de votar no candidato Serra. Eleitores com um nível de sofisticação média e baixo tem 54\% e 53,7\% de chances, respectivamente. Como é possível atestar pelo gráfico, a diferença entre os grupos são praticamente inexistentes durante as eleições de 2006 e 2014. Ser muito ou pouco sofisticado não altera as chances de escolher o candidato mais próximo do ponto de vista ideológico.

Para eleitores indiferentes $\left(x_{i}=0\right)$, as conclusões são semelhantes. Para as eleições de 2010, se ele for muito sofisticado, a probabilidade dele votar no candidato do PSDB é de 41,7\%. Se ele possuir um nível médio, a probabilidade é de $39,9 \%$. E se ele for pouco sofisticado, a probabilidade é de 38,2\%. Ou seja, para todos os níveis de sofisticação a candidata do PT possuía uma vantagem baseada em um componente não espacial. Essa vantagem era maior quanto menor a so- 
Figura 3.5: Probabilidade de votar no candidato do PSDB em função dos pontos ideais dos entrevistados por nível de sofisticação política

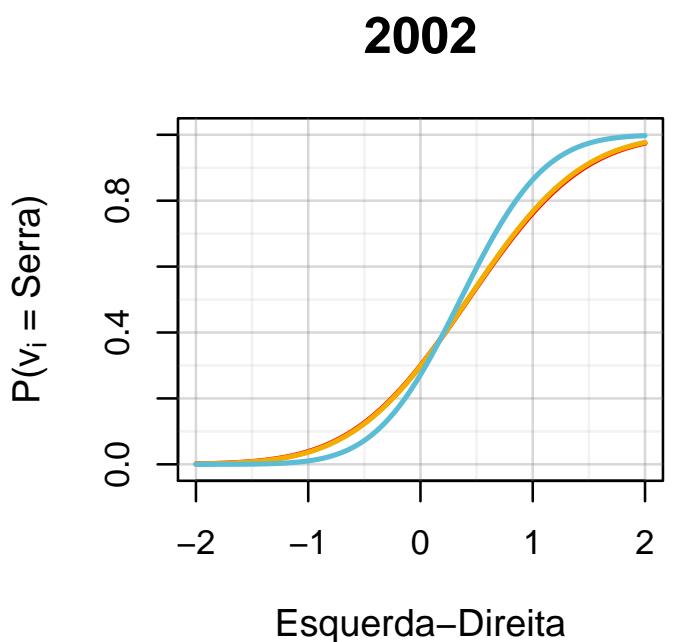

2010

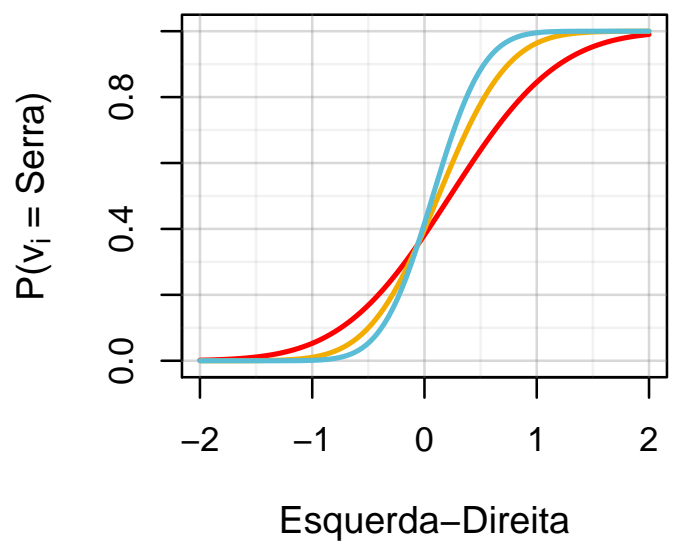

2006

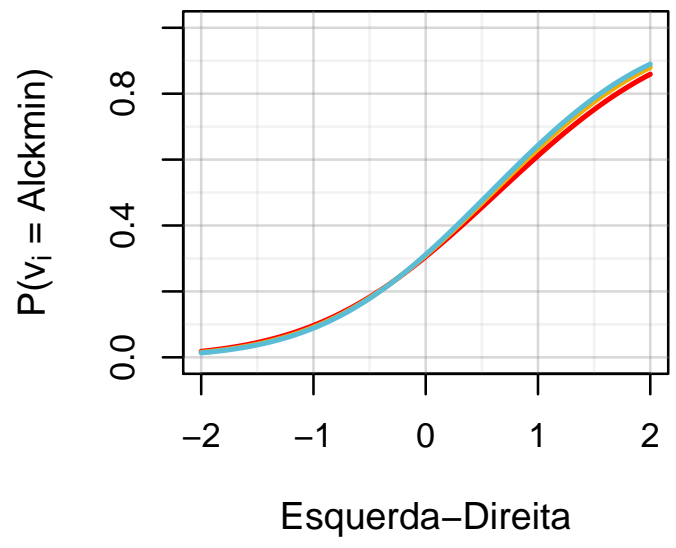

2014

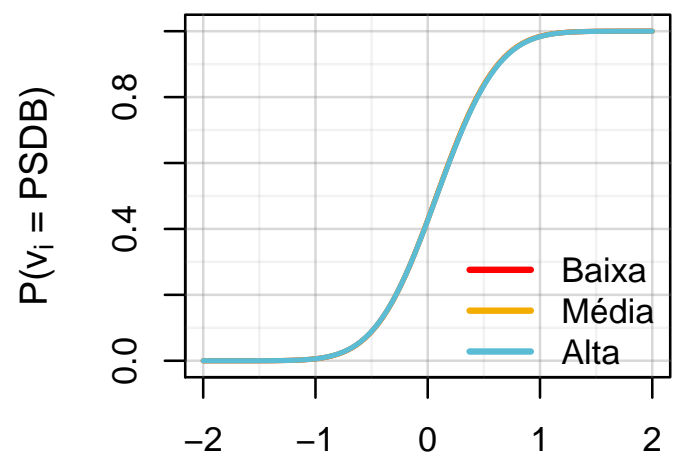

Esquerda-Direita 
fisticação do eleitor. Mas novamente, não podemos afirmar que eleitores menos informados votariam por critérios não espacias e eleitores sofisticados votariam por critérios ideológicos. Ambos levam em consideração a distância relativa dos candidatos. E o mesmo pode ser dito para os outros pleitos.

\subsection{Conclusões}

O objetivo deste capítulo foi testar empiricamente o principal pressuposto da teoria espacial do voto no Brasil. De acordo com esse modelo, eleitores devem votar no candidato que está mais próximo deles do ponto de vista ideológico. Se eles forem indiferentes às opções oferecidas, a probabilidade deles escolherem qualquer um dos candidatos deve ser igual. Além disso, os resultados devem ser independentes do nível de sofisticação dos eleitores. Isto é, o fato de um eleitor ser pouco informado não deve alterar significativamente essas probabilidades.

Como vimos, o modelo espacial parece prever razoavelmente bem o comportamento dos eleitores brasileiros. E isso vale para todos os níveis de sofisticação política. Eleitores altamente sofisticados se encaixam quase que perfeitamente ao modelo espacial. Eles possuem uma alta probabilidade de votar no candidato que está mais próximo deles. Se eles estiverem no ponto de indiferença, a probabilidade deles escolherem qualquer um dos dois candidatos é de quase $50 \%$. A literatura brasileira sobre comportamento eleitoral (Carreirão, 2002; Reis, 2000) não tinha muitas dúvidas sobre esse resultado. A parcela mais informada da população guiaria o seu voto a partir de elementos ideológicos.

A dúvida estaria sobre a parcela menos informada da população. Esse subconjunto de eleitores, que seria a parcela predominante do eleitorado brasileiro, utilizaria elementos não ideológicos na hora do voto. Os resultados apresentados neste capítulo mostram um cenário diferente. A probabilidade deles escolherem um candidato que está mais próximo deles é extremamente alta. 


\subsection{Anexo}

Figura 3.6: Estímulos e distribuição dos entrevistados

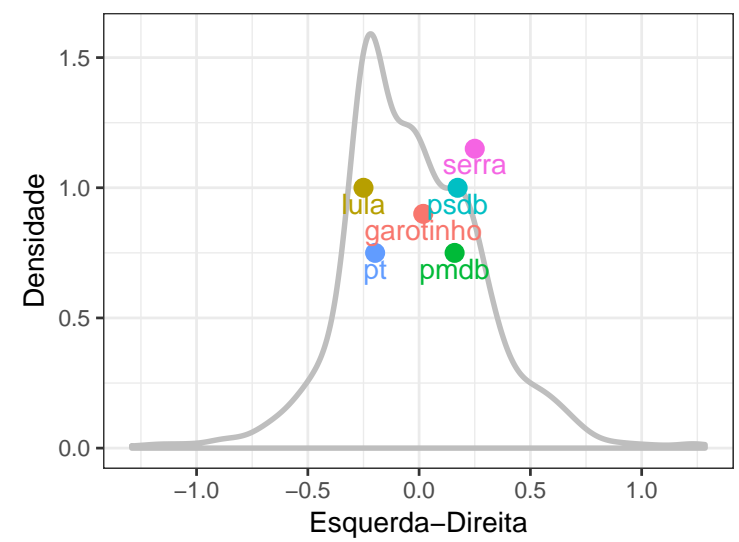

(a) 2002

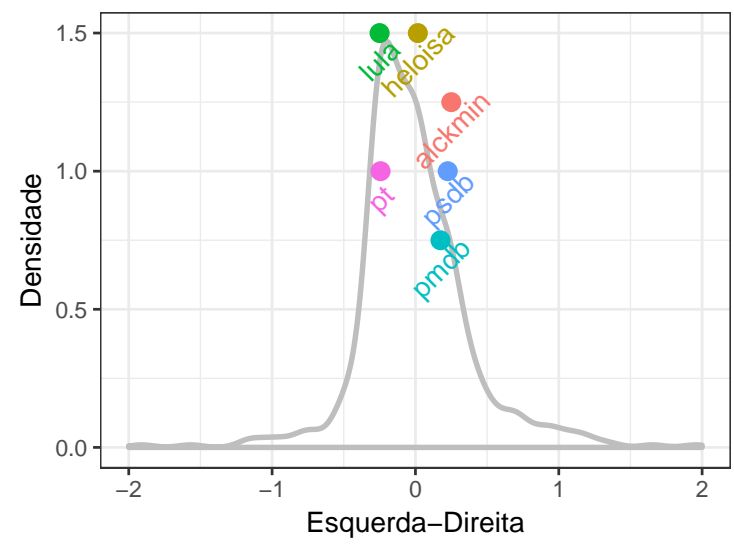

(b) 2006

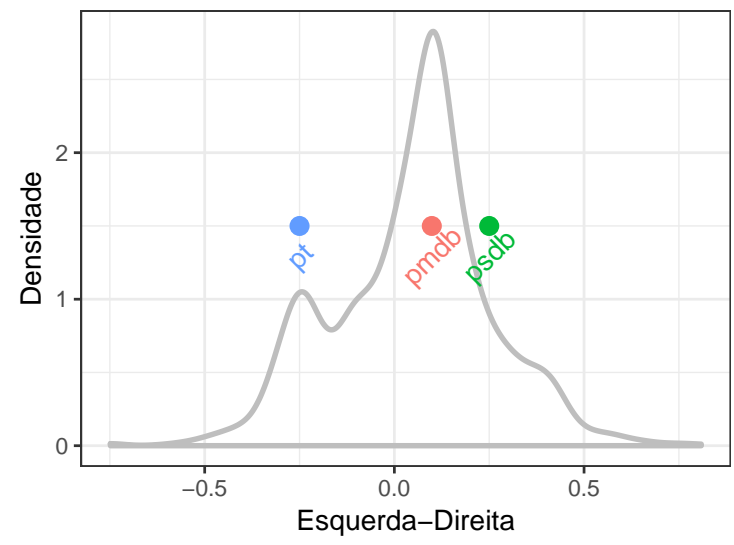

(c) 2014 
Figura 3.7: Comparação entre o autoposicionamento e os pontos ideais estimados

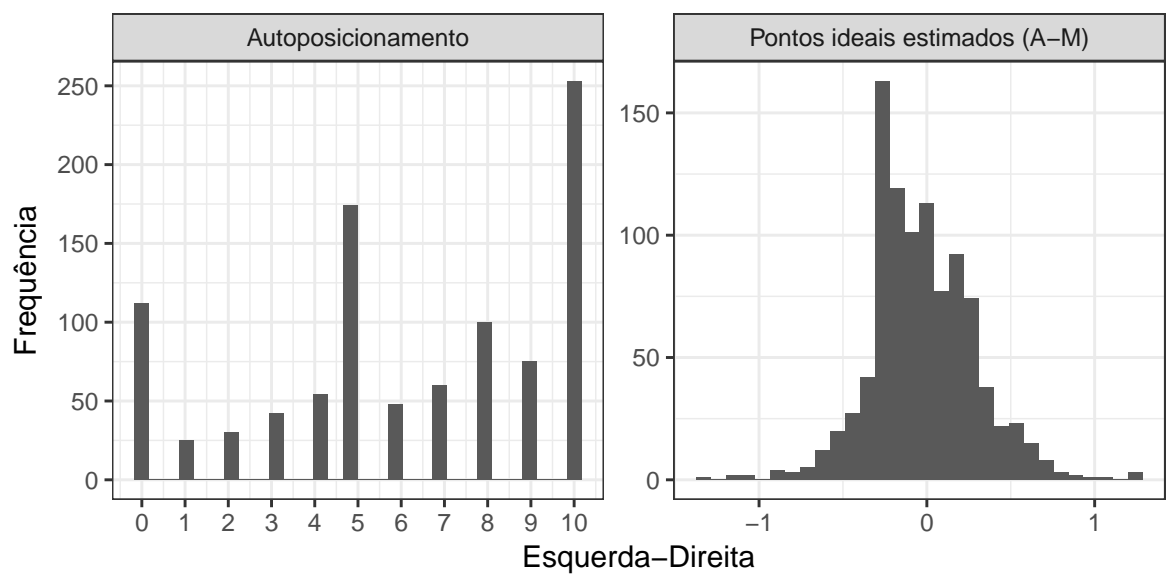

(a) 2002

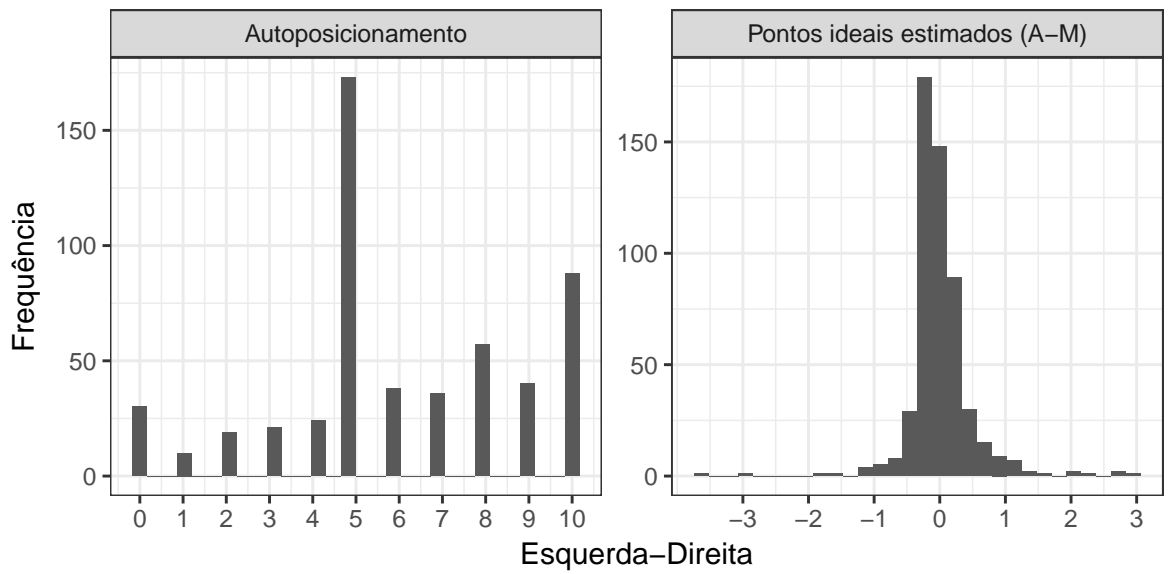

(b) 2006

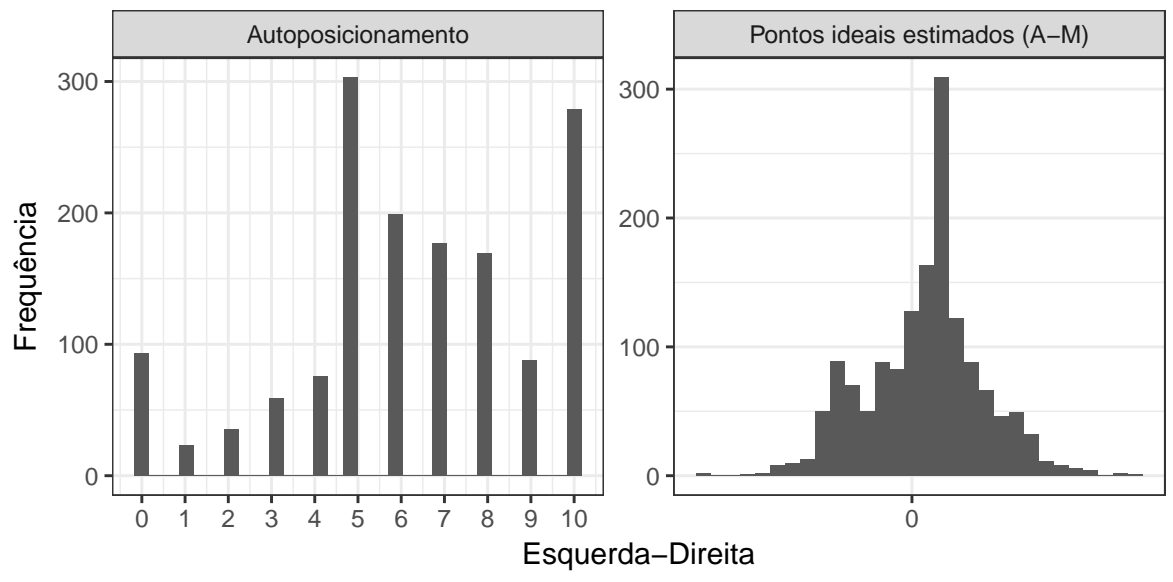

(c) 2014 
Figura 3.8: Distribuição dos entrevistados por voto

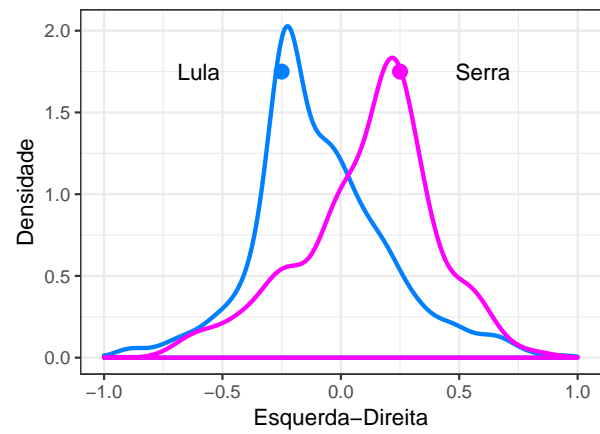

Voto no

2o turno

- Lula

(a) 2002

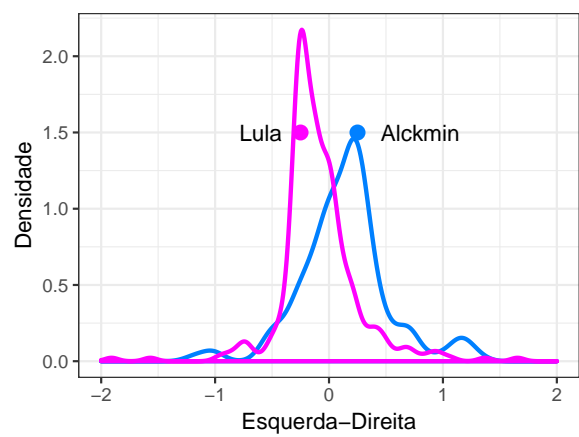

Voto no

- Alckmin

$1-$ Lula

(b) 2006

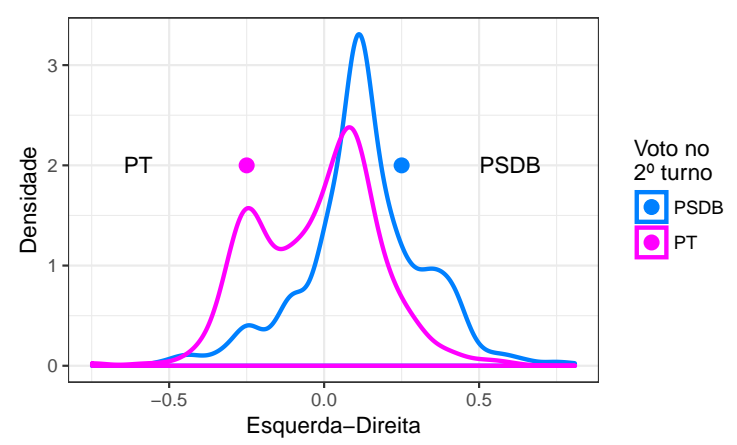

(c) 2014 
Tabela 3.4: Questões de conhecimento político

\section{2:}

1. Na sua opinião, qual é o partido do Presidente Fernando Henrique Cardoso?

2. Na sua opinião o número 13 é de qual partido?

3. Nessa eleição, Denise Frossard foi eleita Deputada Estadual, Deputada Federal ou Senadora?

4. E Carlos Minc, foi eleito Deputado Estadual, Deputado Federal ou Senador? 2006:

Agora para finalizar, gostaria que o(a) sr(a) dissesse se as seguintes frases estão certas ou erradas:

1. Geraldo Alckmin pertence ao PTB.

2. O presidente da república tem um mandato de 4 anos.

3. Os deputados da Câmara Federal são eleitos pelo voto majoritário.

4. O presidente Lula foi eleito pelo PT.

2010:

1. Geraldo Alckmin é filiado ao PTB?

2. O presidente da república tem um mandato de 4 anos?

3. Os deputados da Câmara Federal são eleitos pelo voto majoritário?

4. O presidente Lula quando foi eleito era filiado ao PT?

5. De qual partido Aécio Neves é filiado?

6. De qual partido Aloísio Mercadante é filiado?

7. De qual partido Ciro Gomes é filiado?

8. De qual partido Eduardo Suplicy é filiado?

9. De qual partido Fernando Henrique Cardoso é filiado?

10. De qual partido Itamar Franco é filiado?

11. De qual partido Jorge Bornhausen é filiado?

12. De qual partido José Aníbal é filiado?

13. De qual partido José Dirceu é filiado?

14. De qual partido José Sarney é filiado?

15. De qual partido José Serra é filiado?

16. De qual partido Lula é filiado?

17. De qual partido Marco Maciel é filiado?

18. De qual partido Marina Silva é filiado?

19. De qual partido Michel Temer é filiado?

20. De qual partido Pedro Simon é filiado?

21. De qual partido Roseana Sarney é filiado?

2014:

1. Pelo que o(a) sr(a) sabe ou ouviu falar, qual dessas pessoas foi o Ministro da Fazenda durante o governo Dilma?

2. E pelo que o(a) sr(a) sabe ou ouviu falar, qual dessas foi a taxa de desemprego do Brasil em AGOSTO de 2014?

3. E pensando no que o(a) sr(a) sabe ou ouviu falar, qual é hoje o segundo maior partido na Câmara dos Deputados?

4. Qual dessas pessoas é o atual Secretário Geral da ONU - Organização das Nações Unidas? 


\section{Capítulo 4}

\section{Ser eleito para um cargo público é um bom negócio? Evidências das eleições municipais no Brasil}

\subsection{Introdução}

Ser eleito para um cargo público traz benefícios econômicos privados? Isto é, políticos tiram proveito de seus cargos para enriquecerem? Não é raro encontrarmos nos noticiários denúncias sobre a evolução do patrimônio de políticos. Em notícia publicada em 19 de maio de 2014 o portal O Tempo afirma que o patrimônio de políticos cresce em até 500\% entre eleições. Um exemplo desse aumento patrimonial é o deputado federal Aelton Freitas (PR-MG). Em 2006 ele informou ao Tribunal Superior Eleitoral (TSE) um patrimônio de R\$1,4 milhão. Porém, quatro anos mais tarde, quando foi reeleito, o deputado informou um patrimônio de $\mathrm{R} \$ 5,4$ milhões. Um aumento de $321 \%$ em um mandato como deputado federal ${ }^{1}$.

Parte da literatura parece comprovar essa relação positiva entre o exercício de um cargo eletivo e o avanço patrimonial dos candidatos. De acordo com Fisman et al. (2012), o crescimento anual dos ativos financeiros dos candidatos eleitos é de $3 \%$ a $5 \%$ maior do que dos candidatos não eleitos na Índia. Esse

\footnotetext{
${ }^{1}$ Ver www.otempo.com.br.
} 
crescimento é maior nas regiões em que os índices de corrupção são mais altos e também é maior conforme o político progride na sua carreira. Estudando o caso britânico, Eggers and Hainmueller (2009) encontraram que o efeito de ser eleito ao parlamento varia conforme a filiação partidária do candidato. Para os membros do partido conservador há um efeito positivo de exercer um cargo eletivo sobre o patrimônio, mas para os membros do partido trabalhista não há nenhum efeito. Querubin and Snyder Jr (2011) estimaram o efeito de ser eleito para o congresso norte-americano entre 1850 e 1870. Os autores não encontraram evidências de acumulação de bens entre os candidatos eleitos durante as décadas de 1850 e segunda metade da década de 1860. No entanto encontraram retornos significativos durante o período da Guerra Civil (primeira metade da década de 1860). Parlamentares eleitos durante esse período acumularam 30\% mais bens do que os não eleitos.

Outra parte da literatura vai no sentido contrário. Lenz and Lim (2009) estudando o caso norte-americano no período recente (entre 1995 e 2005) concluíram que a corrupção no Congresso não é uma prática disseminada. Comparando o patrimônio dos parlamentares com o patrimônio de uma amostra representativa da população, os autores argumentam que políticos teriam acumulado o mesmo patrimônio caso não tivessem sido eleitos. De acordo com os autores, indivíduos que já são ricos e com um alto nível de educação acumulam riqueza de forma muito rápida, sejam eles políticos ou não. Resultados semelhantes foram encontrados por Lundqvist (2013) para o caso sueco. Os autores estimaram o efeito de ser eleito (em eleições apertadas) no nível local sobre o patrimônio dos candidatos. Os resultados mostram que não há retornos monetários aos candidatos eleitos tanto no curto quanto no longo prazo.

Este capítulo busca contribuir com essa literatura estudando um país no qual o enriquecimento de agentes públicos por meio de atos corruptos é visto como um problema crônico. Iremos testar o efeito de ser eleito para um cargo público sobre o patrimônio individual no Brasil. Sendo mais preciso, iremos estimar o efeito de ser eleito para o cargo de prefeito sobre o total de bens declarados pelos candidatos quatro anos mais tarde. Para isso utilizaremos modelos de 
regressão descontínua comparando os pares de candidatos que foram eleitos e que não foram eleitos em eleições apertadas e que se reapresentaram na eleição subsequente para o mesmo cargo.

Além de contribuir com a discussão sobre corrupção e enriquecimento de políticos, este capítulo também está relacionado com a literatura sobre a desvantagem eleitoral de candidatos incumbentes em países subdesenvolvidos (Brambor and Ceneviva, 2011; Klašnja, 2015; Klašnja and Titiunik, 2017; Schiumerini, 2015; Titiunik, 2009; Uppal, 2009). Klašnja (2015) argumenta que a principal explicação para essa desvantagem enfrentada pelos candidatos incumbentes é a corrupção. Durante o mandato, políticos agiriam de forma oportunista extraindo recursos do Estado para enriquecimento próprio. Eleitores, por sua vez, puniriam os candidatos corruptos nas urnas. Nossos achados vão contra essa visão.

Os resultados sugerem que ser eleito a um cargo público não tem efeito sobre a quantidade de bens declarada pelos candidatos no futuro. Eleitos e não eleitos em eleições acirradas apresentam um patrimônio semelhante após os primeiros exercerem o cargo de prefeito. Esse resultado não é afetado pela autosseleção dos candidatos em concorrer à eleição, pela possibilidade dos candidatos não declararem todo o seu patrimônio ou pela competitividade das eleições. Também não encontramos efeito de ser eleito sobre o patrimônio de seus familiares e nem efeitos de longo prazo. Além disso, os resultados encontrados não variam conforme a filiação partidária, a região ou a experiência política dos candidatos. Para todos, ser eleito ao cargo de prefeito não traz benefícios econômicos privados.

\subsection{Dados e estratégia empírica}

Identificar o efeito causal do cargo público sobre a renda individual não é uma tarefa trivial. A quantidade de interesse que queremos estimar é a diferença do patrimônio de um indivíduo $i$ quando eleito menos o patrimônio do mesmo indivíduo $i$ caso ele não tivesse sido eleito. O problema é que não observamos as duas quantidades ao mesmo tempo. Apenas observamos o indivíduo quando 
eleito ou quando não eleito. Em outras palavras, não temos o contrafactual. Este é o problema fundamental da inferência causal (Holland, 1986).

Comparar a média do patrimônio de candidatos que foram eleitos com a média do patrimônio de candidatos que não foram eleitos provavelmente irá gerar estimativas viesadas devido a questões de endogeneidade. Eleitos são diferentes dos não eleitos em diversas características que estão associadas tanto com a eleição como com a evolução do patrimônio pessoal. Como lembra Manin (1997), eleições possuem um caráter eminentemente aristocrático. Em geral, os eleitos são mais ricos, mais educados, do sexo masculino, brancos e possuem profissões mais rentáveis do que os não eleitos. Devido a essas diferenças, não seria possível saber se a evolução do patrimônio de um candidato é fruto do exercício do cargo político ou fruto de suas características distintivas.

Idealmente, para capturarmos o efeito causal de interesse deveríamos planejar um experimento no qual o resultado eleitoral fosse decidido de forma aleatória. Neste experimento ideal teríamos um grupo de candidatos eleitos (grupo de tratamento) e outro grupo de candidatos não eleitos (grupo de controle). Se a atribuição dos indivíduos aos grupos de tratamento e de controle fosse aleatória, eles seriam, em média, similares em todas as características observáveis e não observáveis. A única diferença é que um seria eleito e o outro não. Assim, a diferença da média do patrimônio entre os dois grupos seria o efeito causal de exercer um cargo público sobre o patrimônio individual.

Infelizmente esse experimento é inviável. Porém, eleições decididas por margens apertadas de votos podem ser utilizadas como uma aproximação desse desenho de pesquisa ideal. A estratégia de identificação está baseada na ideia de que candidatos que perderam por uma pequena margem de votos são um bom contrafactual para os candidatos que venceram por uma pequena margem (Lee, 2008). A validade das estimativas depende do fato de que os candidatos não são capazes de manipular de forma precisa o resultado de eleições apertadas. Embora o resultado de uma eleição dependa fortemente da habilidade e dos recursos dos candidatos, estes não são capazes de manipular o número exato de votos que irão receber. Assim, em eleições apertadas, isto é, decididas 
por uma pequena margem de votos, o resultado final tem um forte componente aleatório. Em eleições desse tipo é como se a decisão de ser eleito fosse aleatória.

Esta estratégia de identificação desenvolvida por Lee (2008) tem sido largamente utilizada pela ciência política. Apenas para citar alguns exemlos, diversos autores a utilizaram para estimar a vantagem eleitoral de candidatos incumbentes (Titiunik, 2009; Uppal, 2009; Magalhães, 2015); Brollo and Nannicini (2012) estimaram o efeito do alinhamento político sobre as transferências intergovernamentais de recursos para os municípios; Boas and Hidalgo (2011) estimaram o efeito da incumbência sobre a probabilidade de aprovação de licenças de rádios; e Eggers and Hainmueller (2009) e Fisman et al. (2012) estimaram o efeito de ser eleito para cargos públicos sobre o patrimônio individual.

Neste capítulo iremos seguir uma estratégia semelhante à empregada por Fisman et al. (2012). Iremos comparar os pares de candidatos a prefeito em eleições apertadas que se recandidataram ao mesmo cargo na eleição subsequente.

O Brasil possui 5565 municípios. Em média, os municípios tem 22.630 eleitores registrados. Em municípios com menos de 200 mil eleitores registrados, prefeitos são eleitos por maioria simples. Em municípios com mais de $200 \mathrm{mil}$ eleitores registrados, temos um segundo turno entre os dois primeiros colocados, caso ninguém obtenha mais de 50\% dos votos. Quase 99\% dos municípios brasileiros tem menos de 200 mil eleitores. Uma vez eleitos, prefeitos podem permanecer no cargo por apenas dois mandatos consecutivos.

Os dados utilizados neste capítulo são do TSE. Utilizaremos os resultados eleitorais dos anos de 2004 e 2008 para o cargo de prefeito. Com esses dados iremos identificar os pares de candidatos em eleições apertadas que se recandidataram na eleição subsequente para o mesmo cargo. Além disso, iremos analisar apenas os municípios que utilizavam um único turno para eleger os seus prefeitos (isto é, municípios com menos de 200 mil eleitores registrados) e que possuíam pelo menos dois candidatos concorrendo. O patrimônio dos candidatos (variável dependente) será medido a partir da declaração de bens que os candidatos fazem no momento do registro de suas candidaturas ${ }^{2}$. É importante

\footnotetext{
${ }^{2}$ No ano de 2012 nós descartamos duas observações. Excluímos o patrimônio dos candidatos
} 
Tabela 4.1: Estatística descritiva do patrimônio dos candidatos

\begin{tabular}{|c|c|c|c|c|c|c|}
\hline & Média & $\mathrm{DP}$ & Min & Max & Missings & $\mathrm{N}$ \\
\hline \multicolumn{7}{|c|}{ Painel A: Todos os candidatos (dois primeiros colocados) } \\
\hline Eleitos & $\mathrm{R} \$ 707.200$ & $\mathrm{R} \$ 2.420 .598$ & $\mathrm{R} \$ \mathrm{o}$ & $\mathrm{R} \$ 60.230 .000$ & 5592 & 10.599 \\
\hline Não eleitos & $\mathrm{R} \$ 557.600$ & $\mathrm{R} \$ 1.655 .147$ & $\mathrm{R} \$ \mathrm{o}$ & $\mathrm{R} \$ 52.770 .000$ & 5356 & 10.599 \\
\hline \multicolumn{7}{|c|}{ Painel B: Mesmo par de candidatos nas duas eleições para prefeito } \\
\hline Eleitos & $\mathrm{R} \$ 702.100$ & $\mathrm{R} \$ 2.309 .956$ & $\mathrm{R} \$ \mathrm{o}$ & $\mathrm{R} \$ 55.440 .000$ & $\mathrm{O}$ & 1408 \\
\hline Não eleitos & $\mathrm{R} \$ 670.300$ & $\mathrm{R} \$ 2.180 .360$ & $\mathrm{R} \$ \mathrm{o}$ & $\mathrm{R} \$ 52.770 .000$ & $\mathrm{O}$ & 1408 \\
\hline \multicolumn{7}{|c|}{ Painel C: Mesmo par de candidatos nas duas eleições para prefeito: Margem de $2 \%$} \\
\hline Eleitos & $\mathrm{R} \$ 527 \cdot 500$ & $\mathrm{R} \$ 1.077 .612$ & $\mathrm{R} \$ \mathrm{o}$ & $\mathrm{R} \$ 11.670 .000$ & $\mathrm{O}$ & 225 \\
\hline Não eleitos & $\mathrm{R} \$ 529.500$ & $\mathrm{R} \$ 1.413 .680$ & $\mathrm{R} \$ \mathrm{o}$ & $\mathrm{R} \$ 16.830 .000$ & $\mathrm{O}$ & 225 \\
\hline \multicolumn{7}{|c|}{ Painel D: Mesmo par de candidatos nas duas eleições para prefeito: Margem de 8,2\% } \\
\hline Eleitos & $\mathrm{R} \$ 640.800$ & $\mathrm{R} \$ 2.242 .226$ & $\mathrm{R} \$ \mathrm{o}$ & $\mathrm{R} \$ 55.440 .000$ & $\mathrm{O}$ & 833 \\
\hline Não eleitos & $\mathrm{R} \$ 694.700$ & $\mathrm{R} \$ 2.466 .935$ & $\mathrm{R} \$ \mathrm{o}$ & $\mathrm{R} \$ 52.770 .000$ & $\mathrm{O}$ & 833 \\
\hline
\end{tabular}

notar que se o candidato não se reapresenta na próxima eleição para o cargo de prefeito, vice-prefeito ou vereador, não observamos o seu patrimônio. As consequências dessa autosseleção serão analisadas na seção 4.5.1. Como queremos verificar o efeito de ser eleito para o cargo de prefeito sobre o patrimônio pessoal, iremos utilizar as declarações feitas pelos candidatos nas eleições de 2008 e 2012. Ou seja, iremos estimar o efeito de ser eleito em 2004 sobre o patrimônio em 2008 e o efeito de ser eleito em 2008 sobre o patrimônio em 2012. Além dessas informações, iremos utilizar dados sobre o perfil dos candidatos como sexo, idade, escolaridade, profissão e partido para checar o balanceamento dos grupos.

No painel A da tabela 4.I apresentamos uma estatística descritiva de todas nossas observações $(\mathrm{N}=21.198)$. Nela temos os dois primeiros colocados em municípios com menos de 200 mil eleitores registrados e com pelo menos dois candidatos. Temos aproximadamente $95 \%$ de todos os municípios brasileiros nessa amostra. Em média, esses municípios tem 14.910 eleitores registrados. $\mathrm{Na}$ primeira linha são os dados dos candidatos eleitos (incumbentes) e na segunda

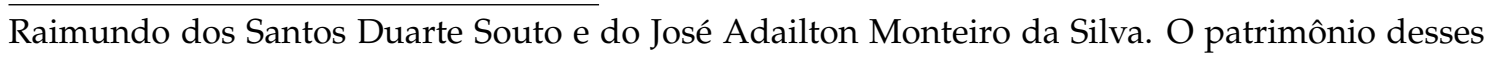
dois candidatos claramente apresentavam erros de digitação. 
linha os dados dos candidatos não eleitos (não incumbentes). Como dito anteriormente, os dados do patrimônio apenas são observados para os candidatos que se recandidataram na eleição subsequente aos cargos de prefeito, vice-prefeito ou vereador. Quando o candidato não se rencandidata não observamos o seu patrimônio. Em primeiro lugar, podemos observar o grande número de candidatos que não se recandidataram para a próxima eleição para nenhum cargo, mais da metade. Em segundo lugar, observamos que, em média, os eleitos possuem uma renda maior do que os não eleitos, cerca de $\mathrm{R} \$ 150.000,00$ a mais. No entanto a variação é muito grande. Isso pode ser visto tanto pelo desvio padrão quanto pela amplitude dos dados.

No painel B selecionamos apenas os candidatos de municípios em que o mesmo par de candidatos concorreu a prefeito em eleições subsequentes $(\mathrm{N}=$ 2816). Essa amostra corresponde a cerca de $13 \%$ de todos os municípios brasileiros. Em média, esses municípios tem 16.580 eleitores registrados. Assim como no painel A, em média, os eleitos possuem um patrimônio maior do que o dos não eleitos. No entanto a diferença é menor, cerca de $\mathrm{R} \$ 30.000,00$.

No painel C temos os mesmos dados do painel B, mas agora selecionando os municípios em que a diferença de votos entre o primeiro e o segundo colocados foi menor do que $2 \%$ dos votos válidos $(\mathrm{N}=450)$. Essa amostra engloba cerca de 2\% dos municípios brasileiros. Em média, esses municípios tem 15.770 eleitores registrados. Como podemos observar, as médias dos patrimônios são praticamente iguais ( $\mathrm{R} \$ 527 \cdot 500,00$ para os eleitos e $\mathrm{R} \$ 529.500,00$ para os não eleitos).

Por fim, no painel $\mathrm{D}$ utilizamos uma margem de $8,2 \%$ de votos $(\mathrm{N}=1666)$. Esse valor foi calculado utilizando o algoritmo desenvolvido por Imbens and Kalyanaraman (2011). Essa amostra possui cerca de $7 \%$ dos municípios brasileiros. Em média, esses municípios tem 15.530 eleitores registrados. Para essa especificação podemos ver que, em média, os candidatos não eleitos possuem um patrimônio um pouco maior do que os eleitos, cerca de $\mathrm{R} \$ 50.000,00$. Em conjunto, as estatísticas descritivas apresentadas nos painéis $C$ e D sugerem que os candidatos que foram eleitos não obtiveram um patrimônio maior do que os não eleitos. Em outras palavras, nessas duas especificações em que comparamos 
candidatos que disputaram eleições acirradas e que, portanto, são similiares em diversas covariáveis, o exercício de um cargo eletivo não apresentou um efeito positivo sobre o patrimônio pessoal.

\subsection{Balanceamento dos grupos}

A hipótese de identicação é a de que candidatos que venceram ou que perderam por uma margem pequena de votos não são capazes de sistematicamente vencer as eleições. Ou seja, os dois grupos de candidatos, em média, devem ser iguais em todas as características observáveis e não observáveis. Nesta seção iremos apresentar algumas evidências da plausibilidade desse pressuposto em nosso desenho de pesquisa. Primeiramente, iremos verificar se covariáveis determinadas antes da aplicação do tratamento são estatisticamente indistinguíveis entre os eleitos e os não eleitos. Para isso iremos estimar a diferença de médias entre os dois grupos em diversas variáveis. Por construção, todas as características ao nível do município estão balanceadas. Assim, iremos testar apenas variáveis que foram mensuradas ao nível do candidato. Na figura 4.1 apresentamos a estatística $\mathrm{t}$ associada aos testes de diferenças de médias.

Como é possível observar, os resultados obtidos a partir da amostra com todos os candidatos mostram um claro desbalanceamento entre os grupos. Em média, o grupo dos eleitos possui candidatos mais jovens e do sexo masculino, uma maior proporção de candidatos filiados ao PSDB e ao PP e uma menor proporção de advogados. No entanto, quando reduzimos a amostra para os candidatos em eleições apertadas, o balanceamento melhora significativamente. Tanto para as eleições decididas por uma margem menor do que $2 \%$ de votos como para as decididas por uma margem menor do que $8,2 \%$ todos os testes possuem uma estatísista t próxima de 1,96.

Outra forma de verificar a validade de nosso de pesquisa é implementando o teste de McCrary (2008). Nele testamos a hipótese nula de continuidade da densidade da nossa running variable no ponto de descontinuidade. A hipótese alternativa é a de há um salto na função de densidade nesse ponto. Encontramos 
Figura 4.1: Balanceamento dos grupos de tratamento e controle

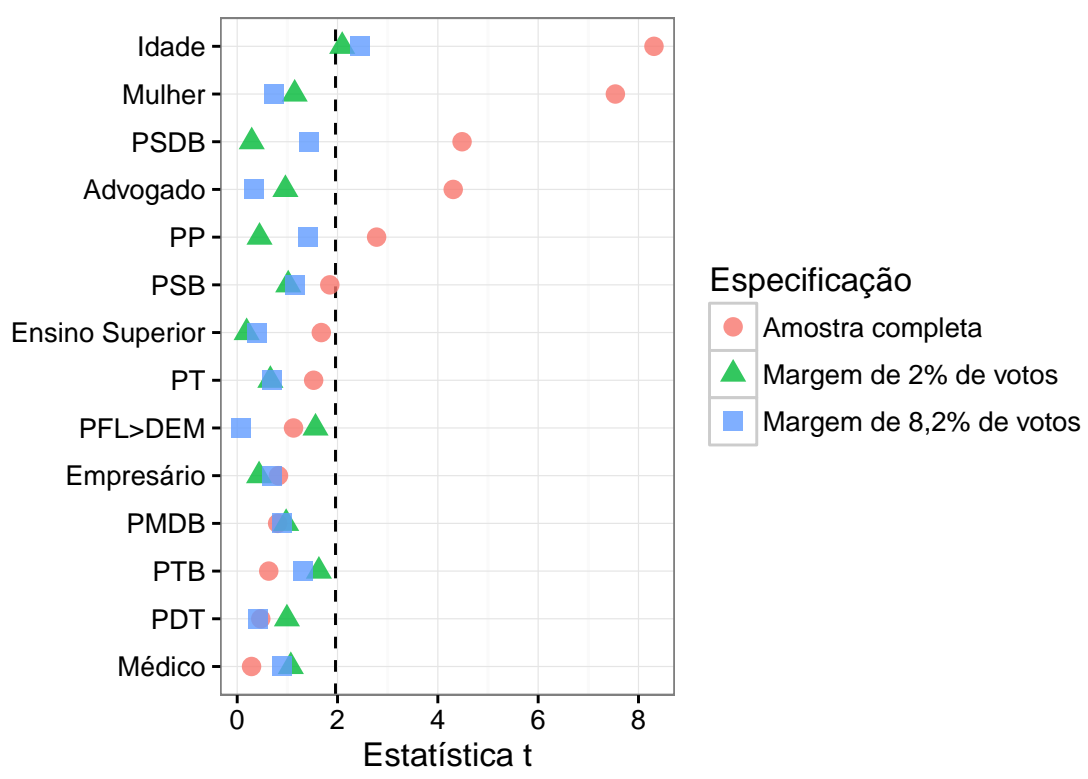

Nota: Neste gráfico temos a estatística $t$ de testes de diferenças de médias entre o grupo dos eleitos e dos não eleitos em 14 covariáveis. O círculo é o resultado do teste para a amostra completa $(\mathrm{N}=21.198)$. O triângulo é o resultado para o mesmo par de candidatos em um bandwidth de $2 \%(\mathrm{~N}=450)$. O quadrado é o resultado para o bandwidth de $8,2 \%(\mathrm{~N}=1666)$. A linha tracejada na vertical indica o valor de 1,96.

um valor de p igual a o,83. Portanto não rejeitamos a hipótese nula de continuidade da distribuição em torno da margem de vitória igual a zero. Esse resultado também pode ser visto na figura 4.4 dos Anexos.

Em conjunto, esses resultados dão suporte à hipótese de identificação. Candidatos eleitos e não eleitos são similares em covariáveis determinadas antes da aplicação do tratamento (ser eleito). Isto é, eles não são capazes de manipular o resultado eleitoral. Para os candidatos que venceram ou perderam por uma pequena margem de votos é como se o resultado da eleição fosse aleatório.

\subsection{Resultados}

Nesta seção iremos testar a hipótese de que candidatos quando eleitos utilizam o cargo para aumentarem o patrimônio pessoal. Iniciamos a análise com um modelo simples de regressão linear no qual a nossa variável dependente é o valor total do patrimônio declarado pelos candidatos (Patrimônio $i, t+1$ ) e nossa 
única variável independente é um indicador de se ele foi eleito ou não a prefeito na eleição anterior $\left(\right.$ Eleito $\left._{i, t}\right)$. Neste modelo utilizamos todas as nossas observações, isto é, temos os dois primeiros colocados que se recandidataram na eleição subsequente para os cargos de prefeito, vice-prefeito ou vereador $(\mathrm{N}=10.250)$. O resultado deste teste pode ser visto na equação abaixo ${ }^{3}$ :

$$
\text { Patrimônio }_{i, t+1}=\underset{(28.516)}{557.643}+\underset{(40.801)}{149.526} \times \text { Eleito }_{i, t}
$$

Em primeiro lugar, os candidatos que não foram eleitos possuem um patrimônio médio de $R \$ 557.643,00$. Em segundo lugar, e mais importante, ser eleito ao cargo de prefeito está associado a um aumento de $\mathrm{R} \$ 149.526$,oo no total de bens declarados pelos candidatos. Isso equivale a um aumento de $27 \%$ no patrimônio. No entanto, esse resultado é pouco informativo sobre o efeito causal de ser eleito a um cargo público sobre o patrimônio. Como dito anteriormente, candidatos eleitos são muito diferentes dos não eleitos. Os dois grupos de candidatos diferem em várias características observáveis e não observáveis que estão associadas tanto com a probabilidade de ser eleito como com o aumento do patrimônio. Indivíduos mais educados, por exemplo, tem maiores chances de serem eleitos assim como maiores chances de aumentarem as suas rendas. Assim, não sabemos se o maior patrimônio dos canditados eleitos é devido ao exercício do cargo público ou simplesmente devido ao fato deles serem mais educados. Para contornar esse problema iremos utilizar a regressão descontínua.

Na figura 4.2 apresentamos um resultado visual. No eixo y temos o patrimônio declarado pelos candidatos e no eixo $x$ a margem de votos centrada em zero. Do lado direito em azul temos os candidatos que venceram as eleições e do lado esquerdo em vermelho os que perderam. Para cada um dos grupos nós ajustamos um modelo cúbico. Como é possível observar não há uma diferença do patrimônio declarado entre os dois grupos. Em outras palavras, o exercício de um cargo eletivo parece não aumentar a quantidade de bens dos candidatos.

${ }^{3}$ Erros padrões entre parênteses. 
Figura 4.2: Efeito de ser eleito sobre o patrimônio

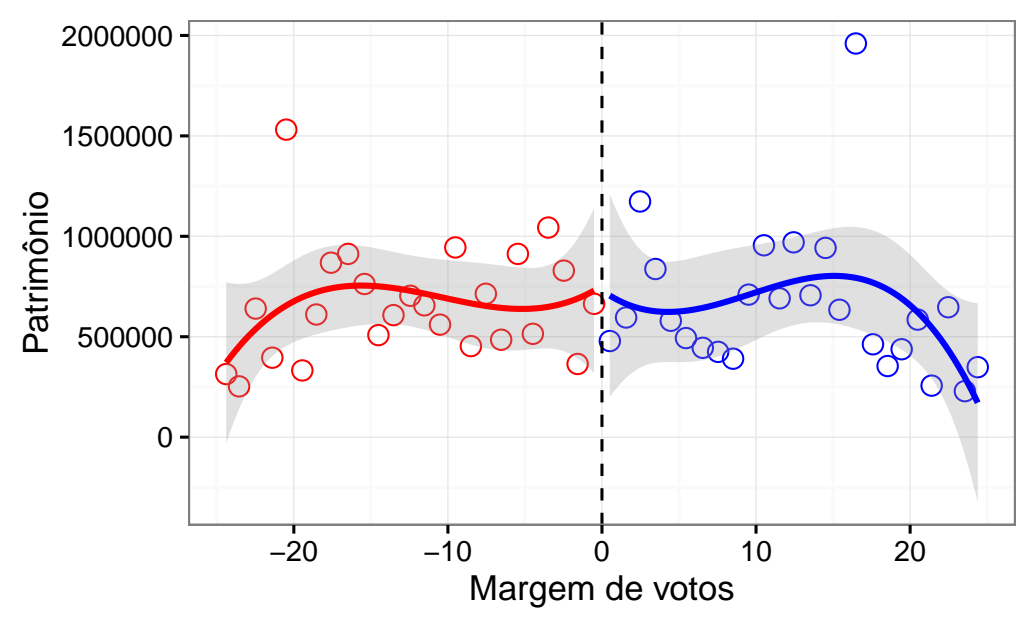

Nota: Cada ponto do gráfico representa a média do patrimônio declarado pelos candidatos em intervalos de $1 \%$ de votos. Os pontos em vermelho são os candidatos que não foram eleitos e os pontos em azul são os candidatos que foram eleitos. A linha tracejada na vertical indica o cutoff. Além disso, ajustamos um modelo cúbico em cada um dos grupos com um intervalo de confiança de $95 \%$.

Tabela 4.2: Efeito do tratamento sobre o patrimônio

\begin{tabular}{lccccc}
\hline & $(1)$ & $(2)$ & $(3)$ & $(4)$ & $(5)$ \\
\hline Tratamento & -302.415 & -302.415 & -514.245 & -713.197 & -406.507 \\
& $(283.048)$ & $(283.366)$ & $(609.158)$ & $(1.071 .161)$ & $(362.088)$ \\
Termo Quadrático & Não & Não & Sim & Sim & Sim \\
Termo Cúbico & Não & Não & Não & Sim & Sim \\
Efeito da Eleição & Não & Sim & Sim & Sim & Sim \\
Bandwidth & $2 \%$ & $2 \%$ & $2 \%$ & $2 \%$ & $8,2 \%$ \\
Observações & 450 & 450 & 450 & 450 & 1666 \\
\hline
\end{tabular}

Nota: Erros padrões robustos clusterizados ao nível do município entre parênteses.

Caso o cargo público tivesse um efeito sobre o patrimônio nós iríamos observar uma descontinuidade no ponto zero.

Na tabela 4.2 fazemos a análise formal. Nas quatro primeiras colunas temos o resultado para o conjunto de eleições cuja margem de votos entre o primeiro e o segundo colocados foi menor do que $2 \%$. Na quinta coluna utilizamos uma margem de $8,2 \%$. Junto com as estimativas do efeito do tratamento temos também os respectivos erros padrões clusterizados ao nível do município. O primeiro modelo possui uma especificação linear. Como vemos, encontramos um coeficiente negativo de $\mathrm{R} \$ 302.415,00$, mas que não é estatisticamente significante aos 
níveis convencionais. A inclusão de uma variável que indica o ano da eleição no segundo modelo não altera a nossa estimativa. No terceiro modelo incluímos um termo quadrático. Neste modelo o coeficiente continua negativo e não significante do ponto de vista estatístico. E o mesmo acontece ao incluírmos um termo cúbico no quarto modelo. Por fim, no quinto e último modelo em que aumentamos o bandwidth para $8,2 \%$ os resultados se mantem praticamente inalterados.

Em resumo, para todas as nossas diferentes especificações chegamos a resultados semelhantes. Em todos os modelos encontramos um coeficiente negativo, mas não estatisticamente significante. Os resultados corroboram a inspeção visual feita anteriormente de que ser eleito para um cargo público não traz um aumento no patrimônio individual. Ou dito de forma contrafactural, caso o candidato que foi eleito não tivesse sido eleito, ele teria adquirido o mesmo patrimônio.

\subsection{Hipóteses alternativas}

\subsubsection{Autosseleção}

Na seção anterior não encontramos nenhum efeito de ser eleito para um cargo público sobre o patrimônio dos candidatos. Esse resultado nulo, no entanto, pode ser fruto de um problema de autosseleção. Vejamos, a nossa amostra é composta pelos dois primeiros colocados em eleições apertadas que se recandidataram ao cargo de prefeito. Utilizamos esse critério porque quando o candidato não entra na competição não observamos o seu patrimônio. Mas o problema é que se recandidatar é uma decisão endógena. É possível imaginar o seguinte cenário: os não incumbentes irão se recandidatar apenas se eles realmente tiverem chances de vencer as eleições. Como concorrer a uma eleição tem custos, apenas os candidatos não incumbentes 'fortes' irão entrar na corrida eleitoral novamente. Por outro lado, os custos do candidato incumbente concorrer são menores. Ele é o eleito. Assim, provavelemente ele irá concorrer à reeleição, 
seja ele um candidato 'forte' seja ele um candidato 'fraco'. Como consequência teríamos um desbalanceamento dos grupos. Do lado dos incumbentes teríamos candidatos 'fortes' e 'fracos' e do lado dos não incumbentes teríamos apenas candidatos 'fortes'. Por tal razão estaríamos encontrando um efeito negativo (embora não estatisticamente significante) da incumbência sobre o patrimônio.

Vamos analisar esse problema de uma maneira um pouco mais formal. Seja $Y_{i}$ o patrimônio do candidato i. Existem dois resultados potenciais: $Y_{1 i}$ é o patrimônio do candidato $i$, se ele é o incumbente; e $Y_{\text {oi }}$ é o patrimônio do candidato $i$, se ele não é o incumbente. Ser o incumbente é o tratamento e não ser o incumbente é o controle. O efeito causal médio da incumbência sobre o patrimônio é definido por $E\left[Y_{1 i}-Y_{o i}\right]$. Essa é a quantidade que gostaríamos de estimar.

Seguindo Magalhães (2015), definimos outro indicador de interesse: $R_{i}$ que assume o valor 1 , se o candidato i se recandidatou ao cargo de prefeito; e o, caso contrário. Podemos reescrever $E\left[Y_{1 i}-Y_{o i}\right]$ em termos de $R_{i}$.

Sejam

$$
\begin{aligned}
& E\left[Y_{1 i}\right]=E\left[Y_{1 i} \mid R_{1 i}=1\right] \times E\left[R_{1 i}=1\right]+E\left[Y_{1 i} \mid R_{1 i}=0\right] \times E\left[R_{1 i}=0\right] \\
& E\left[Y_{o i}\right]=E\left[Y_{o i} \mid R_{o i}=1\right] \times E\left[R_{o i}=1\right]+E\left[Y_{o i} \mid R_{o i}=0\right] \times E\left[R_{o i}=0\right]
\end{aligned}
$$

Temos que:

$$
\begin{aligned}
E\left[Y_{1 i}-Y_{o i}\right]= & \left\{E\left[Y_{1 i} \mid R_{1 i}=1\right] \times E\left[R_{1 i}=1\right]+E\left[Y_{1 i} \mid R_{1 i}=0\right] \times E\left[R_{1 i}=0\right]\right\}- \\
& \left\{E\left[Y_{o i} \mid R_{o i}=1\right] \times E\left[R_{o i}=1\right]+E\left[Y_{o i} \mid R_{o i}=0\right] \times E\left[R_{o i}=0\right]\right\}
\end{aligned}
$$

Somando e subtraindo $E\left[Y_{o i} \mid R_{o i}=1\right] \times E\left[R_{1 i}=1\right]$ na equação 4.4 concluímos que:

$$
\begin{aligned}
E\left[Y_{1 i}-Y_{o i}\right]= & \left\{E\left[Y_{1 i} \mid R_{1 i}=1\right]-E\left[Y_{o i} \mid R_{o i}=1\right]\right\} \times E\left[R_{1 i}=1\right]+ \\
& E\left[Y_{o i} \mid R_{o i}=1\right] \times\left\{E\left[R_{1 i}=1\right]-E\left[R_{o i}=1\right]\right\}+ \\
& \left\{E\left[Y_{1 i} \mid R_{1 i}=0\right]-E\left[Y_{o i} \mid R_{o i}=o\right]\right\} \times\left\{E\left[R_{1 i}=o\right]-E\left[R_{o i}=o\right]\right\}
\end{aligned}
$$


Tabela 4.3: Efeito do tratamento sobre a probabilidade de concorrer a prefeito em $t+1$

\begin{tabular}{lccccc}
\hline & $(1)$ & $(2)$ & $(3)$ & $(4)$ & $(5)$ \\
\hline Tratamento & $-0,123$ & $-0,123$ & $-0,067$ & $-0,185$ & $-0,133$ \\
& $(0,045)$ & $(0,045)$ & $(0,071)$ & $(0,098)$ & $(0,045)$ \\
Termo quadrático & Não & Não & Sim & Sim & Sim \\
Termo cúbico & Não & Não & Não & Sim & Sim \\
Efeito da eleição & Não & Sim & Sim & Sim & Sim \\
Bandwidth & $2 \%$ & $2 \%$ & $2 \%$ & $2 \%$ & $8,2 \%$ \\
N & 2116 & 2116 & 2116 & 2116 & 8594 \\
\hline
\end{tabular}

Nota: Erros padrões robustos clusterizados ao nível do município entre parênteses.

Se todos os incumbentes e não incumbentes se reapresentarem ao cargo de prefeito, isto é, se $E\left[R_{1 i}=1\right]=1, E\left[R_{1 i}=1\right]-E\left[R_{o i}=1\right]=$ o e $E\left[R_{1 i}=0\right]-$ $E\left[R_{o i}=o\right]=0$, então o efeito incondicional da incumbência sobre o patrimônio $\left(E\left[Y_{1 i}-Y_{0 i}\right]\right)$ é igual ao seu efeito condicional $\left(E\left[Y_{1 i} \mid R_{1 i}=1\right]-E\left[Y_{o i} \mid R_{o i}=1\right]\right)$.

No entanto, nem todos os candidatos se reapresentam. Mas se incumbentes e não incumbentes se reapresentarem em taxas semelhantes, isto é, se $E\left[R_{1 i}=\right.$ $1]<1, E\left[R_{1 i}=1\right]-E\left[R_{o i}=1\right]=$ o e $E\left[R_{1 i}=0\right]-E\left[R_{o i}=0\right]=0$, o efeito da incumbência sobre o patrimônio será igual ao seu efeito condicional vezes a probabilidade do incumbente se reapresentar $\left(E\left[R_{1 i}=1\right]\right)$. Assim, embora o efeito condicional seja maior do que o efeito incondicional, a direção do efeito (sinal) será a mesma já que $0 \leqslant E\left[R_{1 i}=1\right] \leqslant 1$.

$\mathrm{Na}$ tabela 4.3 estimamos o efeito de ser eleito no tempo $t$ sobre a probabilidade de concorrer à prefeito no tempo $t+1$. A variável dependente é um indicador que vale 1 , caso o candidato se recandidate a prefeito na eleição subsequente e vale o, caso contrário. As especificações dos modelos são idênticas as dos modelos apresentados na seção anterior.

As duas primeiras especificações (colunas 1 e 2 da tabela 4.3) sugerem que ser o incumbente reduz as chances de concorrer à próxima eleição para o mesmo cargo em $12 \%$. Esse resultado vai contra as nossas expectativas. Esperávamos encontrar um efeito positivo da incumbência sobre a probabilidade de se recandidatar. No entanto, esse resultado não se mantém nas próximas duas especifi- 
Tabela 4.4: Análise de sensibilidade imputando a média e o primeiro e terceiro quartil

\begin{tabular}{|c|c|c|c|c|c|}
\hline & $(1)$ & $(2)$ & (3) & (4) & (5) \\
\hline \multicolumn{6}{|c|}{ Painel A: Imputando a média do patrimônio } \\
\hline Tratamento & $\begin{array}{c}-91.770 \\
(113.769)\end{array}$ & $\begin{array}{c}-91.770 \\
(113.796)\end{array}$ & $\begin{array}{l}-107.114 \\
(186.556)\end{array}$ & $\begin{array}{c}-41.416 \\
(258.069)\end{array}$ & $\begin{array}{c}-70.160 \\
(119.281)\end{array}$ \\
\hline \multicolumn{6}{|c|}{ Painel B: Imputando o primeiro quartil do patrimônio } \\
\hline Tratamento & $\begin{array}{l}-196.288 \\
(116.868)\end{array}$ & $\begin{array}{l}-196.288 \\
(116.896)\end{array}$ & $\begin{array}{l}-183.797 \\
(190.392)\end{array}$ & $\begin{array}{l}-158.567 \\
(262.124)\end{array}$ & $\begin{array}{l}-187.859 \\
(122.197)\end{array}$ \\
\hline \multicolumn{6}{|c|}{ Painel C: Imputando o terceiro quartil do patrimônio } \\
\hline Tratamento & $\begin{array}{l}-110.988 \\
(114.044)\end{array}$ & $\begin{array}{l}-110.988 \\
(114.071)\end{array}$ & $\begin{array}{l}-121.214 \\
(186.814)\end{array}$ & $\begin{array}{c}-62.957 \\
(258.192)\end{array}$ & $\begin{array}{c}-89.963 \\
(119.479)\end{array}$ \\
\hline quadrático & Não & Não & Sim & Sim & Sim \\
\hline Termo cúbico & Não & Não & Não & Sim & Sim \\
\hline Efeito da eleição & Não & Sim & Sim & Sim & Sim \\
\hline Bandwidth & $2 \%$ & $2 \%$ & $2 \%$ & $2 \%$ & $8,2 \%$ \\
\hline $\mathrm{N}$ & 2116 & 2116 & 2116 & 2116 & 8594 \\
\hline
\end{tabular}

Nota: Erros padrões robustos clusterizados ao nível do município entre parênteses.

cações (colunas 3 e 4). Como vemos, embora os resultados sejam negativos, eles não são estatisticamente significantes aos níveis convencionais. Por fim, quando utilizamos um bandwidth de $8,2 \%$ (coluna 5), os resultados voltam aos patamares anteriores.

Como os resultados não são robustos às diferentes especificações, não somos capazes de rejeitar a hipótese de que eleitos e não eleitos se reapresentam na eleição subsequente em taxas semelhantes. Assim, ao restringir as nossas observações aos candidatos que se recandidataram ao cargo de prefeito ainda somos capazes de estimar a direção do efeito causal. E como encontramos um efeito nulo de ser eleito sobre o patrimônio na seção anterior, o fato de estarmos superestimando o coeficiente não altera as nossas conclusões.

Outra forma de se analisar os impactos da autosseleção sobre os nossos resultados é implementando uma análise de sensibilidade. O teste consiste em imputar os valores do patrimônio quando os candidatos não se recandidatam (isto é, quando não observamos o seu patrimônio) e estimar o efeito da incum- 
Tabela 4.5: Análise de sensibilidade imputando valores preditos pelo modelo de regressão

\begin{tabular}{lcccc}
\hline & $(1)$ & $(2)$ & $(3)$ & $(4)$ \\
\hline Tratamento & -446.087 & -334.269 & -4444 & -360.223 \\
& $(238.824)$ & $(399.709)$ & $(563.325)$ & $(242.070)$ \\
Termo quadrático & Não & Sim & Sim & Sim \\
Termo cúbico & Não & Não & Sim & Sim \\
Bandwidth & $2 \%$ & $2 \% 2 \%$ & $8,2 \%$ & \\
N & 986 & 986 & 986 & 4140 \\
\hline
\end{tabular}

Nota: Erros padrões robustos clusterizados ao nível do município entre parênteses.

bência como se tivéssemos o banco de dados completo (Lee and Lemieux, 2014). Os resultados estão na tabela 4.4. Imputamos três valores diferentes. No painel A, imputamos a média do patrimônio $(\mathrm{R} \$ 583.598,70$ para um bandwidth de $2 \%$ e $\mathrm{R} \$ 613 \cdot 360,10$ para um bandwidth de $8,2 \%$ ). No painel $\mathrm{B}$, imputamos o primeiro quartil do patrimônio ( $\mathrm{R} \$ 80.000$ para um bandwidth de $2 \%$ e $\mathrm{R} \$ 84.946,51$ para um bandwidth de $8,2 \%$ ). No painel C, imputamos o terceiro quartil do patrimônio ( $\mathrm{R} \$ 491.000$ para um bandwidth de $2 \%$ e $\mathrm{R} \$ 250.000$ para um bandwidth de $8,2 \%$ ). Como podemos observar na tabela 4 , todos os resultados são semelhantes aos nossos principais achados: coeficientes negativos, mas que não são estatisticamente significantes.

A estratégia de imputar os mesmos valores para todos os indivíduos que não se recandidataram possui algumas limitações. Além de subestimar o desvio padrão da distribuição, estamos distorcendo a relação entre as variáveis puxando a correlação para zero (Gelman and Hill, 2007). Uma alternativa mais sofisticada de imputação é usar os valores preditos por um modelo de regressão. Implementamos esse teste para os resultados eleitorais de $2012^{4}$. Em primeiro lugar, estimamos um modelo de regressão para prever o patrimônio declarado no ano de 2012 a partir de diversas covariáveis (tabela 4.6). Mais detalhes sobre esse modelo estão na seção "Municípios competitivos". Utilizamos, então, os valo-

${ }^{4}$ Não implementamos esse teste para o patrimônio declarado em 2008 porque não temos os dados de patrimônio dos candidatos no ano de 2004. E uma das principais variáveis para se explicar o patrimônio em $t+1$ é o patrimônio em $t$. 
res preditos pelo modelo para imputar o patrimônio dos candidatos que não se reapresentaram na eleição de 2012. A segunda etapa foi estimar o efeito da incumbência sobre o patrimônio utilizando essa base de dados completa. Os resultados estão na tabela 4.5. Novamente os coeficientes do modelo são negativos e não são estatisticamente significantes.

Em conjunto, todos esses resultados sugerem que a autosseleção não está afetando os nossos achados.

\subsubsection{Patrimônio não declarado}

Outra possível explicação para o efeito nulo de exercer o cargo de prefeito sobre o patrimônio está relacionada com o fato de que a informação sobre o patrimônio é declarada pelos próprios candidatos. Todos os modelos que estimamos anteriormente assumem que os candidatos estão declarando $100 \%$ do seu patrimônio. No entanto, é possível que alguns candidatos estejam reportando uma quantidade de bens menor do que a que eles realmente tem. Podemos pensar no seguinte cenário: os candidatos que não foram eleitos estão reportando o valor total de seus bens. Como eles não exerceram o cargo de prefeito, o crescimento patrimonial foi fruto do exercício profissional. Assim, eles não tem motivos para reportar um patrimônio menor. Por outro lado, os candidatos que foram eleitos podem ter outro incentivo. Um crescimento patrimonial não condizente com o salário de um prefeito criaria suspeitas sobre a sua atuação no cargo público. Assim, eles estariam divulgando um patrimônio abaixo do que eles realmente tem. Em um cenário como este, estaríamos encontrando um efeito nulo do cargo eletivo somente porque os eleitos estão reportando um valor menor e os não eleitos estão reportando o valor total de seus bens. 
Figura 4.3: Simulação

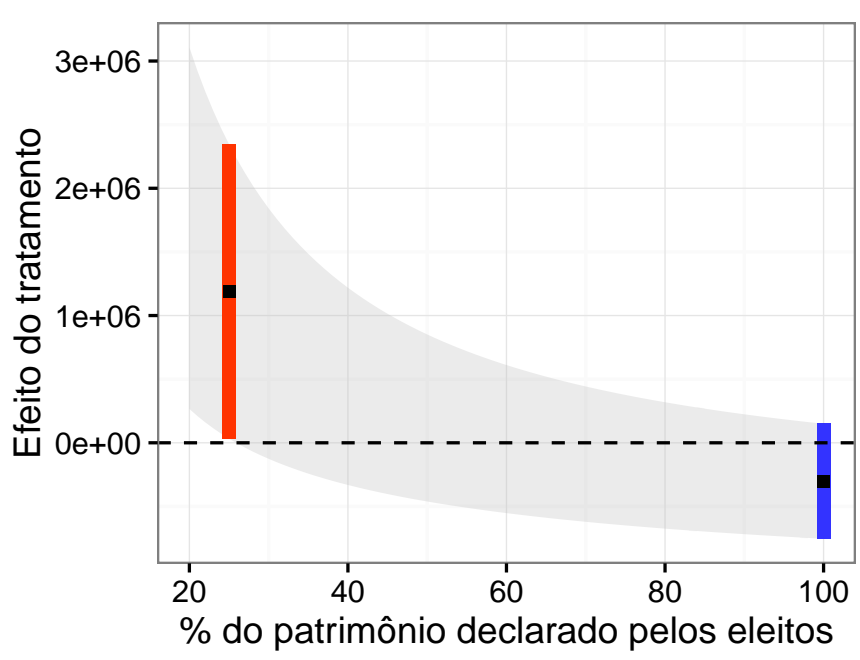

Nota: Neste gráfico temos o efeito de ser eleito sobre o patrimônio simulado dos candidatos. Os resultados são baseados no modelo 1. Nesta simulação assumimos que os candidatos não eleitos declararam todos os seus bens e os candidatos eleitos apresentaram apenas uma parcela de seu patrimônio. A linha tracejada na horizontal indica quando o efeito do tratamento é igual a zero. A linha vertical em azul indica o intervalo de confiança de $95 \%$ do efeito do tratamento estimado na situação em que os candidatos eleitos declararam 100\% de seus bens. A linha vertical em vermelho indica o intervalo de confiança de $95 \%$ do efeito do tratamento na situação em que os candidatos eleitos declararam apenas $25 \%$ dos seus bens. A partir desse ponto o efeito efeito do tratamento deixa de ser nulo e passa a ser positivo.

Para verificar a validade desta hipótese nós simulamos a porcentagem do patrimônio que os candidatos eleitos deveriam deixar de divulgar para que possamos encontrar um efeito positivo do tratamento. Na simulação assumimos que os candidatos não eleitos declararam 100\% de seu patrimônio e os candidatos eleitos apenas uma parcela dele. Por exemplo, se um candidato eleito divulgou um total de bens igual a $\mathrm{R} \$ 100.000,00$, nós simulamos uma situação em que esse valor seria apenas 50\% do total. Isto é, ele deixou de divulgar outros 50\%. Assim o total de seu patrimônio, na verdade, seria de $\mathrm{R} \$ 200.000,00$. Utilizamos então esse valor de $\mathrm{R} \$ 200.000,00$ para estimar os modelos. Os resultados estão no gráfico $4 \cdot 3$.

Como é possível observar, o efeito só passa a ser positivo e estatisticamente significante ao nível de $95 \%$ quando assumimos que os candidatos eleitos estão reportando apenas $25 \%$ de seu patrimônio (e os não eleitos estão reportando $100 \%$ ). Isto é, somente quando eles deixam de divulgar $75 \%$ de seu patrimônio 
é que encontramos um efeito positivo de ser eleito a um cargo público sobre o patrimônio. Para termos uma ideia, o patrimônio médio declarado pelos candidatos eleitos em nossa amostra de eleições apertadas é igual a R \$527.511,50. Assim, em média, eles deveriam deixar de declarar $\mathrm{R} \$ 1.582 .535,00$. Um valor muito alto.

\subsubsection{Municípios competitivos}

A explicação para o nosso resultado nulo pode estar relacionada com o fato de estarmos comparando candidatos em eleições apertadas. Em nossa amostra completa de eleições com pelo menos dois candidatos e com menos de 200 mil eleitores registrados temos ao todo 5296 municípios. No entanto, temos apenas 225 e 833 municípios com eleições em que os dois primeiros candidatos voltam a se enfrentar e que foram decididas por uma margem igual ou menor a $2 \%$ e $8,2 \%$, respectivamente. Para esse subconjunto de municípios somos capazes de estimar o efeito causal do exercício do cargo público sobre o patrimônio. Mas se por um lado a validade interna deste desenho de pesquisa é alta, por outro, a validade externa é baixa. Municípios que possuem eleições acirradas são muito diferentes de municípios em que, por exemplo, um único candidato recebe mais de $90 \%$ dos votos. Em ambientes mais competitivos os candidatos podem ter menos incentivos para tentar enriquecer ilicitamente no cargo público.

Tabela 4.6: Regressão incluindo municípios com eleições não apertadas

\begin{tabular}{lcc}
\hline Variável & Estimativa & Erro padrão \\
\hline Intercepto & 153.826 & 83.190 \\
Incumbente & -19.674 & 50.060 \\
Patrimônio em 2008 & 0,957 & 0,016 \\
Masculino & 71.531 & 80.070 \\
Superior completo & -46.229 & 50.810 \\
Empresário & 392.258 & 82.240 \\
\hline
\end{tabular}

Nota: $\mathrm{N}=4767$.

Para testarmos essa hipótese propusemos um modelo de regressão no qual utilizamos todos os candidatos (dois primeiros colocados) a prefeito nas elei- 
ções de 2008 que se reapresentaram em 2012 para qualquer cargo. Ao todo estamos incluindo candidatos de 4980 municípios. Neste modelo nossa variável dependente é o patrimônio declarado nas eleições de 2012 e a principal variável independente é um indicador de se o candidato foi ou não eleito em 2008. Utilizamos como controles o patrimônio declarado em 2008, um indicador de se o candidato é do sexo masculino, um indicador de se o candidato possui nível superior completo e um indicador de se o candidato é empresário.

Esse modelo não possui uma interpretação causal, como os modelos anteriores, porque podem existir outras covariáveis não observadas que estão associadas tanto com a probabilidade de ser eleito prefeito como com o patrimônio futuro dos candidatos. Apesar disso, este modelo pode nos indicar se o nosso principal resultado se mantém para o conjunto de municípios em que as eleições não foram decisões apertadas.

Na tabela 4.6 apresentamos os resultados. Como é possível observar, ser eleito em 2008 não está associado ao patrimônio dos candidatos em 2012, mesmo incluindo os municípios menos competitivos. As únicas variáveis que parecem estar associadas do ponto de vista estatístico à quantitade de bens dos candidatos são a quantidade de bens em 2008 e ser empresário. Em outras palavras, o nosso resultado nulo não parece estar associado ao fato de estarmos comparando municípios com eleições apertadas.

\subsubsection{Patrimônio dos familiares}

Outra possível explicação para termos encontrado um resultado nulo está relacionada com o patrimônio dos familiares dos candidatos. Muitos políticos podem enriquecer no exercício do cargo. No entanto, eles podem repassar boa parte do patrimônio aos seus familiares de modo a não levantarem suspeita sobre a sua conduta. Deste modo, o efeito de ser eleito para um cargo público estaria agindo sobre o patrimônio dos familiares e não sobre o patrimônio do candidato.

A existência de famílias políticas e o seu efeito sobre a qualidade do governo tem sido analisada pela literatura. Para o caso brasileiro, Bragança et al. (2015) mostram que candidatos que venceram uma eleição apertada tem $60 \%$ 
mais chances de ter um familiar eleito no futuro. Esse resultado indica como o poder de dinastias políticas persiste ao longo do tempo. Além disso, candidatos provenientes de famílias políticas tendem a investir mais em infraestrutura, saúde e saneamento básico. Embora não haja uma melhora na qualidade desses serviços.

Para o caso sueco, Folke et al. (2015) mostram que parentes, em especial os filhos, de candidatos que venceram eleições apertadas possuem salários mais altos do que parentes de candidatos que perderam. Além disso, filhos de políticos eleitos tem maiores chances de morar na mesma cidade em que o pai foi eleito e menores chances de serem estudantes. Essas escolhas estariam relacionadas com as boas oportunidades de emprego oferecidas a eles. Resultados semelhantes foram encontrados por Gagliarducci and Manacorda (2016) para o caso italiano. De acordo com os autores, o retorno monetário de ter um político na família é cerca de 3,5\% por ano no setor privado.

Nesta seção iremos testar qual o efeito de ser eleito para um cargo público sobre o patrimônio dos familiares dos candidatos. O foco estará sobre os familiares que se candidataram nas eleições municipais de 2008 e 2012. Essa escolha foi feita pois observamos apenas o patrimônio de indivíduos que concorreram à eleição. Embora essa seja uma limitação, podemos ter uma aproximação do efeito de interesse. Para identificarmos os familiares dos candidatos utilizamos a mesma estratégia adotada por Bragança et al. (2015). Nela assume-se que candidatos que possuem o mesmo sobrenome e que concorreram na mesma cidade fazem parte da mesma família. Em nossa amostra completa, 82\% dos candidatos possuem ao menos um parente que concorreu à eleição subsequente.

Na tabela 4.7 apresentamos os resultados desses testes. Os modelos estimados são iguais aos da seção 4.4. A única diferença é que a variável dependente agora é o total do patrimônio dos familiares do candidato. Como é possível observar, em nenhuma especificação encontramos um resultado estatisticamente significante aos níveis convencionais. Isto é, não há nenhuma evidência de que ser eleito prefeito afete a quantidade de bens materiais de seus familiares. Esse resultado, em conjunto com os apresentados nas seções anteriores, corroboram 
Tabela 4.7: Efeito do tratamento sobre o patrimônio dos familiares

\begin{tabular}{lccccc}
\hline & $(1)$ & $(2)$ & $(3)$ & $(4)$ & $(5)$ \\
\hline Tratamento & 149.663 & 149.663 & 91.165 & -74.344 & 13.502 \\
& $(272.832)$ & $(272.935)$ & $(192.683)$ & $(427.265)$ & $(319.564)$ \\
Termo Quadrático & Não & Não & Sim & Sim & Sim \\
Termo Cúbico & Não & Não & Não & Sim & Sim \\
Efeito da Eleição & Não & Sim & Sim & Sim & Sim \\
Bandwidth & $2 \%$ & $2 \%$ & $2 \%$ & $2 \%$ & $8,2 \%$ \\
Observações & 1328 & 1328 & 1328 & 1328 & 5482 \\
\hline
\end{tabular}

Nota: Erros padrões robustos clusterizados ao nível do município entre parênteses.

o nosso achado principal. Ser eleito para um cargo público não traz benefícios econômicos aos candidatos.

\subsubsection{Efeitos de longo prazo}

Mostramos na seção 4.4 que ser eleito prefeito não traz benefícios econômicos imediatos, isto é, logo após o exercício do cargo público. No entanto, é possível que o efeito seja de longo prazo. Os benefícios de ter sido prefeito podem ser decorrentes das conexões feitas ao longo do mandato. Os frutos gerados por essas conexões podem vir apenas no futuro. Para testarmos essa hipótese iremos comparar os pares de candidatos eleitos e não eleitos em eleições apertadas que se recandidataram para qualquer cargo 8 anos e 12 anos depois. Por exemplo, iremos estimar o efeito de ter sido eleito em 2000 (2004) sobre o patrimônio declarado 8 anos depois em 2008 (2012). Da mesma forma, iremos estimar o efeito de ter sido eleito em 1996 (2000) sobre o patrimônio declarado 12 anos depois em 2008 (2012).

No painel A da tabela 4.8 apresentamos os resultados do efeito de ter sido eleito sobre o patrimônio declarado 8 anos depois. Como é possível observar, para todas as especificações e amostras, não há evidências de que exercer um cargo público leva a um aumento do patrimônio dos candidatos. Conclusões semelhantes podem ser tiradas do painel B, em que estimamos o efeito 12 anos depois. Assim como no painel A, não encontramos nenhum efeito estatisticamente significante aos níveis convencionais. Ou seja, ser eleito prefeito parece 
Tabela 4.8: Efeitos de longo prazo do tratamento sobre o patrimônio

\begin{tabular}{lccccc}
\hline & $(1)$ & $(2)$ & $(3)$ & $(4)$ & $(5)$ \\
\hline Painel A: 8 anos & & & & & \\
Tratamento & -1.742 .986 & -1.742 .986 & -3.386 .278 & -886.125 & -1.466 .025 \\
& $(3.324 .753)$ & $(3 \cdot 331.021)$ & $(4.694 .590)$ & $(3.865 .042)$ & $(2.400 .246)$ \\
& {$[270]$} & {$[270]$} & {$[270]$} & {$[270]$} & {$[1484]$} \\
& $\{2 \%\}$ & $\{2 \%\}$ & $\{2 \%\}$ & $\{2 \%\}$ & $\{13 \%\}$ \\
Painel B: 12 anos & & & & & \\
Tratamento & 90.693 & 90.693 & 271.578 & 103.542 & -1884 \\
& $(268.004)$ & $(268.878)$ & $(451.339)$ & $(621.879)$ & $(194.281)$ \\
& {$[158]$} & {$[158]$} & {$[158]$} & {$[158]$} & {$[952]$} \\
Termo Quadrático & $\{2 \%\}$ & $\{2 \%\}$ & $\{2 \%\}$ & $\{2 \%\}$ & $\{15 \%\}$ \\
Termo Cúbico & Não & Não & Sim & Sim & Sim \\
Efeito da Eleição & Não & Não & Não & Sim & Sim \\
\hline
\end{tabular}

Nota: Erros padrões robustos clusterizados ao nível do município entre parênteses, número de observações entre colchetes e bandwidth entre chaves.

não levar a um aumento de riqueza no longo prazo.

\subsection{Heterogeneidade dos efeitos}

\subsubsection{Partidos políticos}

O principal resultado encontrado neste capítulo é o de que ser eleito para um cargo público não traz benefícios econômicos aos políticos. No entanto, esse resultado pode variar conforme a filiação partidária. Por exemplo, Eggers and Hainmueller (2009) encontraram que ser eleito ao parlamento britânico dobra o patrimônio dos membros do partido conservador. Mas não há nenhum benefício para os membros do partido trabalhista. De acordo com os autores, o aumento do patrimônio dos conservadores está associado com a contratação de seus membros em posições de alto nível no interior de empresas de capital. Por outro lado, os trabalhistas não encontram o mesmo ganho devido à pressão exercida pelos sindicatos para que os seus membros não prestem serviços a outros clientes. 
Tabela 4.9: Efeito do tratamento sobre o patrimônio por partido

\begin{tabular}{lccccc}
\hline & $(1)$ & $(2)$ & $(3)$ & $(4)$ & $(5)$ \\
\hline PT & 55.891 & 63.335 & 31.791 & 272.618 & -356.449 \\
& $(336.564)$ & $(315.815)$ & $(384.466)$ & $(589.571)$ & $(472.960)$ \\
PSDB & {$[124]$} & {$[124]$} & {$[124]$} & {$[124]$} & {$[449]$} \\
& 43.596 & 98.578 & -187.022 & -497.328 & -377.282 \\
& $(258.768)$ & $(239.326)$ & $(389.988)$ & $(630.389)$ & $(683.684)$ \\
PMDB & {$[150]$} & {$[150]$} & {$[150]$} & {$[150]$} & {$[633]$} \\
& -912.068 & -1.035 .313 & -1.356 .302 & -1.431 .181 & -950.892 \\
& $(723.151)$ & $(767.521)$ & $(1.262 .357)$ & $(1.477 .817)$ & $(740.334)$ \\
PFL>DEM & {$[209]$} & {$[209]$} & {$[209]$} & {$[209]$} & {$[898]$} \\
& 178.500 & 240.806 & 63.143 & 47.012 & 365.075 \\
& $(246.045)$ & $(261.786)$ & $(432.580)$ & $(390.031)$ & $(259.658)$ \\
Termo Quadrático & {$[168]$} & {$[168]$} & {$[168]$} & {$[168]$} & {$[528]$} \\
Termo Cúbico & Não & Não & Sim & Sim & Sim \\
Efeito da Eleição & Não & Não & Não & Sim & Sim \\
Bandwidth & São & Sim & Sim & Sim & Sim \\
\hline
\end{tabular}

Nota: Erros padrões robustos clusterizados ao nível do município entre parênteses e número de observações entre colchetes.

Para testarmos a hipótese de que o efeito de ser eleito prefeito varia conforme a filiação do candidato estimamos os mesmos modelos da seção 4.4 separando os candidatos por partido. Assim, na primeira linha da tabela 4.9 temos apenas os candidatos do PT que se reapresentaram para qualquer cargo na eleição subsequente, onde o grupo de tratamento são os candidatos eleitos e o grupo de controle são os candidatos não eleitos. Estimamos os modelos para os quatro maiores partidos, sendo um de esquerda (PT), dois de centro (PSDB e PMDB) e um de direita (PFL>DEM). Como podemos observar, não encontramos nenhum resultado estatisticamente significante aos níveis convencionais para nenhuma das legendas. Isto é, ser eleito para um cargo público não aumenta o patrimônio dos candidatos e esse resultado não varia conforme com o partido. 


\subsubsection{Região}

Outra possível fonte de variação é a região. De acordo com Fisman et al. (2012), candidatos eleitos em estados com maiores índices de corrupção possuem um retorno financeiro maior do que em estados não relacionados à corrupção. Para testarmos essa hipótese nós estimamos os mesmos modelos da seção 4.4 separando os municípios brasileiros por região. A expectativa é a de que possamos encontrar um efeito positivo de ser eleito prefeito sobre o patrimônio no Nordeste. De modo geral, os municípios dessa região são governados por máquinas políticas dominadas por poucas famílias (Hidalgo, 2010). Alguns exemplos desse fenômeno são os Magalhães no estado da Bahia e os Sarneys no estado do Maranhão.

Tabela 4.10: Efeito do tratamento sobre o patrimônio por região

\begin{tabular}{lccccc}
\hline & $(1)$ & $(2)$ & $(3)$ & $(4)$ & $(5)$ \\
\hline Norte & -499.054 & -499.054 & -170.347 & 1.572 .776 & -1.200 .018 \\
& $(406.717)$ & $(418.508)$ & $(892.094)$ & $(1.574 .637)$ & $(672.379)$ \\
Nordeste & {$[22]$} & {$[22]$} & {$[22]$} & {$[22]$} & {$[140]$} \\
& 104.383 & 104.383 & 121.041 & 582.743 & 144.077 \\
& $(243.416)$ & $(244.190)$ & $(414.002)$ & $(618.732)$ & $(261.824)$ \\
Centro-Oeste & {$[162]$} & {$[162]$} & {$[162]$} & {$[162]$} & {$[546]$} \\
& -4.653 .089 & -4.653 .089 & -9.391 .134 & -11.547 .533 & -2.651 .601 \\
& $(3.259 .367)$ & $(3.311 .520)$ & $(5.243 .433)$ & $(6.288 .901)$ & $(3.926 .235)$ \\
Sudeste & {$[36]$} & {$[36]$} & {$[36]$} & {$[36]$} & {$[146]$} \\
& 190.007 & 190.007 & 155.603 & -176.394 & -80.271 \\
& $(242.454)$ & $(243.350)$ & $(477.906)$ & $(694.218)$ & $(360.076)$ \\
Sul & {$[140]$} & {$[140]$} & {$[140]$} & {$[140]$} & {$[524]$} \\
& -78.154 & -78.154 & 193.616 & -270.481 & -974.220 \\
& $(145.537)$ & $(146.390)$ & $(290.261)$ & $(340.618)$ & $(838.326)$ \\
Termo Quadrático & {$[90]$} & {$[90]$} & {$[90]$} & {$[90]$} & {$[310]$} \\
Termo Cúbico & Não & Não & Sim & Sim & Sim \\
Efeito da Eleição & Não & Não & Não & Sim & Sim \\
Bandwidth & Não & Sim & Sim & Sim & Sim \\
\hline & $2 \%$ & $2 \%$ & $2 \%$ & $2 \%$ & $8,2 \%$ \\
\hline
\end{tabular}

Nota: Erros padrões robustos clusterizados ao nível do município entre parênteses e número de observações entre colchetes.

Como vemos na tabela 4.10, não encontramos nenhum efeito da incumbência 
sobre o patrimônio dos candidatos para todas as regiões. Isto é, ser eleito para um cargo público não traz benefícios econômicos em nenhuma região do país.

\subsubsection{Experiência política}

A experiência política prévia dos candidatos também pode fazer diferença. Se existir um processo de aprendizagem associado ao enriquecimento no cargo público, esperamos encontrar um efeito positivo para o grupo de candidatos mais experientes. Para testarmos essa hipótese separamos os candidatos em dois grupos. O primeiro é composto por candidatos que exerceram o cargo de prefeito há no máximo oito anos. Isto é, são os candidatos que estão tentando se eleger ao segundo mandato consecutivo ou que foram eleitos há oito anos e perderam ou não concorreram há quatro anos. Esses são os candidatos que possuem alguma experiência política como prefeito. Comparamos então o patrimônio declarado pelos candidatos experientes que se elegeram por uma pequena margem de votos com aqueles que perderam por uma pequena margem de votos. Por exemplo, para a eleição de 2004, selecionamos os candidatos que foram eleitos prefeitos em 2000 ou em 1996 e comparamos o patrimônio declarado em 2008. Utilizamos o patrimônio de candidatos que concorreram para qualquer cargo em 2008. Os resultados desse teste estão no painel A da tabela 4.11.

O segundo grupo de candidatos é composto por aqueles sem experiência política. Isto é, são os candidatos que não foram eleitos prefeitos há no máximo oito anos. Os resultados para esse grupo são apresentados no painel B.

Ao contrário de nossas expectativas, não encontramos nenhum efeito para o grupo de candidatos experientes. Não há evidências de um aprendizado associado ao enriquecimento no cargo de prefeito. Tanto candidatos experientes como sem experiência não apresentaram um enriquecimento após o exercício público.

\subsection{Discussão e conclusão}

O objetivo deste capítulo foi verificar se ser eleito a um cargo público traz benefícios privados aos candidatos. Para responder a essa pergunta utilizamos 
Tabela 4.11: Efeito do tratamento sobre o patrimônio por experiência política

\begin{tabular}{|c|c|c|c|c|c|}
\hline & (1) & (2) & (3) & (4) & (5) \\
\hline \multicolumn{6}{|c|}{ Painel A: Candidatos com experiência politica } \\
\hline \multirow[t]{3}{*}{ Tratamento } & -426.872 & $-229 \cdot 944$ & -615.010 & $-753 \cdot 964$ & -786.690 \\
\hline & $(552.445)$ & $\left(497 \cdot 45^{2}\right)$ & $(1.030 .644)$ & $(1.629 .228)$ & $(899 \cdot 422)$ \\
\hline & [182] & {$[182]$} & [182] & [182] & [757] \\
\hline \multicolumn{6}{|c|}{ Painel B: Candidatos sem experiência politica } \\
\hline \multirow[t]{3}{*}{ Tratamento } & $-149 \cdot 595$ & -121.675 & -153.147 & -5631 & $-124 \cdot 341$ \\
\hline & $(184 \cdot 520)$ & $(178.960)$ & $(299 \cdot 305)$ & $(403.470)$ & $(201.315)$ \\
\hline & [1189] & [1189] & [1189] & [1189] & {$[4663]$} \\
\hline Termo Quadrático & Não & Não & Sim & Sim & Sim \\
\hline Termo Cúbico & Não & Não & Não & Sim & Sim \\
\hline Efeito da Eleição & Não & Sim & Sim & Sim & Sim \\
\hline Bandwidth & $2 \%$ & $2 \%$ & $2 \%$ & $2 \%$ & $8,2 \%$ \\
\hline
\end{tabular}

Nota: Nota: Erros padrões robustos clusterizados ao nível do município entre parênteses e número de observações entre colchetes.

modelos de regressão descontínua em que comparamos o patrimônio dos candidatos que venceram e que perderam por uma pequena margem de votos e se recandidataram ao mesmo cargo. Os resultados apresentados sugerem que ser eleito ao cargo de prefeito não tem efeito sobre o patrimônio declarado pelos candidatos. Eleitos e não eleitos em eleições acirradas apresentam uma quantidade de bens semelhantes após o período do mandato.

Sugerimos também que esse resultado não é fruto da autosseleção dos candidatos em se recandidatarem ao mesmo cargo, do patrimônio não declarado pelos mesmos ou do fato de estarmos comparando municípios com eleições apertadas. Também não encontramos efeitos sobre os bens de seus familiares ou efeitos de longo prazo. Além disso, não encontramos diferenças entre os partidos políticos, regiões do país ou experiência política prévia dos candidatos.

Esses resultados são, à primeira vista, contraintuitivos. Sobretudo porque no período recente, diversas denúncias de corrupção tem sido veiculadas pelos principais jornais do país. A grande cobertura dos casos do Mensalão e da Lava Jato são exemplos disso. Também não é raro que em pesquisas de opinião as pessoas considerem a corrupção como um dos maiores problemas do Brasil. Em pesquisa realizada por Filgueiras and Avritzer (2010), os autores apontam 
que $73 \%$ dos brasileiros consideram a corrupção como muito grave e $24 \%$ como grave.

Para muitos analistas, a raiz do problema da corrupção é institucional. Em um importante trabalho sobre o tema, Ferraz and Finan (2011) estimaram o efeito da possibilidade de reeleição sobre os níveis de corrupção no Brasil. Os autores mostraram que em municípios nos quais os prefeitos tem a possibilidade de serem reeleitos os níveis de corrupção são significativamente menores. Prefeitos com o incentivo da reeleição desviam $27 \%$ menos recursos do que prefeitos sem esse incentivo. De acordo com os autores, isso ocorre porque os incumbentes com interesses eleitorais restringem as suas ações corruptas devido à possibilidade dos eleitores punirem os seus atos nas urnas. Dito de modo inverso, políticos sem a possibilidade de reeleição possuem mais chances de se engajarem em atos corruptos porque não temem ser punidos eleitoralmente.

Argumento semelhante foi desenvolvido por Klašnja and Titiunik (2017) para explicar a desvantagem eleitoral dos partidos de candidatos incumbentes. De acordo com os autores, políticos sem incentivos eleitorais (isto é, que estão no segundo mandato como prefeito) e despreocupados em construir longas carreiras no interior do partido (dada a fragilidade dos partidos políticos no Brasil) teriam mais incentivos de se engajar em um comportamento oportunista. Eleitores, por sua vez, puniriam o partido incumbente devido ao mau comportamento de seus candidatos.

Diversos trabalhos apresentaram evidências de que eleitores punem os candidatos envolvidos em casos de corrupção. Castro and Nunes (2014) mostraram que ter o nome envolvido em algum escândalo tem um impacto negativo sobre as eleições legislativas. Winters and Weitz-Shapiro (2013) mostraram que eleitores reagem de forma negativa às alegações de corrupção, mesmo quando os candidatos fazem um bom governo e fornecem diversos bens públicos. Ferraz and Finan (2008) mostraram que municípios que reportaram informações sobre práticas corruptas dos prefeitos reduziram significativamente as chances de reeleição dos candidatos incumbentes.

Em outras palavras, a desvantagem eleitoral dos incumbentes estaria associ- 
ada ao próprio comportamento oportunista dos prefeitos. Sem incentivos eleitorais e com frágeis laços partidários, os candidatos em segundo mandato teriam incentivos de se engajar em atos corruptos. Eleitores, por sua vez, puniriam de forma retrospectiva os maus políticos e selecionariam de forma prospectiva os candidatos desafiantes.

No entanto, em trabalho recente, Schiumerini (2015) mostra que a desvantagem dos candidatos incumbentes no Brasil é condicional ao acesso a recursos orçamentários. Municípios que possuem recursos e que, portanto, o prefeito tem a possibilidade de prover bens públicos, a incumbência tem um efeito positivo sobre as chances de reeleição do incumbente. Por outro lado, em municípios com dotações orçamentárias escassas, a incumbência é um fardo. Sem recursos para prover bens públicos, prefeitos não teriam como usar o mandato para assegurar uma vantagem sobre os candidatos desafiantes. Assim, a desvantagem eleitoral do incumbente não estaria associada ao seu mau comportamento, mas sim a fatores exógenos a ele.

O enriquecimento no cargo de prefeito pode seguir uma lógica parecida. Isto é, o enriquecimento via corrupção só seria possível em municípios com dotações orçamentárias abundantes. Se o município não possui recursos, o governo local não tem capacidade de firmar contratos e convênios com o setor privado. Lembremos que os casos de corrupção analisados por Ferraz and Finan (2011) dizem respeito à fraude em contratos públicos de bens e serviços, desvio de fundos e superfaturamento na contratação de bens e serviços. Todas essas ações somente são possíveis se as prefeituras são dotadas de capacidade orçamentária.

Para alcançar a identificação causal, no entanto, limitamos as análises sobre as cidades com eleições apertadas em que o mesmo par de candidatos se recandidataram na eleição subsequente para o mesmo cargo. Quando consideramos um bandwidth de $2 \%$ de votos, os municípios incluídos em nossa amostra possuem, em média, 15.770 eleitores registrados. Isto é, deixamos de fora justamente os municípios grandes e que possuem mais recursos. Assim pode parecer razoável argumentar que os nossos resultados são creditados ao fato de estarmos analisando municípios com escassos recursos financeiros. Com poucas chances 
de firmar contratos com o setor privado, prefeitos dessas cidades teriam poucas oportunidades para se engajar em atos ilícitos. Mas é importante lembrar que boa parte dos municípios brasileiros são pequenos. Dos mais de 5500 municípios, $75 \%$ possuem menos do que 15.750 eleitores registrados (terceiro quartil da distribuição) e menos de 10\% possuem mais de 40.000 eleitores registrados. Dito de outra forma, nossos resultados são generalizáveis para a maior parte dos municípios brasileiros.

É difícil saber o que poderia acontecer em municípios maiores. Em geral, municípios maiores e com mais recursos também possuem maior disponibilidade de informações, bem como mais instituições de controle horizontal. Pode-se argumentar que a disponibilidade de informações reduz as chances de políticos atuarem de forma corrupta. A ideia é que existe uma assimetria de informações entre políticos e cidadãos que favorece os primeiros. Cidadãos não são capazes de observar todas as ações dos políticos. Sabendo disso, políticos mal intencionados tirariam vantagens dessa assimetria extraindo recursos do Estado. Se eleitores possuem informações sobre o mau comportamento dos políticos, então estes seriam punidos no dia da eleição. De acordo com Ferraz and Finan (2011), a presença de uma mídia local reduz o efeito do incentivo à releeição sobre os níveis de corrupção. Isto é, a disponibilidade de informações reduz as chances de políticos agirem de forma corrupta.

Saber se os nossos resultados podem ser generalizados para municípios maiores e com mais recursos não é uma questão fácil. Mas uma opção interessante para trabalhos futuros seria analisar o efeito da incumbência sobre o patrimônio para cargos em que os políticos tenham acesso a mais recursos orçamentários. Cargos como o de governador e de deputado federal, por exemplo, poderiam ser analisados utilizando a mesma estratégia empírica aqui empreendida. A comparação de resultados em diversos contextos pode nos ajudar a entender se os achados são generalizáveis bem como se fatores contextuais afetam a relação de interesse (Dunning, 2012, 296). Portanto, mais pesquisas precisam ser realizadas. 


\subsection{Anexo}

Figura 4.4: Teste de McCrary (2008)

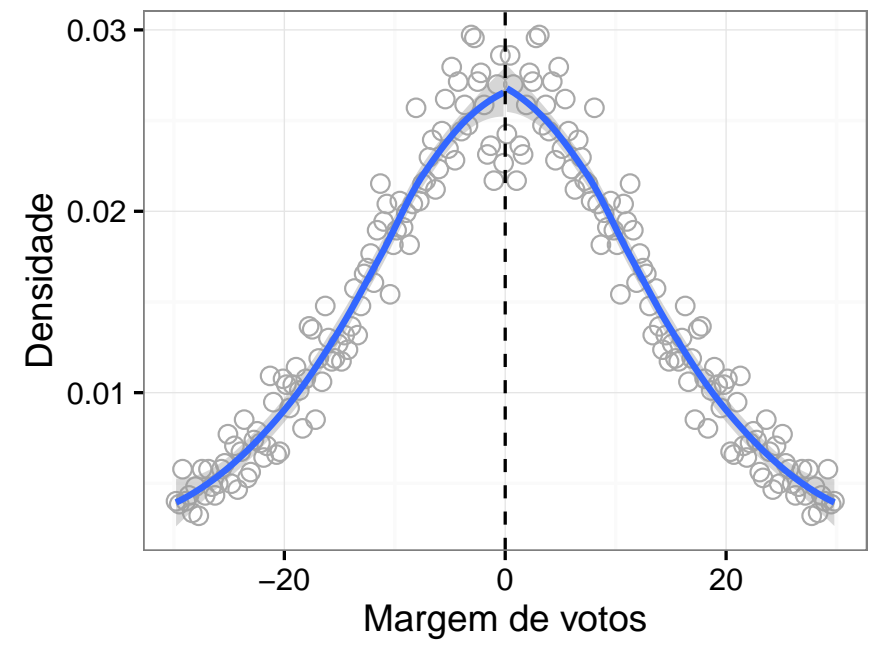

Nota: Neste gráfico temos as funções de densidade da margem de votos antes e depois de zero estimadas conforme McCrary (2008). Binsize $=0,29$ e bandwidth $=12,98$. 


\section{Referências Bibliográficas}

Aldrich, J. H. and McKelvey, R. D. (1977). A method of scaling with applications to the 1968 and 1972 presidential elections. The American Political Science Review, 71(1):111-130.

Armstrong, D. A., Bakker, R., Carroll, R., Hare, C., Poole, K. T., Rosenthal, H., et al. (2014). Analyzing spatial models of choice and judgment with R. CRC Press.

Blei, D. M., Ng, A. Y., and Jordan, M. I. (2003). Latent dirichlet allocation. the Journal of machine Learning research, 3:993-1022.

Boas, T. C. and Hidalgo, F. D. (2011). Controlling the airwaves: Incumbency advantage and community radio in brazil. American Journal of Political Science, 55(4):869-885.

Brady, H. E. (1985). The perils of survey research: Inter-personally incomparable responses. Political Methodology, pages 269-291.

Bragança, A., Ferraz, C., and Rios, J. (2015). Political dynasties and the quality of government. Working Paper.

Brambor, T. and Ceneviva, R. (2011). Incumbency advantage in brazilian mayoral elections.

Brollo, F. and Nannicini, T. (2012). Tying your enemy's hands in close races: the politics of federal transfers in brazil. American Political Science Review, 106(04):742-761.

Burgess, M., Giraudy, E., Katz-Samuels, J., Walsh, J., Willis, D., Haynes, L., and Ghani, R. (2016). The legislative influence detector: Finding text reuse in state 
legislation. In Proceedings of the 22nd ACM SIGKDD International Conference on Knowledge Discovery and Data Mining, pages 57-66. ACM.

Carreirão, Y. d. S. (2002). A decisão do voto nas eleições presidenciais brasileiras. FGV Editora.

Carreirão, Y. d. S. (2007). Identificação ideológica, partidos e voto na eleição presidencial de 2006. Opinião Pública, 13(2):307-339.

Castro, M. M. M. d. and Nunes, F. (2014). Candidatos corruptos são punidos?: accountability na eleição brasileira de 2006. Opinião Pública, 20(1):26-48.

Cesop (2017). Estudo eleitoral brasileiro. in: Banco de dados do centro de estudos de opinião pública - cesop-unicamp.

Clinton, J., Jackman, S., and Rivers, D. (2004). The statistical analysis of roll call data. American Political Science Review, 98(02):355-370.

Clinton, J. D. and Jackman, S. (2009). To simulate or nominate? Legislative Studies Quarterly, 34(4):593-621.

Dahl, R. (1997). Poliarquia: participação e oposição. Edusp.

Downs, A. (1957). An economic theory of democracy. Harper and Row.

Dunning, T. (2012). Natural experiments in the social sciences: a design-based approach. Cambridge University Press.

Eggers, A. C. and Hainmueller, J. (2009). Mps for sale? returns to office in postwar british politics. American Political Science Review, 103(04):513-533.

Enelow, J. M. and Hinich, M. J. (1982). Nonspatial candidate characteristics and electoral competition. The Journal of Politics, 44(1):115-130.

Enelow, J. M. and Hinich, M. J. (1984). The spatial theory of voting: An introduction. Cambridge University Press. 
Ferraz, C. and Finan, F. (2008). Exposing corrupt politicians: the effects of brazil's publicly released audits on electoral outcomes. The Quarterly Journal of Economics, 123(2):703-745.

Ferraz, C. and Finan, F. (2011). Electoral accountability and corruption: Evidence from the audits of local governments. The American Economic Review, 101(4):1274-1311.

Figueiredo, A. and Limongi, F. (1999). Executivo e Legislativo na nova ordem constitucional. Editora FGV.

Filgueiras, F. and Avritzer, L. (2010). Corrupção e controles democráticos no brasil. República, Democracia e Desenvolvimento, page 209.

Fisman, R., Schulz, F., and Vig, V. (2012). Private returns to public office. National Bureau of Economic Research.

Folke, O., Persson, T., and Rickne, J. (2015). Dynastic political rents. Working Paper.

Fox, J.-P. (2010). Bayesian item response modeling: Theory and applications. Springer Science \& Business Media.

Freitas, A. (2016). O Presidencialismo da Coalizão. Fundação Konrad Adenauer.

Gagliarducci, S. and Manacorda, M. (2016). Politics in the family: Nepotism and the hiring decisions of italian firms. IZA Discussion Paper.

Garrett, K. N. and Jansa, J. M. (2015). Interest group influence in policy diffusion networks. State Politics E Policy Quarterly, 15(3):387-417.

Gelman, A. and Hill, J. (2007). Data analysis using regression and multilevelhierarchical models, volume 1. Cambridge University Press New York, NY, USA.

Gerrish, S. and Blei, D. M. (2011). Predicting legislative roll calls from text. In Proceedings of the 28th international conference on machine learning (icml-11), pages 489-496. 
Geweke, J. (1992). Evaluating the accuracy of sampling-based approaches to calculating posterior moments. In Bernando, J., Berger, J., Dawid, A., and Smith, A., editors, Bayesian statistics 4, pages 169-193. Oxford Univerisyt Press.

Grimmer, J. (2010). A bayesian hierarchical topic model for political texts: Measuring expressed agendas in senate press releases. Political Analysis, 18(1):1-35.

Grimmer, J. and Stewart, B. M. (2013). Text as data: The promise and pitfalls of automatic content analysis methods for political texts. Political Analysis, $21(3): 267-297$.

Hare, C., Armstrong, D. A., Bakker, R., Carroll, R., and Poole, K. T. (2014). Using bayesian aldrich-mckelvey scaling to study citizens' ideological preferences and perceptions. American Journal of Political Science, 59(3):759-774.

Hidalgo, D. (2010). Digital democratization: Suffrage expansion and the decline of political machines in brazil. Manuscript, University of California at Berkeley.

Holland, P. W. (1986). Statistics and causal inference. Journal of the American statistical Association, 81(396):945-960.

Holzhacker, D. O. and Balbachevsky, E. (2007). Classe ideologia e política: uma interpretação dos resultados das eleições de 2002 e 2006. Opinião Pública, 13(2):283-306.

Imai, K., King, G., and Lau, O. (2008). Toward a common framework for statistical analysis and development. Journal of Computational Graphics and Statistics, $17(4): 892-913$.

Imbens, G. and Kalyanaraman, K. (2011). Optimal bandwidth choice for the regression discontinuity estimator. The Review of Economic Studies, pages 1-27.

Izumi, M. (2016). Governo e oposição no senado brasileiro (1989-2010). Dados, 59(1):91-138. 
Jessee, S. A. (2012). Ideology and Spatial Voting in American Elections. Cambridge University Press.

Jurafsky, D. and Martin, J. H. (2014). Speech and language processing, volume 3. Pearson.

King, G., Murray, C. J., Salomon, J. A., and Tandon, A. (2004). Enhancing the validity and cross-cultural comparability of measurement in survey research. American political science review, 98(01):191-207.

Klašnja, M. (2015). Corruption and the incumbency disadvantage: Theory and evidence. The Journal of Politics, 77(4):928-942.

Klašnja, M. and Titiunik, R. (2017). The incumbency curse: weak parties, term limits, and unfulfilled accountability. American Political Science Review, $111(1): 129-148$.

Kroeger, M. (2015). Plagiarizing policy: Model legislation in state legislatures. In Working Paper.

Lauderdale, B. and Herzog, A. (2016). Measuring political positions from legislative speech. Political Analysis, 24(3):374-394.

Laver, M., Benoit, K., and Garry, J. (2003). Extracting policy positions from political texts using words as data. American Political Science Review, 97(02):311-331.

Lawrence, C. N. (2007). Should voters be encyclopedias? measuring political sophistication of survey respondents. In Midwest Political Science Association Meeting.

Lee, D. S. (2008). Randomized experiments from non-random selection in us house elections. Journal of Econometrics, 142(2):675-697.

Lee, D. S. and Lemieux, T. (2014). Regression discontinuity designs in social sciences. Regression Analysis and Causal Inference, H. Best and C. Wolf (eds.), Sage. 
Lenz, G. S. and Lim, K. (2009). Getting rich (er) in office? corruption and wealth accumulation in congress.

Levendusky, M. S. and Jackman, S. D. (2003). Reconsidering the measurement of political knowledge. In Unpublished manuscript, Stanford University.

Li, W. P., Larochelle, D., and Lo, A. W. (2014). Estimating policy trajectories during the financial crisis. In Working Paper.

Liu, B. (2012). Sentiment analysis and opinion mining. Synthesis lectures on human language technologies, 5(1):1-167.

Lo, J., Proksch, S.-O., and Gschwend, T. (2014). A common left-right scale for voters and parties in europe. Political Analysis, 22(2):205-223.

Lowe, W. (2008). Understanding wordscores. Political Analysis, 16(4):356-371.

Lundqvist, H. (2013). Is it worth it? on the returns to holding political office.

Magalhães, L. d. (2015). Incumbency effects in a comparative perspective: Evidence from brazilian mayoral elections. Political Analysis, 23(1):113-126.

Manin, B. (1997). The principles of representative government. Cambridge University Press.

Martin, A. D. and Quinn, K. M. (2002). Dynamic ideal point estimation via markov chain monte carlo for the us supreme court, 1953-1999. Political Analysis, 10(2):134-153.

McCrary, J. (2008). Manipulation of the running variable in the regression discontinuity design: A density test. Journal of Econometrics, 142(2):698-714.

Monroe, B. L. and Schrodt, P. A. (2009). Introduction to the special issue: The statistical analysis of political text. Political Analysis, 16(4):351-355.

Murphy, K. P. (2012). Machine learning: a probabilistic perspective. MIT press.

Nay, J. J. (2016). Predicting and understanding law-making with machine learning. In Working Paper. 
Pang, B. and Lee, L. (2008). Opinion mining and sentiment analysis. Foundations and trends in information retrieval, 2(1-2):1-135.

Pereira, F. B. (2013). Sofisticação política e opinião pública no brasil: revisitando hipóteses clássicas. Opinião Pública, 19(2):291-319.

Plummer, M. (2015). rjags: Bayesian Graphical Models using MCMC. R package version $4-4$.

Poole, K. and Rosenthal, H. (2007). Ideology and congress. Transaction Pub.

Power, T. J. and Zucco Jr, C. (2009). Estimating ideology of brazilian legislative parties, 1990-2005: a research communication. Latin American Research Review, 44(1):218-246.

Querubin, P. and Snyder Jr, J. M. (2011). Wealth accumulation by us congressmen, 1845-1875: Were the civil war years exceptional (ly good)? In NBER Working Paper Series.

Quinn, K. M., Monroe, B. L., Colaresi, M., Crespin, M. H., and Radev, D. R. (2010). How to analyze political attention with minimal assumptions and costs. American Journal of Political Science, 54(1):209-228.

Reis, F. W. (2000). Mercado e utopia: teoria politica, sociedade brasileira. Edusp.

Reis, F. W. and de Castro, M. M. M. (2006). Democracia, civismo e cinismo: um estudo empírico sobre normas e racionalidade.

Roberts, M. E., Stewart, B. M., Tingley, D., Airoldi, E. M., et al. (2013). The structural topic model and applied social science. In Advances in Neural Information Processing Systems Workshop on Topic Models: Computation, Application, and Evaluation.

Saiegh, S. M. (2015). Using joint scaling methods to study ideology and representation: Evidence from latin america. Political Analysis.

Schiumerini, L. (2015). Resources, party labels, and incumbency effects: evidence from brazil. Working paper. 
Silva, R. and Araújo, S. (2010). Apropriação da agenda do legislativo: como aferir esse fenômeno. Texto para Discussão. Centro de Estudos da Consultoria, Senado Federal, 76.

Singer, A. (1999). Esquerda e direita no eleitorado brasileiro: a identificação ideológica nas disputas presidenciais de 1989 e 1994. Edusp.

Slapin, J. B. and Proksch, S.-O. (2008). A scaling model for estimating time-series party positions from texts. American Journal of Political Science, 52(3):705-722.

Smith, D. A., Cordell, R., Dillon, E. M., Stramp, N., and Wilkerson, J. (2014). Detecting and modeling local text reuse. In Proceedings of the 14th ACM/IEEECS Joint Conference on Digital Libraries, pages 183-192. IEEE Press.

Taboada, M., Brooke, J., Tofiloski, M., Voll, K., and Stede, M. (2011). Lexiconbased methods for sentiment analysis. Computational linguistics, 37(2):267-307.

Titiunik, R. (2009). Incumbency advantage in brazil: Evidence from municipal mayor elections. University of California-Berkeley, mimeo.

Uppal, Y. (2009). The disadvantaged incumbents: estimating incumbency effects in indian state legislatures. Public Choice, 138(1):9-27.

Wilkerson, J., Smith, D., and Stramp, N. (2015). Tracing the flow of policy ideas in legislatures: A text reuse approach. American Journal of Political Science, 59(4):943-956.

Winters, M. S. and Weitz-Shapiro, R. (2013). Lacking information or condoning corruption: When do voters support corrupt politicians? Comparative Politics, $45(4): 418-436$.

Yano, T., Smith, N. A., and Wilkerson, J. D. (2012). Textual predictors of bill survival in congressional committees. In Proceedings of the 2012 Conference of the North American Chapter of the Association for Computational Linguistics: Human Language Technologies, pages 793-802. Association for Computational Linguistics. 
Zucco, C. (2009). Ideology or what? legislative behavior in multiparty presidential settings. The Journal of Politics, 71(3):1076-1092.

Zucco, C. and Lauderdale, B. (2011). Distinguishing between influences on brazilian legislative behavior. Legislative Studies Quarterly, 36(3):363-396. 